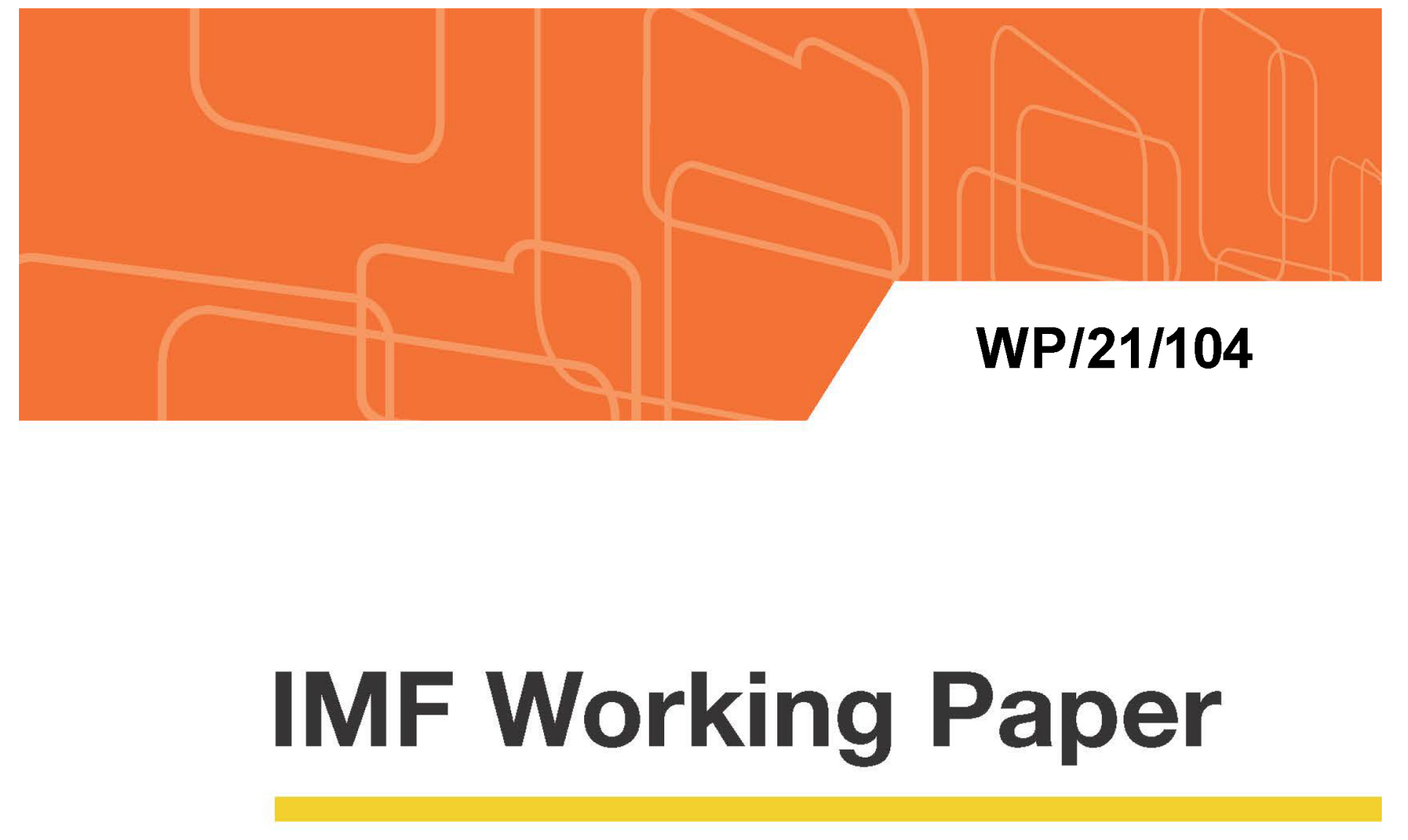

\title{
Commodity Shocks and Exchange Rate Regimes: Implications for the Caribbean Commodity Exporters
}

\author{
By Ali Al-Sadiq, Pablo Bejar, and İnci Ötker
}

IMF Working Papers describe research in progress by the author(s) and are published to elicit comments and to encourage debate. The views expressed in IMF Working Papers are those of the author(s) and do not necessarily represent the views of the IMF, its Executive Board, or IMF management. 


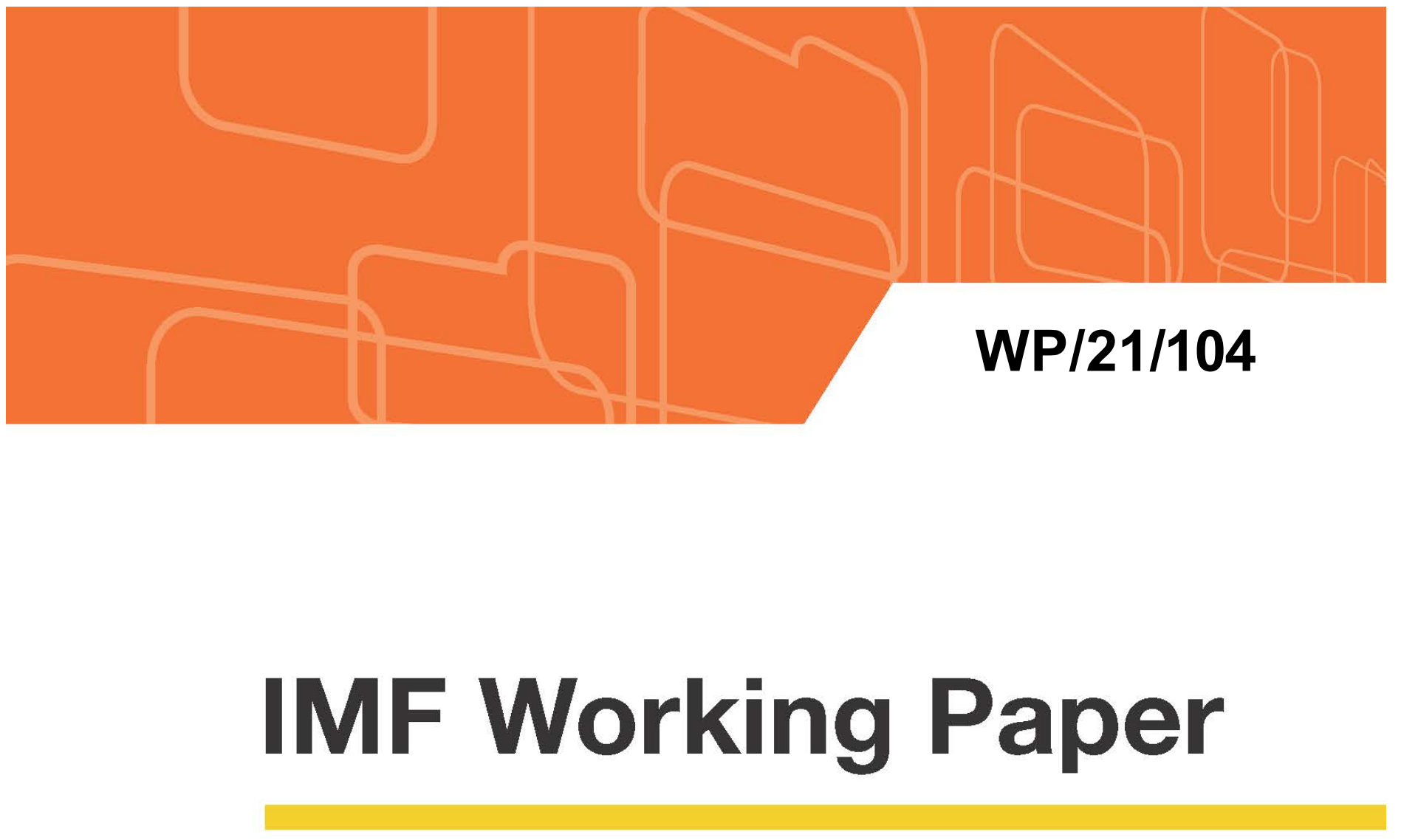

\section{Commodity Shocks and Exchange Rate Regimes: Implications for the Caribbean Commodity Exporters}

By Ali Al-Sadiq, Pablo Bejar, and İnci Ötker

IMF Working Papers describe research in progress by the author(s) and are published to elicit comments and to encourage debate. The views expressed in IMF Working Papers are those of the author(s) and do not necessarily represent the views of the IMF, its Executive Board, or IMF management. 


\title{
IMF Working Paper
}

Western Hemisphere Department

\section{Commodity Shocks and Exchange Rate Regimes: Implications for the Caribbean Commodity Exporters}

\author{
Prepared by Ali Al-Sadiq, Pablo Bejar, and İnci Ötker ${ }^{1}$ \\ Authorized for distribution by İnci Ötker
}

April 2021

\begin{abstract}
IMF Working Papers describe research in progress by the author(s) and are published to elicit comments and to encourage debate. The views expressed in IMF Working Papers are those of the author(s) and do not necessarily represent the views of the IMF, its Executive Board, or IMF management.
\end{abstract}

\begin{abstract}
Declining commodity prices during mid-2014-2016 posed significant challenges to commodityexporting economies. The severe terms of trade shock associated with a sharp fall in world commodity prices have raised anew questions about the viability of pegged exchange rate regimes. More recently, the COVID-19 pandemic and the measures needed to contain its spread have been associated with a significant disruption in several economic sectors, in particular, travel, tourism, and hospitality industry, adding to the downward pressure on commodity prices, a sharp fall in foreign exchange earnings, and depressed economic activity in most commodity exporters. This paper reviews country experiences with different exchange rate regimes in coping with commodity price shocks and explores the role of flexible exchange rates as a shock absorber, analyzing the macroeconomic impact of adverse term-of-trade shocks under different regimes using event study and panel vector autoregression techniques. It also analyzes, conceptually and empirically, policy and technical considerations in making exchange rate regime choices and discusses the supporting policies that should accompany a given regime choice to make that choice sustainable. It offers lessons that could be helpful to the Caribbean commodity-exporters.
\end{abstract}

JEL Classification Numbers: E50, F31, O24, Q02

Keywords: Exchange rate regimes, Commodity shocks, Commodity exporters, the Caribbean Author's E-Mail Address: AAlsadia@,imf.org, PBejarVera@,imf.org, IOtker@imf.org

\footnotetext{
${ }^{1}$ The authors are gra teful for guidance and suggestions from Aasim Husain and Alejandro Werner. Input and contributions from Marcos Chamon, Thomas Dowling, Oscar Hendrick, Marie Kim, and Lulu Shui at the initial sta ges of this project, and helpful comments from Marco Arena, Hussein Bidawi, Paul Cashin, Nicola s Magud, and Ken Miyajima, and the Central Bank of Costa Rica are gratefully a cknowledged. The paper benefitted from and draws heavily on the ex isting litera ture on this topic, including in particular the MCMMacro-Financial Note on "Commodity Price Shocks and Grea ter Exchange RateFlexibility: Why, If, To What, and How."
} 


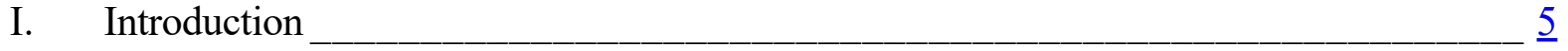

II. Impact of the Commodity Shock and Policy Response: Stylized Facts ___ ___ 8

III. Empirical Analysis: Exchange Rate Flexibility as a Shock Absorber _______

A. An Event Study Approach _____ 20

B. The PVAR Approach ________ 24

IV. Assessing the Exchange Rate Regime Choice__________ 28

V. Policies to Support Exchange Rate Regime Choices and Transitions ______

A. Supporting the Prevailing Pegged Exchange Rate Regime__ $\underline{32}$

B. Moving to Greater Exchange Rate Flexibility _____

What Regime to Exit to? ____________________________________

Modalities of Transition to Greater Flexibility ________ $\underline{36}$

VI. Conclusions and Policy Implications ______

\section{Tables}

1. The Caribbean Commodity Exporters: Key Exports

2. Exchange Rate Arrangements and Monetary Policy Frameworks

3. Policy Measures Taken During the 2014 Commodity Price Shock: 2014-17____

4. Reclassifications Based on Developments as of end-2017 ___

5. Exchange Rate Regimes of Commodity Exporting Countries, $2017 \_18$

6. Factors Affecting the Choice of Exchange Rate Regime for Commodity Exporters_ 29

7. Determinants of Exchange Regime Choice: Empirical Results _____

8. Detailed Country Experiences with Exit to Greater Exchange Rate Flexibility ____

\section{Figures}

1. Macroeconomic Impacts of the Commodity Shock Across Regions

2. Macroeconomic Impacts of the Commodity Shock Across Exchange Rate Regimes_11

3. Macroeconomic Impacts of Commodity Shocks Across Commodity Exporters, 2010-14

4. Macroeconomic Impact of the Commodity Shock across the Caribbean Commodity Exporters

5. Reserves and Exchange Rates Following the Commodity Shock

6a. Macroeconomic Performance Before/After the Commodity Shock: Event Study ${ }^{1}$ (Real Sector)

6b. Macroeconomic Performance Before/After the Commodity Shock: Event Study ${ }^{1}$ (External Sector)

6c. Macroeconomic Performance Before/After the Commodity Shock: Event Study (Fiscal Sector)

7. Differences in Macroeconomic Performance Pre/Post Commodity Shock____ 23

8. Baseline: Impulse Responses to a 10 Percent Drop in Commodity Terms of Trade__ 26

9. Impulse Responses of Real GDP per capita Growth to a 10-percent Negative Commodity ToT Shock under Altemative Model Specifications

10. Gradual Exits to Floating through More Flexible Pegged Regimes

11. Exit Episodes Toward Greater Flexibility 
12. Evolution of Key Economic Indicators Before and After the Exit to More Flexible ER Regime

\section{Boxes}

1. Ingredients of a Successful Move to Exchange Rate Flexibility $\underline{35}$

2. Transitions to Greater Flexibility Through More Flexible Pegged Regimes $\underline{39}$

\section{Appendices}

I. Commodity Terms-of-Trade Index $\underline{47}$

II. Data Descriptions and Sources for the Choice of Exchange Rate Regimes $\underline{48}$

III. Sample of Countries that Switched Exchange Rate Regimes; 2013-2017 $\underline{50}$

References $\underline{52}$ 


\section{INTRODUCTION}

1. Macroeconomic performance in commodity-exporting countries tends to be closely linked to unpredictable fluctuations of commodity prices. Commodity-price shocks can be large and persistent and lead to disruptive swings in fiscal and external positions, often translating into weaker and more volatile growth performance. The sharp decline in commodity prices during mid-2014 to early-2016 posed significant challenges to the commodity export-dependent economies. For countries with flexible exchange rates, the commodity shock contributed to sizable depreciations, loss of reserves, or higher interest rates to contain inflation from large currency depreciations. Countries with pegged exchange rates - the dominant exchange rate regime among commodity exporters - intervened to support their pegs and faced questions about their viability when combined with an appreciation of the US dollar to which many commodity exporters tie their currencies. Some countries shifted to more flexible exchange rates following the shock.
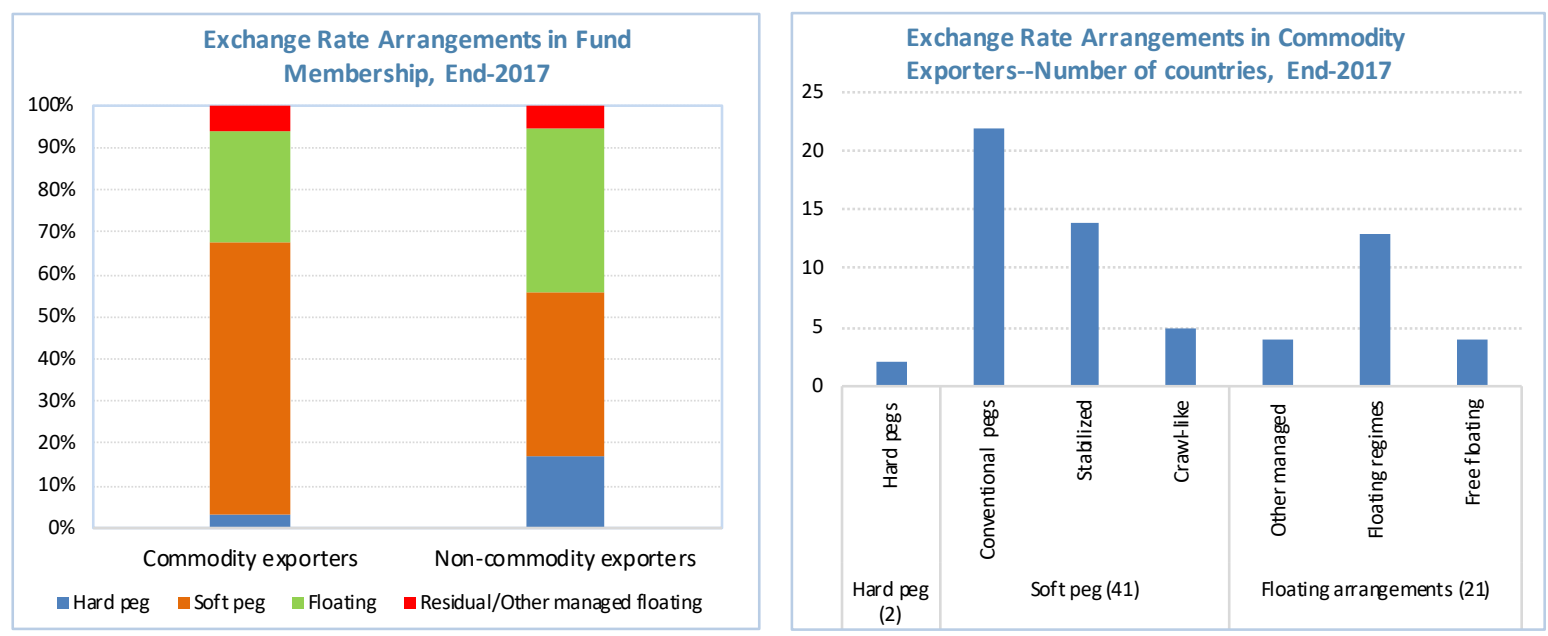

Sources: IMF Annual Report on Exchange Arrangements and Exchange Restrictions, and authors' computations.

2. Commodity-exporting Caribbean economies have been facing similar

challenges. Caribbean commodity exporters rely heavily on a few commodities as their main source of foreign exchange (Table 1 and text Figure): Trinidad and Tobago on oil and gas;

Suriname on gold, oil, alumina, and bauxite, and Guyana on gold, aluminum, bauxite, and agricultural products, with recent oil discoveries adding to the range of products in its commodity-based economy. The concentrated production and export structures make the countries vulnerable to large fluctuations in commodity prices. Belize and Jamaica have large tourism sectors but also had significant commodity exports until recently, and experienced challenges during the 2014-16 commodity price decline. During this period, many countries faced pressures on their currencies, deterioration in fiscal, external and growth

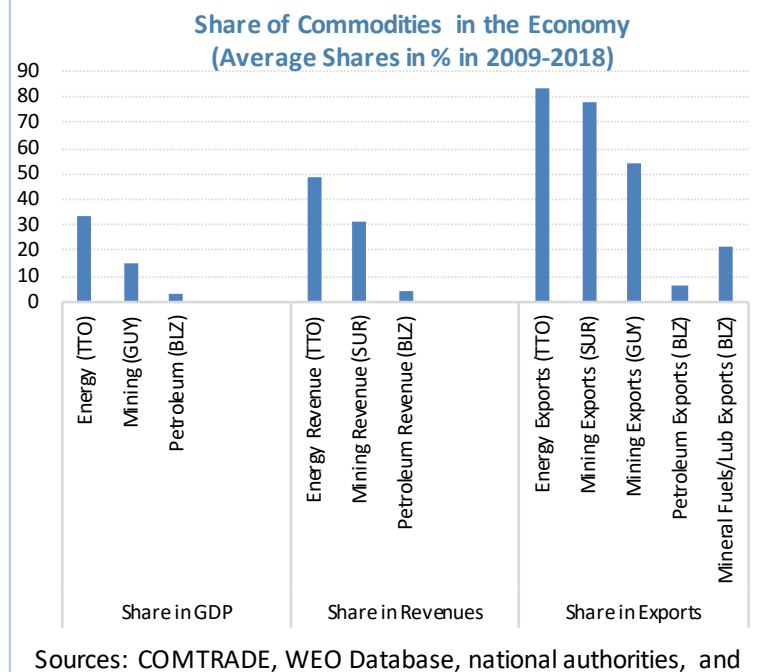
authors' computations. performance, and pressure on their foreign reserves. 


\begin{tabular}{|lcc|}
\hline \multicolumn{2}{|c|}{ Table 1. The Caribbean Commodity Exporters: Key Exports } \\
Country & (In percent of total exports of goods and services; Average 2014-2018) \\
Belize & Exports & 11 \\
Guyana & Sugar, banana, citrus products, marine products, petroleum & 46 \\
Jamaica & Aluminum, bauxite, fish products, gold, rice, wood & 19 \\
Suriname & Aluminum, bauxite, coffee, petroleum products, sugar & 68 \\
Trinidad and Tobago & Alumina, gold, crude oil, petroleum products, bauxite & 41 \\
& Natural gas, petroleum, petroleum products, petrochemicals & \\
\hline Sources: COMTRADE, IFS Database, national authorities, and authors' computations. & \\
\hline
\end{tabular}

3. Exchange rate flexibility can soften the impact of terms of trade shocks on the economy, but the scope for the exchange rate to be a shock absorber is limited for most Caribbean countries. In general, the limited flexibility under the prevailing exchange rate regimes reduces the scope for the exchange rate to be an automatic stabilizer in the face of shocks. The three highly commodity-dependent Caribbean countries (Guyana, Suriname, and Trinidad and Tobago) have formally floating exchange rate regimes, but the exchange rate has been broadly stable under tightly managed exchange rate arrangements in recent years (Table 2). Trinidad and Tobago allowed a gradual depreciation of about 6 percent during 2015-16 under its de facto "stabilized arrangement" but the

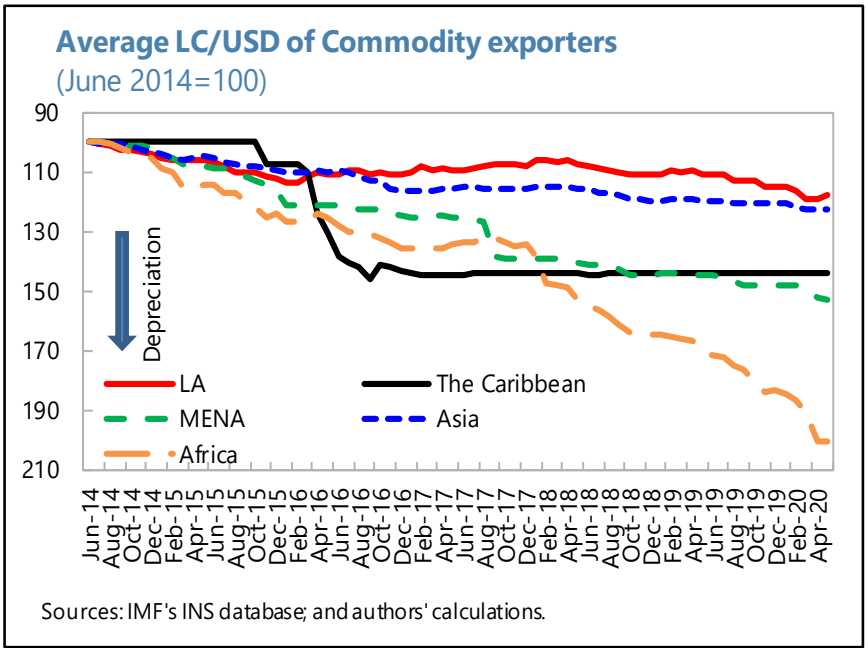
rate has been kept broadly stable since then. Suriname, under a similar arrangement, let the exchange rate float and depreciate sharply under intense market pressures in 2015, but reversed the move from 2016 as volatility in the market continued. For Guyana and Belize, the exchange rate moved very little over the past decade, while Jamaica switched from a crawl-like arrangement to a floating regime in 2017. As a result, after a brief period of sharp depreciation over the episode of commodity price collapse, the Caribbean currencies returned to stable exchange rates as commodity prices recovered from their lows.

4. From a theoretical perspective, adverse impacts of a sharp drop in commodity prices could be less severe for commodity exporters with flexible exchange rates, compared to those with pegged exchange rates. Maintaining a stable exchange rate regime under sustained market pressure raises many challenges in the absence of supporting policies. A more flexible exchange rate regime could, in principle, allow for a smoother output adjustment to a terms-of-trade (ToT) shock. At the same time, moving to greater flexibility can be complex in the absence of well-developed financial markets and adequate capacity to implement monetary policy under greater exchange rate flexibility to safeguard monetary and financial stability. The difficulty of assessing whether the ToT shock is permanent also adds to the challenge. The prospect of persistently low, or more volatile, commodity prices in the future, as shown by the recent COVID-19 shock, highlights the need for monetary and fiscal policy frameworks that can help cushion the impact of future shocks, and for reforms that facilitate economic diversification to reduce over-reliance on commodity exports and increase resilience to commodity shocks. 


\begin{tabular}{|llll|}
\hline \multicolumn{2}{|c|}{ Table 2. Exchange Rate Arrangements and Monetary Policy Frameworks (2017) } \\
Country & De jure Arrangement & De facto Arrangement & Monetary Policy Framework \\
\hline Belize & Conventional peg & Conventional peg & ER Anchor \\
Guyana & Floating & Stabilized arrangement & ER Anchor \\
Jamaica & Floating & Floating & Inflation Targeting Framework \\
Suriname & Floating & Stabilized arrangement & ER Anchor/Monetary Aggregate Target \\
Trinidad and Tobago & Floating & Stabilized arrangement & ER Anchor \\
\hline Source: IMF Annual Report on Exchange Arrangements and Exchange Restrictions. & \\
\hline
\end{tabular}

5. Against this background, this paper explores a number of related questions. Following some stylized facts on the impact of the 2014-2016 commodity shock and policy responses (Section II), it examines whether the macroeconomic impact of adverse ToT shocks differs systematically across different exchange rate regimes of a broad sample of commodity exporters. In this context, it examines whether flexible exchange rates can increase resilience to commodity price shocks. The paper then analyzes the factors underlying the choice of exchange rate regimes for commodity-exporting countries, drawing on the extensive optimal currency area literature, and reviews the supporting policies that should accompany a given choice, floating or pegged, to make that choice sustainable. It draws on country experiences with managing commodity shocks under different regimes and with moving to greater exchange rate flexibility.

6. The paper relies on a range of approaches to address these questions. First, event study and a panel vector autoregression (PVAR) approaches are used to analyze the evolution of key macro-financial indicators following a commodity shock under alternative exchange rate regimes (Section III. A, B). The PVAR estimates the dynamic paths of real GDP growth, the real effective exchange rate, inflation, and fiscal and external performance following a negative commodity price shock under alternative exchange regimes. Second, using the optimum currency area literature and a logit model, the paper analyzes the determinants of exchange regime choice for a commodity-dependent country (Section IV). Third, the paper draws on lessons from country experiences to discuss the key ingredients necessary to implement a flexible regime, as well as the supportive policies that should accompany any given regime choice (Section V). Section VI summarizes the key findings and implications for the Caribbean commodity exporters.

7. The key findings of the paper are as follows. First, commodity-exporting countries with floating regimes had, on average, higher growth rates than those with pegs and recovered more quickly after a shock, suggesting that greater exchange rate flexibility is an important tool to build resilience to future shocks. Second, there is no robust set of economic, structural, or institutional variables that can systematically explain regime choices among commodity exporters, highlighting the complexity in which trade-offs across various criteria can result in very diverse regime choices. Third, it is critical that commodity exporters with an exchange rate anchor support it with adequate financial and fiscal buffers and prudent monetary, fiscal, financial, and structural policy frameworks that help absorb shocks instead of the exchange rate. Finally, commodity exporters that choose to adopt more flexible regimes should follow a careful approach to facilitate a successful transition, to put in place the essential elements of exchange rate flexibility - including, a credible nominal anchor to replace the exchange rate, well-functioning financial markets to conduct market-based monetary policy and facilitate risk management, a coherent intervention policy, and sound macroeconomic/structural policies that boost credibility and limit volatile exchange rates. 


\section{The IMPACT OF THE COMMODITy SHOCK AND POLICY RESPONSE: STYLized FACTS}

8. Declining commodity prices pose significant challenges to commodity-exporting countries. Between June 2014 and February 2016, global crude oil and natural gas prices fell by more than 70 percent and 57 percent, respectively, resulting in a severe ToT shock for the commodity-exporting economies. ${ }^{2}$ The countries maintaining stabilized or pegged exchange rate regimes vis-à-vis the US dollar saw their currencies appreciate against trading partners along with the US dollar, with the resulting competitiveness loss creating further external difficulties and testing the viability of their pegged exchange rate regimes. Those with flexible exchange rates faced depreciation pressures in foreign exchange (FX) markets.

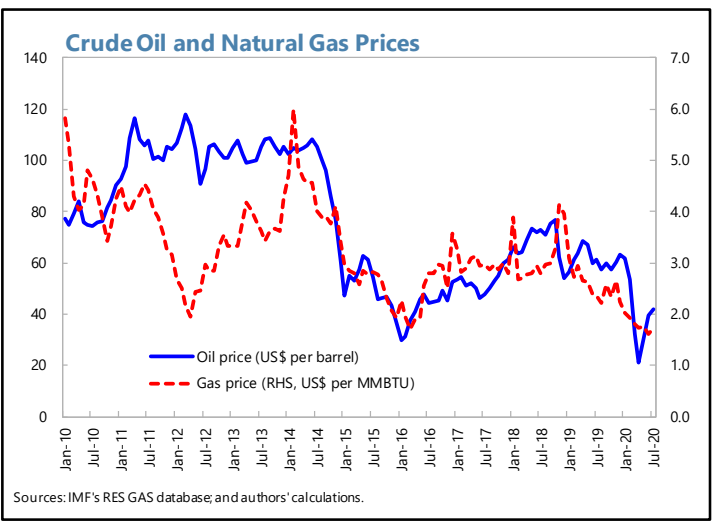
Market pressures were often compounded by other factors, including loose fiscal policy, domestic or regional political uncertainty, weakening economic growth in China, and lower remittances due to a global slowdown.

\section{Macroeconomic performance of many commodity exporters deteriorated} sharply, particularly during the dip in commodity prices (Figures 1-4). Real GDP growth dropped sharply in most commodity-exporting economies, with a consequent pick up in unemployment rates, and inflation rates rose in some, while falling, on average, in others. The trade, current account and fiscal imbalance increased sharply (particularly under pegged regimes), and gross public debt and external debt-to-GDP ratios increased in most, compared to the pre-shock period (more so under flexible regimes, likely reflecting the impact of exchange rate depreciation). Some countries witnessed a sharp appreciation of real exchange rates, while in others the deterioration was less

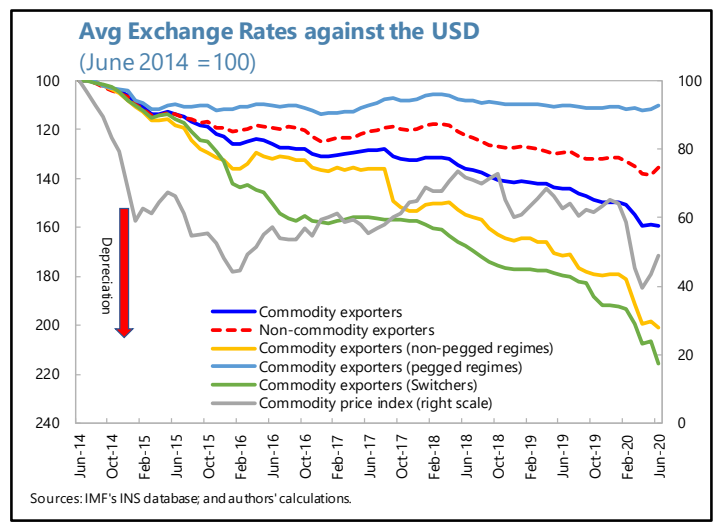
pronounced or not observed (especially where the exchange rate was allowed to adjust). The Caribbean commodity exporters, with the exception of Jamaica, experienced similar developments, with a marked deterioration in fiscal and financial buffers.

10. Exchange rate regimes reacted differently to the commodity shock. Some commodity exporters permitted sizable depreciations under flexible exchange rate regimes and maintained their float, with the average exchange rate starting to depreciate rapidly from mid-2014, compared with those for non-commodity exporters. Commodity exporters lost more reserves on average (Figure 5) in combining exchange rate adjustments with FX interventions in an attempt to contain large exchange rate movements. The ToT-shock played a significant role in many commodity exporters abandoning their pegs.

\footnotetext{
${ }^{2}$ We define commodity exporters as those with fuel/mining exports accounting for about an average of 20 percent of exports over a decade.
} 
Figure 1. Macroeconomic Impacts of the Commodity Shock Across Regions (2011-13 vs 2014-16)

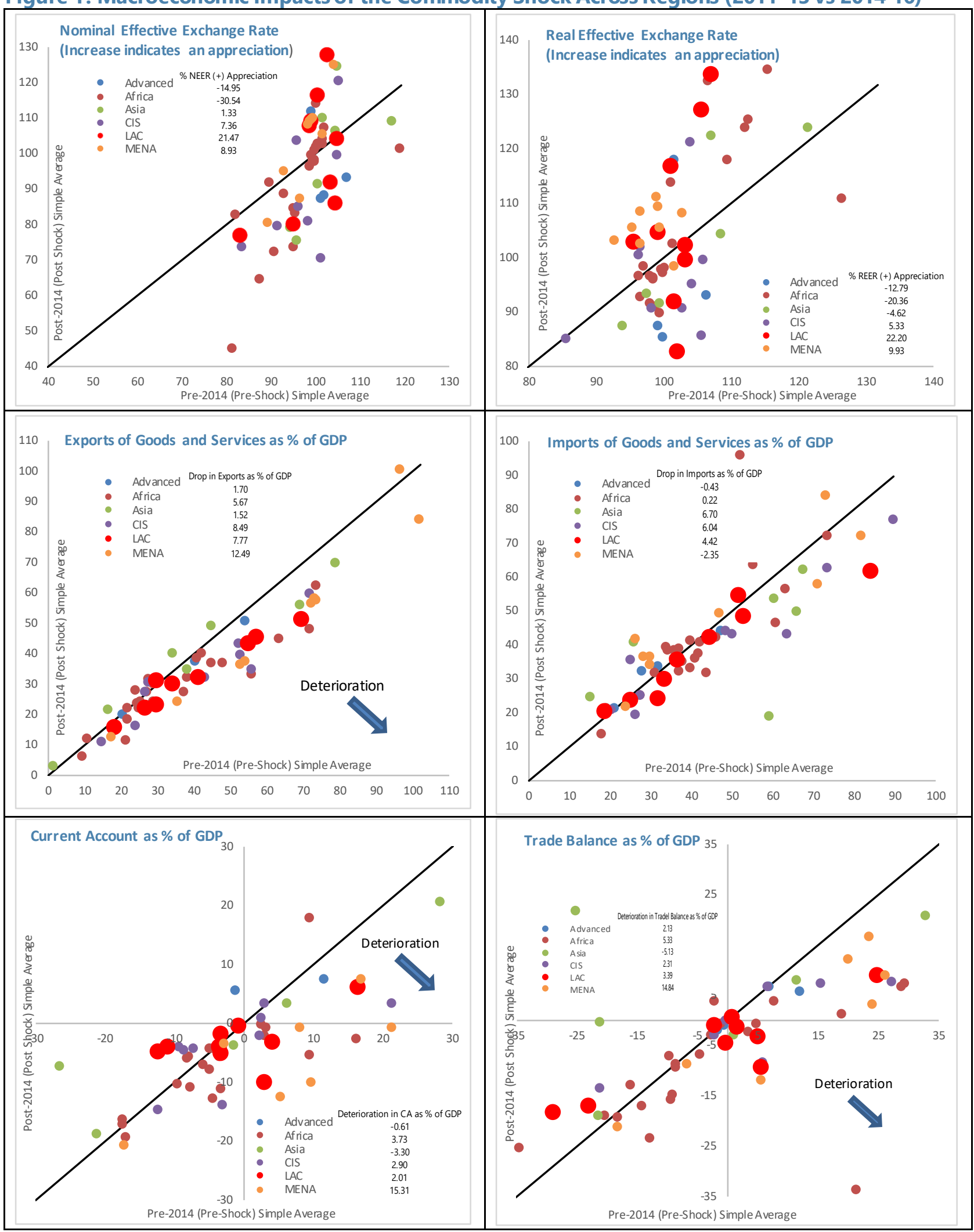

Sources: IMF's WEO database; and authors' calculations. 
Figure 1. Macroeconomic Impacts of the Commodity Shock Across Regions (Cont.)

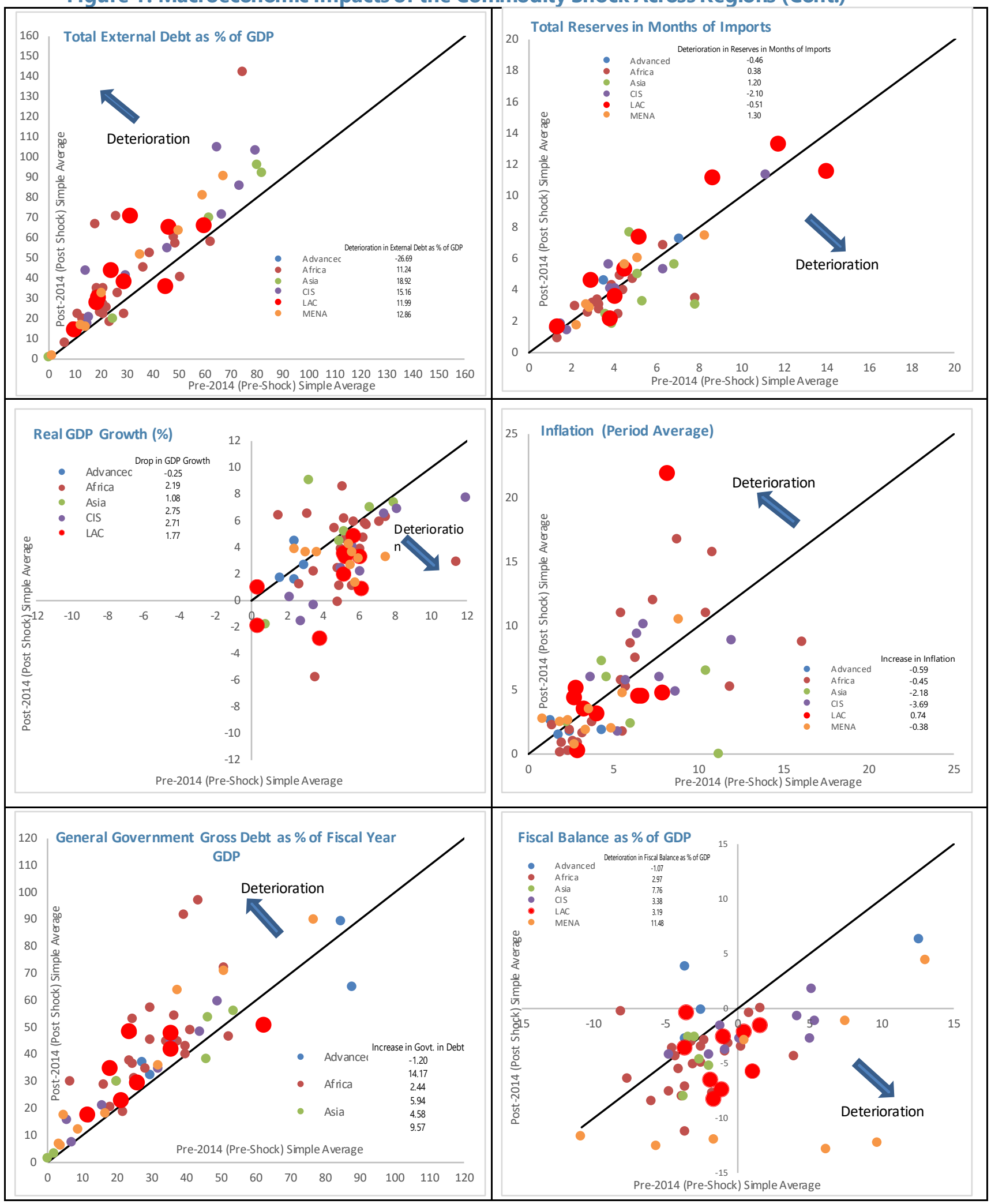

Sources: IMF's WEO database; and authors' calculations. 
Figure 2. Macroeconomic Impacts of the Commodity Shock Across Exchange Rate Regimes

\section{(2011-13 vs 2014-16)}

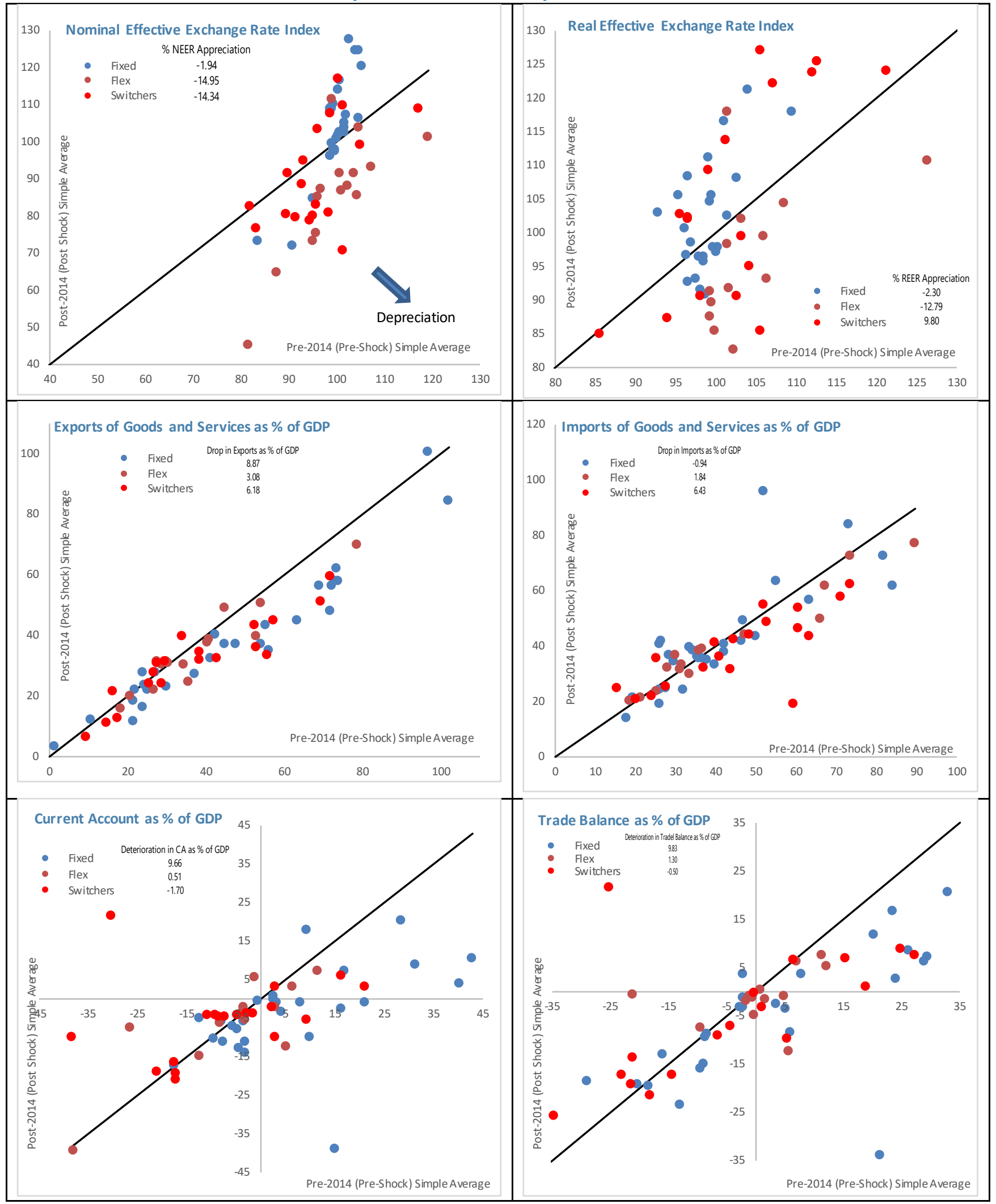

Sources: IMF's WEO database; and authors' calculations. 
Figure 2. Macroeconomic Impacts of the Commodity Shock Across Exchange Rate Regimes

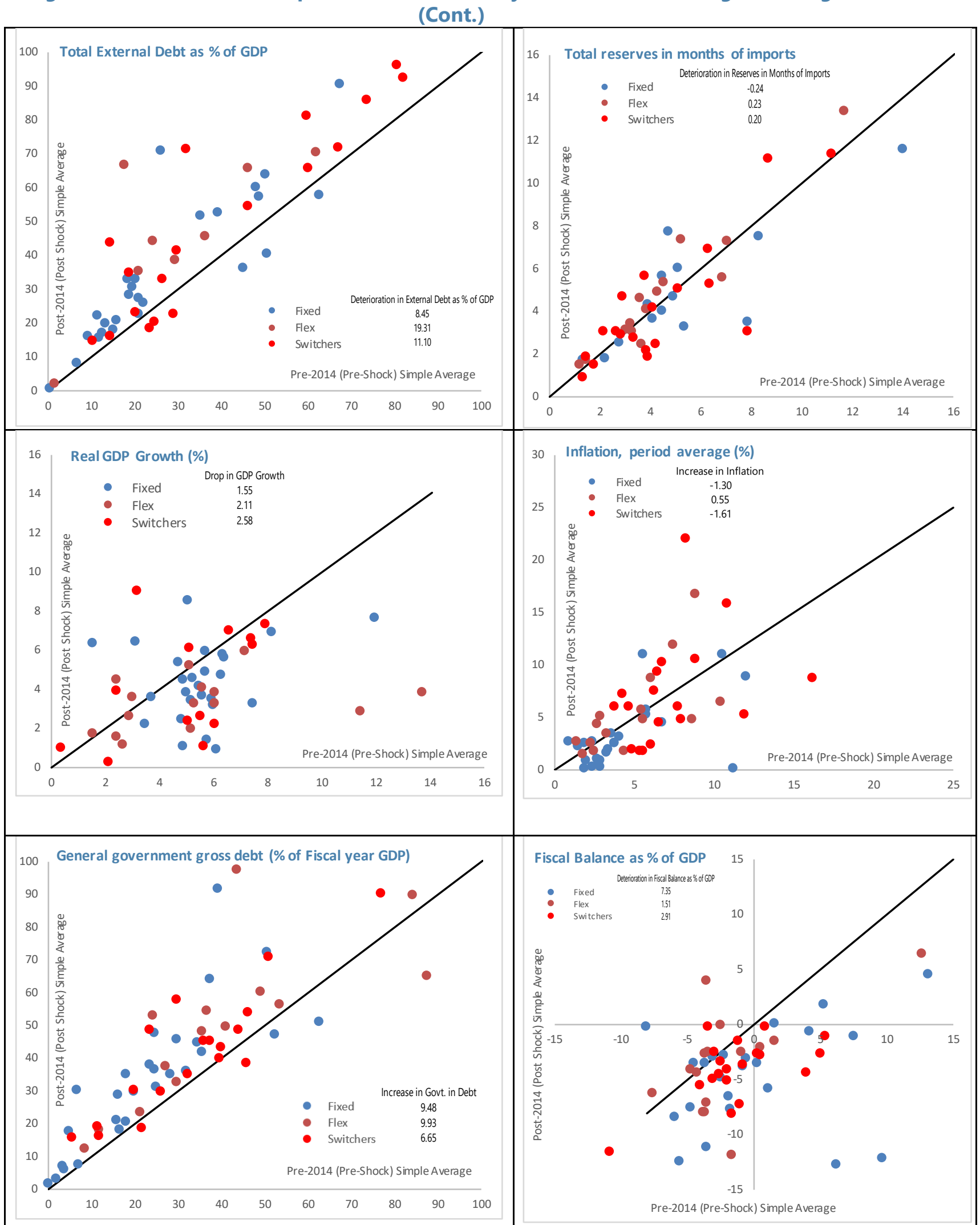

Sources: IMF's WEO database; and authors' calculations. 
Figure 3. Macroeconomic Impacts of Commodity Shock Across Commodity Exporters, 2010-18

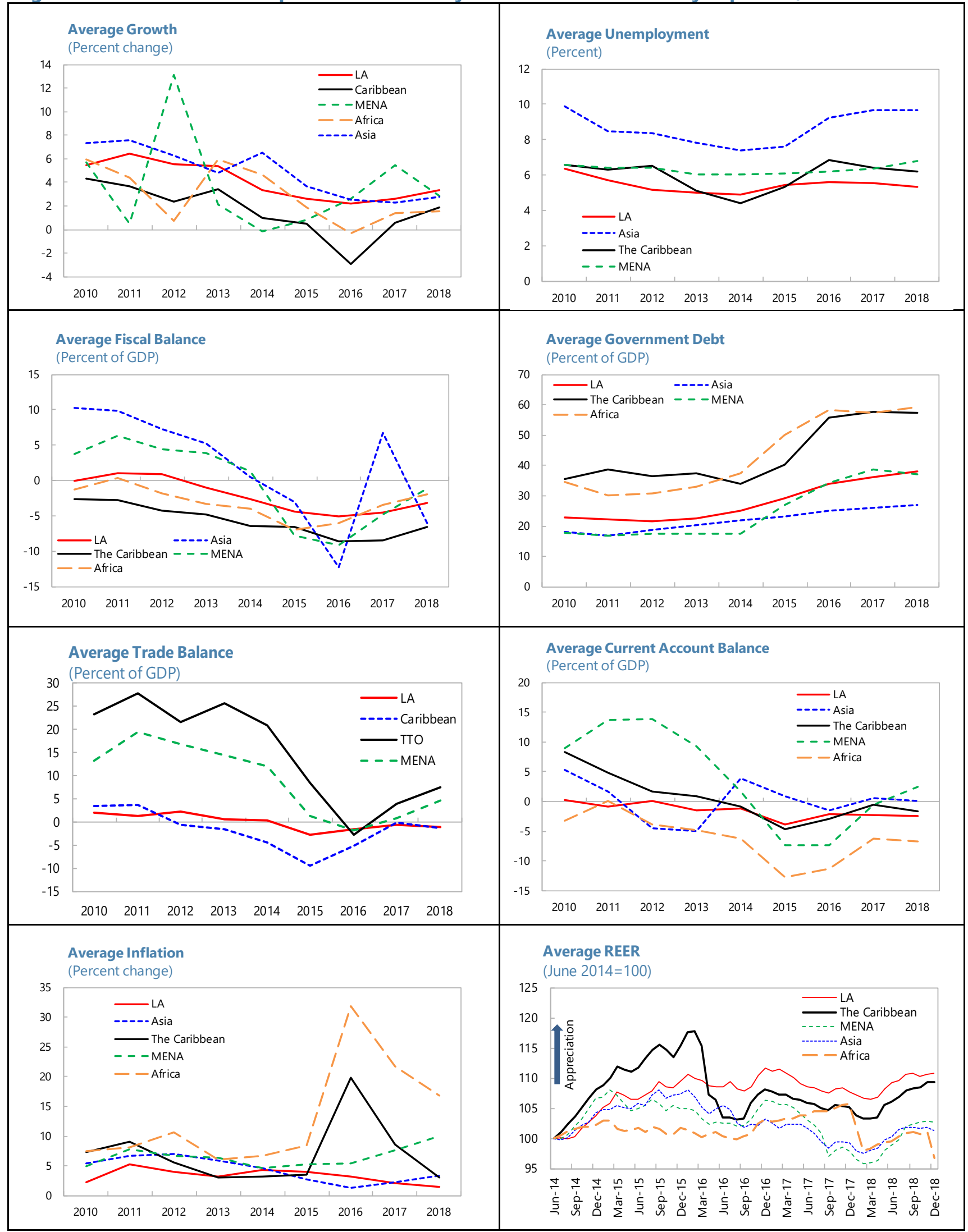

Sources: IMF's WEO database; INS database; and authors' calculations. 
Figure 4. Macroeconomic Impact of the Commodity Shock across the Caribbean Commodity Exporters

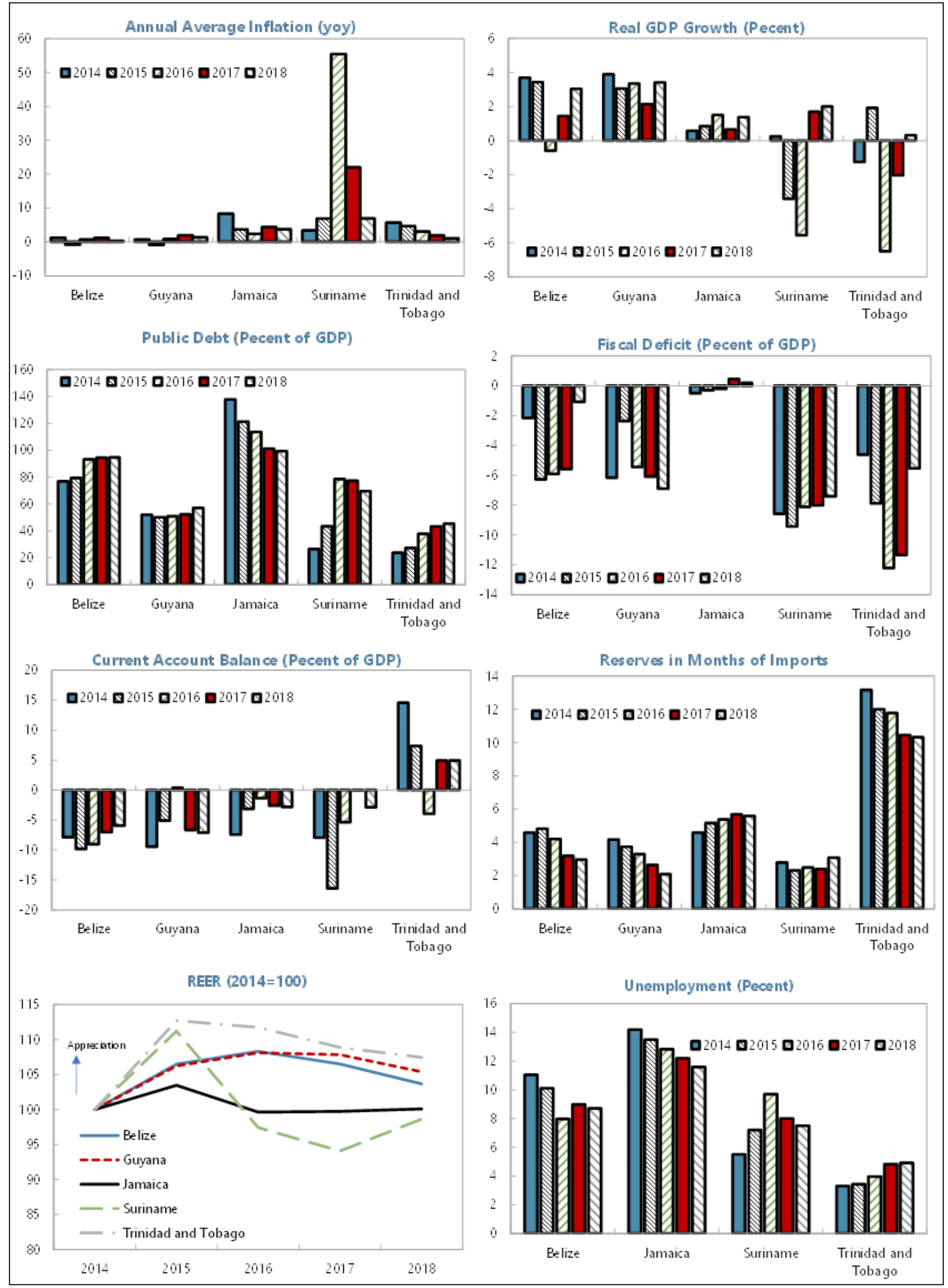

Sources: IMF's WEO database; and authors' calculations. 
Figure 5. Reserves and Exchange Rates Following the Commodity Shock

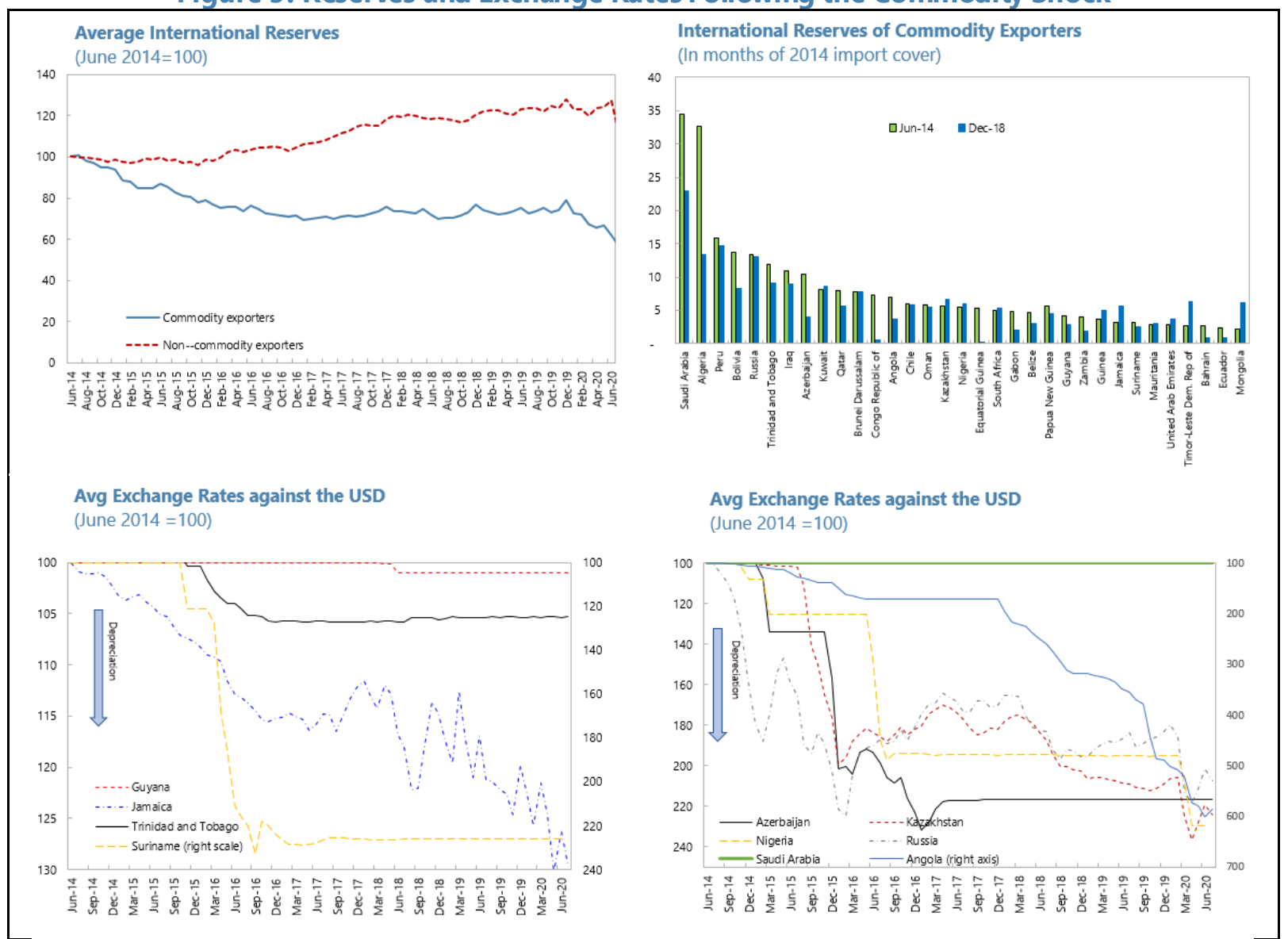

Sources: IMF's WEO database; INS database; and authors' calculations.

11. A combination of different policy measures have been adopted during the commodity shock period (Table 3 ). For most commodity exporters, the ToT shock translated to a massive fiscal shock, warranting large fiscal adjustments over the medium term, with the timing depending on their fiscal buffers and access to financing. Many implemented fiscal consolidation, introduced additional taxes, reduced current or capital spending, set up medium-term fiscal policy frameworks or macro-fiscal units, and increased effort to enhance fiscal transparency in a number of cases. Countries with large fiscal buffers initially delayed consolidation plans to absorb the initial price shock and implemented countercyclical fiscal spending before the tightening measures when price fall continued. Those with limited fiscal buffers resorted to increased borrowing from domestic or international markets or drew down bank deposits or stabilization funds. Several adopted energy price reforms, raising energy prices and/or reducing subsidies, with targeted social transfers to the poor. In a few, energy subsidies were reintroduced as commodity prices started to recover from the very low levels.

\section{Despite large adjustments, fiscal positions overall remained weaker than} before the shock, implying that more adjustment is needed. Some limited data on noncommodity fiscal positions may suggest that the underlying fiscal adjustment may have been facilitated by the exchange rate regime; countries with pegged regimes on average experienced a larger overall fiscal deterioration compared to those with flexible rates (Figure 2 ), but had an overall larger adjustment in noncommodity fiscal balance from two years after 
the shock. Countries such as Chile and Peru with flexible regimes increased spending to accommodate the price shock through countercyclical fiscal policies with adequate fiscal space and medium-term fiscal frameworks to ensure sustainability.

Table 3. Policy Measures Taken During the 2014 Commodity Price Shock: 2014-17

\begin{tabular}{|c|c|}
\hline Type of measure & Countries adopting \\
\hline $\begin{array}{l}\text { Exchange rate } \\
\text { policy }\end{array}$ & $\begin{array}{l}\text { - Maintained pegged regimes through FX intervention (GCC, CEMAC countries on concerns about } \\
\text { balance sheet effects and stability risks; Belize, Bolivia, Ecuador) } \\
\text { - Depreciated the official exchange rate under existing arrangements (allowed flexibility under floating } \\
\text { regimes or adjusted the rate under managed/pegged regimes) to help achieve policy adjustment to } \\
\text { lower prices (Algeria, Angola, Azerbaijan, Chile, Colombia, Ghana, Guinea, Guyana (small), Iran, } \\
\text { Nigeria, Peru, Suriname, Tajikistan, Trinidad \& Tobago (small), Uzbekistan, Zambia) } \\
\text { - Moved to greater ER flexibility (Armenia, Belarus, Burundi, Dem. Rep of Congo, Jamaica, Kazakhstan, } \\
\text { Russia, Switzerland, Venezuela) } \\
\text { - Reversed the move after moving to greater flexibility through tight management or stabilization of } \\
\text { the exchange rate (Angola, Azerbaijan, Egypt, Guinea, Libya, Suriname, Tajikistan, Tanzania, Trinidad } \\
\text { \& Tobago, Turkmenistan, Uzbekistan) }\end{array}$ \\
\hline $\begin{array}{l}\text { Fiscal } \\
\text { consolidation/ } \\
\text { tightening }\end{array}$ & $\begin{array}{l}\text { - Initial response by using existing fiscal/financial buffers (reserves, SWF etc.) to absorb the initial price } \\
\text { shock and smooth policy adjustment (GCC countries, Algeria) } \\
\text { - Consolidation efforts from 2014-15, and ambitious fiscal consolidation plans for } 2017 \text { (most GCC } \\
\text { countries, Algeria, Iran, Iraq) } \\
\text { - Cuts in public spending (reduced capital/current spending etc.) (Algeria, Angola, Azerbaijan, Belarus, } \\
\text { Chad, Rep. of Congo, Colombia, Ecuador, Egypt, Guinea, Gabon, Iraq, Jamaica, Kuwait, Mauritania, } \\
\text { Nigeria, Oman, Peru, Russia, Sudan, Suriname ( } 2016-17 \text { ), Trinidad and Tobago (from 2017)); public } \\
\text { sector hiring freeze (Algeria, Saudi Arabia); plans to reduce arrears and state guarantees (Iraq); cut } \\
\text { transfers to government related entities, subsidies, and grants (UAE) } \\
\text { - Introduction of VAT (Bahrain, Saudi Arabia), increased non-oil taxes to broaden revenue base to } \\
\text { reduce dependence on oil revenues in medium term (Iran, Iraq, Bahrain, Oman); plans to introduce } \\
\text { sales/excise taxes (Iraq); tax adjustment on energy products (Algeria) } \\
\text { - Setting up Medium-term Fiscal Frameworks (Algeria, Kuwait, Qatar, Saudi Arabia, UAE); macrofiscal } \\
\text { units (Kuwait, Oman, Qatar, Saudi Arabia, UAE) and debt management offices (Oman, Kuwait, Saudi } \\
\text { Arabia); increased fiscal transparency (Saudi Arabia) }\end{array}$ \\
\hline $\begin{array}{l}\text { Fiscal expansion/ } \\
\text { loosening }\end{array}$ & $\begin{array}{l}\text { - Slowdown in the pace of consolidation in } 2017 \text { with the rebound in oil prices from 2016/17, especially } \\
\text { in those with substantial fiscal buffers (Some GCC countries-Kuwait, Qatar, Saudi Arabia, UAE) } \\
\text { - Increased spending to accommodate the price shock, through countercyclical fiscal policies with } \\
\text { adequate fiscal space and medium-term fiscal frameworks to ensure sustainability (Chile, Peru) } \\
\text { - Maintained accommodative policies (Bolivia, with some cut in capital spending while drawing down } \\
\text { on buffers) } \\
\text { - Some loosening (Jamaica, Kazakhstan, Mauritania, Mongolia, Namibia, Nigeria Russia, Suriname } \\
\text { ( } 2017-18, \text { with public investment and wage increase), Trinidad and Tobago (initially as a } \\
\text { countercyclical measure), Zambia) }\end{array}$ \\
\hline $\begin{array}{l}\text { Debt/borrowing } \\
\text { policies }\end{array}$ & $\begin{array}{l}\text { - More active recourse by the public sector to domestic financing (including from banks) (Angola, } \\
\text { Bahrain, Chad, Gabon, Kuwait, Qatar, Saudi Arabia, Trinidad and Tobago) } \\
\text { - Governments' increased borrowing from (or drawdown deposits with) the central bank (CEMAC } \\
\text { countries, Algeria, Oman, Saudi Arabia, Trinidad and Tobago) } \\
\text { - Governments drawing down their local bank deposits (Algeria, Qatar, UAE) or stabilization } \\
\text { funds/sovereign wealth funds (Algeria, Kuwait, Oman, Qatar, Saudi Arabia, Trinidad and Tobago, UAE) } \\
\text { - External borrowing through international bonds (Bahrain, Kazakhstan, Qatar, Suriname) or syndicated } \\
\text { loans (Oman, Qatar) }\end{array}$ \\
\hline Monetary policy & $\begin{array}{l}\text { - Monetary tightening (most GCC countries, Azerbaijan, Belarus, Chile (during 2015), Colombia (mid- } \\
\text { 2015-mid-2016), Egypt, Peru (mid-2015-end-2015), Angola, Chad, Gabon, Ghana, Guinea, Jamaica, } \\
\text { Kazakhstan, Mongolia, Namibia, Nigeria (following some reversal from tightening), Russia, Tanzania, } \\
\text { Trinidad and Tobago, Zambia) to prevent excessive weakening of the exchange rates or to limit } \\
\text { exchange rate passthrough to inflation) } \\
\text { - Accommodative monetary policy or easing (Azerbaijan, Chile (after 2017), Colombia (after 2017), } \\
\text { Guyana, Mongolia, Nigeria (Q2-15), Peru (from 2017), Sudan, Uzbekistan) }\end{array}$ \\
\hline
\end{tabular}


Table 3. Policy Measures Taken During the 2014 Commodity Price Shock: 2014-17 (concluded)

\begin{tabular}{|c|c|}
\hline $\begin{array}{l}\text { Exchange } \\
\text { restrictions/ } \\
\text { Administrative } \\
\text { controls }\end{array}$ & $\begin{array}{l}\text { - Easing of capital market restrictions on foreign investors to attract inflows (Saudi Arabia) } \\
\text { - Exchange restrictions (large queues, priority lists for FX, formal/informal restrictions on FX markets, } \\
\text { etc.) (Algeria, Angola, Azerbaijan, Belarus, Libya, Mauritania, Nigeria, Saudi Arabia, Sudan, Suriname, } \\
\text { Trinidad and Tobago, Turkmenistan, Uzbekistan, Venezuela) } \\
\text { - Increased parallel market rate (Algeria, Angola, Belarus, Libya, Mauritania, Nigeria, Sudan, Suriname, } \\
\text { Trinidad and Tobago) }\end{array}$ \\
\hline $\begin{array}{l}\text { Financial sector } \\
\text { measures }\end{array}$ & $\begin{array}{l}\text { - Banking reform (Iran) } \\
\text { - Developing strategy to address challenges of state-owned banks (Iraq) } \\
\text { - Easing of credit policies: Increasing LTV for first time buyers (Saudi Arabia); Easing of access to } \\
\text { financing through introduction of a credit registry (UAE) } \\
\text { - Enhanced liquidity and prudential requirements (Algeria, Bahrain, Oman), enhanced MaPP } \\
\text { frameworks (Bahrain, Chile, Kuwait, Mongolia, Nigeria, Oman, Qatar, Saudi Arabia), and Central Bank } \\
\text { laws (Iran, UAE); loosened MaPP measures (Azerbaijan) } \\
\text { - Introduction of deposit insurance schemes (Kenya, Nigeria, Tanzania, CEMAC countries) }\end{array}$ \\
\hline $\begin{array}{l}\text { Labor market } \\
\text { policies }\end{array}$ & $\begin{array}{l}\text { - Investing in education and innovation to increase labor productivity and diversification (Iran, Oman, } \\
\text { - Saudi Arabia, UAE) } \\
\text { - Programs for job creation for young and women (Iran) } \\
\text { - Wabe protection system (Bahrain), measures to create job flexibility for expatriates (Bahrain, Qatar) } \\
\text { - Wage increases (Angola, Chile, Namibia, Oman, Qatar) } \\
\text { - Wage reductions (Ecuador, Egypt, Jamaica, Mauritania, Mongolia, Russia) } \\
\text { - Labor market flexibility (Peru, to increase labor market formalization) }\end{array}$ \\
\hline $\begin{array}{l}\text { Other structural } \\
\text { policies }\end{array}$ & $\begin{array}{l}\text { - Increased role of the private sector including through PPP (Kuwait, Oman), privatization plans (Iran, } \\
\text { Kuwait, Oman, Saudi Arabia, and modernized investment and labor laws (Algeria, Bahrain, Oman, } \\
\text { Qatar, Saudi Arabia) }\end{array}$ \\
\hline $\begin{array}{l}\text { Diversification } \\
\text { away from } \\
\text { commodities }\end{array}$ & $\begin{array}{l}\text { Diversified export base through financial services (Bahrain, UAE), transport, business services, and } \\
\text { tourism (UAE), and food processing (Bahrain), visa-free entry programs to stimulate tourism (Qatar); } \\
\text { other diversification measures toward new drivers of growth (Angola, Bolivia, Chile, Kuwait, Namibia, } \\
\text { Oman) } \\
\text { - Introduction of corporate bankruptcy law to improve business environment (UAE) }\end{array}$ \\
\hline $\begin{array}{l}\text { Energy/subsidy } \\
\text { reforms }\end{array}$ & $\begin{array}{l}\text { - Increased energy prices (2015/16) (all GCC countries, Algeria, Iran, Yemen) } \\
\text { - Energy price reforms (from late 2015) (Algeria, Bahrain, Iraq, Kuwait, Oman, Qatar, Saudi Arabia) } \\
\text { - Introduction of automatic pricing formula in tandem with international benchmarks to help with the } \\
\text { risk of price reforms being unwound (Kuwait, Oman, Qatar, UAE) } \\
\text { - Decline in energy subsidies (Algeria, Egypt, Kazakhstan, Kuwait, Mauritania, Nigeria, Oman, Qatar, } \\
\text { Sudan, Trinidad \& Tobago, UAE, Yemen) } \\
\text { - Increase in/reemergence of energy subsidies (Bahrain, Namibia, Russia, Sub-Saharan Africa (in } \\
\text { 2017/18)) } \\
\text { - Increase in social welfare transfers to the poor (Yemen) } \\
\text { - Policies to raise energy efficiency, including through renewable sources (many GCC) }\end{array}$ \\
\hline
\end{tabular}

Sources: Husain and others (2015), IMF Regional Economic Studies (for WHD, MCD, AFR), IMF WEO, various issues, IMF Working Papers on the recent commodity shock, IMF (2015a,b,c), IMF (2016), IMF (2107a), IMF Country Reports.

13. Commodity exporters also adopted monetary/financial policy measures. Most countries tightened interest rates to defend, or limit excessive weakening of, their currencies or to limit passthrough to inflation, while a few countries implemented more accommodative monetary policy to support economic activity in the absence of inflation pressures. A number of countries eased credit policies to support the economy, while several others tightened micro/macro-prudential rules to strengthen the banking systems and introduced deposit insurance schemes. Some countries put in place, or tightened, administrative measures to limit FX access and ensure exchange rate stability, which in some cases led to increased parallel market rates. 


\section{Some countries let their exchange rates eventually adjust to absorb the price} shock, in many cases with a significant lag after the commodity price shock. Several commodity-exporters with pegged exchange regimes shifted to more flexible exchange regimes, with an initial sharp depreciation (Armenia, Belarus, Burundi, Democratic Republic of Congo, Jamaica, Kazakhstan, Russia, Venezuela), but others maintained their pegged regimes or returned to soft pegs after an initial float. Some (gradual or step-wise) adjustment was made in a number of cases under the existing stabilized arrangements or before reversing the float (Angola, Azerbaijan, Guyana, Iran, Nigeria, Sudan, Suriname, Tajikistan, Trinidad and Tobago, Uzbekistan)-Table 4. Two thirds of commodity exporters continued with (hard or soft) pegged regimes as of end-2017 (Table 5), limiting the potential role of the exchange rate as a shock absorber.

Table 4. Reclassifications Based on Developments as of end-2017 1/

(Commodity exporters only-WEO definition: fuel and primary products)

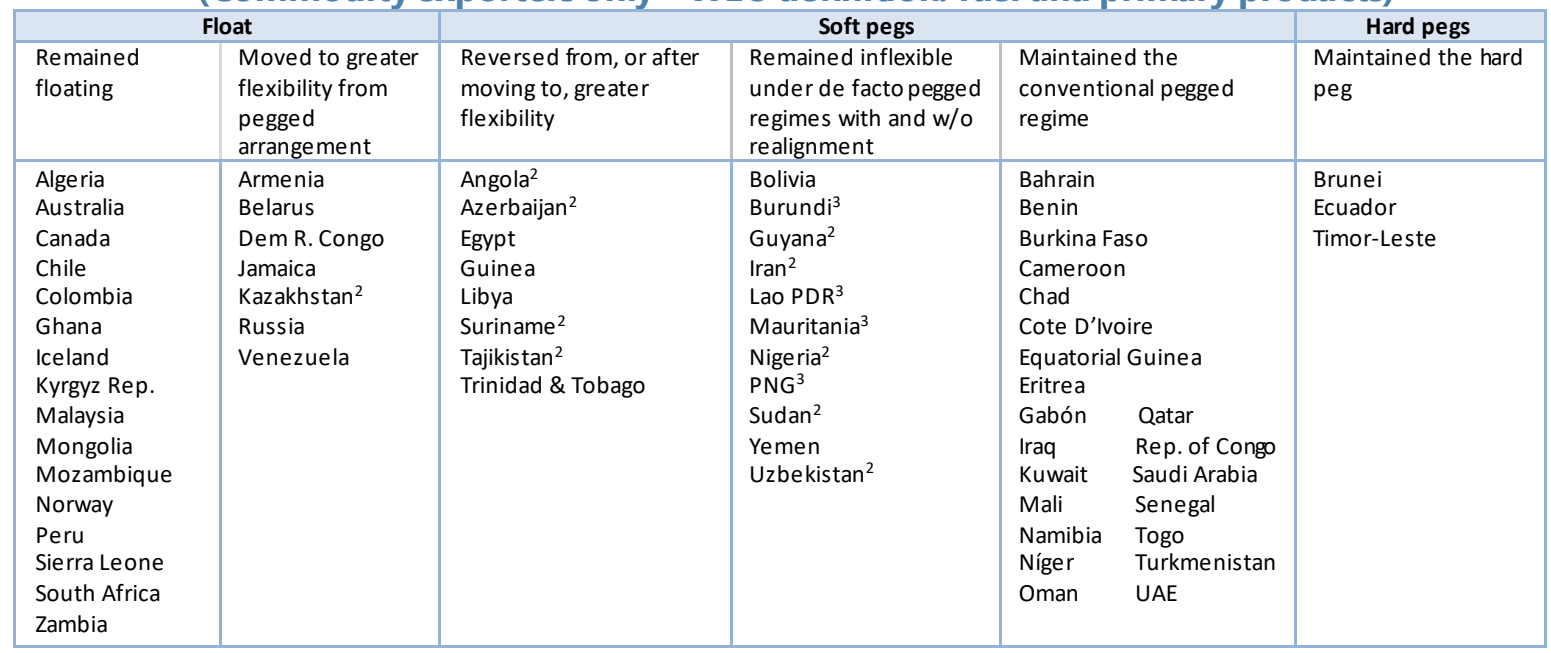

Source: IMF Annual Report on Exchange arrangements and Exchange Restrictions.

Notes: 1: Relative to mid-2014 when commodity shock started; 2: Some discrete exchange rate adjustment within a given regime; 3 : Flexibility increased somewhat from a less flexible to a more flexible peg.

Table 5. Exchange Rate Regimes of Commodity Exporting Countries, 2017

\begin{tabular}{|c|c|c|c|c|c|c|}
\hline Hard peg (3) & Conventional peg (23) & $\begin{array}{l}\text { Stabilized } \\
\text { arrangement (13) }\end{array}$ & Crawl-like (5) & $\begin{array}{l}\text { Other managed } \\
\text { float (5) }\end{array}$ & Floating (12) & $\begin{array}{l}\text { Free } \\
\text { floating (5) }\end{array}$ \\
\hline $\begin{array}{l}\text { Brunei } \\
\text { Ecuador } \\
\text { Timor-Leste }\end{array}$ & $\begin{array}{l}\text { Bahrain } \\
\text { Benin } \\
\text { Burkina Faso } \\
\text { Cameroon } \\
\text { Chad } \\
\text { Côte D'Ivoire } \\
\text { Equatorial Guinea } \\
\text { Eritrea } \quad \text { Oman } \\
\text { Gabon } \quad \text { Qatar } \\
\text { Iraq } \quad \text { Rep.of Congo } \\
\text { Kuwait } \quad \text { Saudi Arabia } \\
\text { Libya } \quad \text { Senegal } \\
\text { Mali } \quad \text { Togo } \\
\text { Namibia } \quad \text { Turkmenistan } \\
\text { Niger } \quad \text { UAE }\end{array}$ & $\begin{array}{l}\text { Angola } \\
\text { Azerbaijan } \\
\text { Bolivia } \\
\text { Egypt } \\
\text { Guinea } \\
\text { Guyana } \\
\text { Nigeria } \\
\text { Sudan } \\
\text { Suriname } \\
\text { Tajikistan } \\
\text { Trinidad \& Tobago } \\
\text { Uzbekistan } \\
\text { Yemen }\end{array}$ & $\begin{array}{l}\text { Burundi } \\
\text { Iran } \\
\text { Lao PDR } \\
\text { Mauritania } \\
\text { PNG }\end{array}$ & $\begin{array}{l}\text { Algeria } \\
\text { Belarus } \\
\text { Dem R. Congo } \\
\text { Kyrgyz Rep. } \\
\text { Venezuela }\end{array}$ & $\begin{array}{l}\text { Armenia } \\
\text { Colombia } \\
\text { Ghana } \\
\text { Iceland } \\
\text { Jamaica } \\
\text { Kazakhstan } \\
\text { Malaysia } \\
\text { Mongolia } \\
\text { Mozambique } \\
\text { Peru } \\
\text { South Africa } \\
\text { Zambia }\end{array}$ & $\begin{array}{l}\text { Australia } \\
\text { Canada } \\
\text { Chile } \\
\text { Norway } \\
\text { Russia }\end{array}$ \\
\hline
\end{tabular}

Source: IMF Annual Report on Exchange arrangements and Exchange Restrictions.

15. A number of commodity exporters have adopted structural policy measures, with a view to limit the adverse effects of the price shock, and/or to enhance the absorptive capacity, or resilience, of their economies to future shocks. In particular, some countries introduced banking reforms and strategies to address the challenges faced by state-owned 
banks exposed to the commodity sector. Some countries introduced wage/hiring freezes as part of their fiscal consolidation plans. A few others adopted policies to increase labor market flexibility or raise labor productivity, undertook efforts to diversify the export base and reduce dependence on the oil sector and measures to strengthen the business climate, including to diversify the energy base.

16. Commodity exporters will continue to face similar pressures on their domestic economies as further shocks to commodity prices materialize in the future. Depressed commodity prices, or possible future drops - as seen in the context of the COVID-19 crisis from early 2020 - are likely to erode countries' ability to maintain pegged or stabilized exchange rates, as FX reserves are exhausted or fiscal buffers, where they exist, are depleted (as a result of falling export revenues or, in some cases, procyclicality of policies). Further shocks will also reduce countries' capacity to limit the cost of exchange rate volatility on their economies where flexible regimes are maintained. With monetary and fiscal policy room to respond to shocks significantly reduced since 2014 in most commodity-exporters, policy frameworks will need to be strengthened to enhance resilience to further shocks.

\section{EMPIRICAL ANALYSIS: EXCHANGE RATE FLEXIBILITY AS A SHOCK ABSORBER}

17. An extensive literature views flexible exchange rates as a key shock absorber for small open economies facing severe ToT shocks. Flexible exchange rates are believed to reduce the burden of adjustment to a ToT shock and smooth the adjustment process that typically takes place through income and expenditure-switching effects (see e.g., Corden 1994). In particular, the reduced purchasing power associated with persistently weaker ToT results in reduced domestic demand and imports (income effect) and relative price changes result in higher exports and a shift from foreign toward domestically produced goods on the demand side and a shift of resources from non-tradable to tradable sectors on the supply side (expenditure-switching), helping to restore the external balance. In this context, exchange rate flexibility is believed to facilitate relative price adjustment and mitigate the real effects of ToT shocks (e.g., Eichengreen and Mason, 1998; Ötker-Robe and Vávra, 2007; Ghosh, Ostry, 2009, and the literature cited therein).

18. At the same time, pegged exchange rate regimes can serve as an anchor for inflation and support macroeconomic stability. Pegged exchange rates are associated with better inflation and growth performance in the absence of an overvalued exchange rate that can undermine competitiveness. However, they can also increase susceptibility to financial and currency crises (e.g., Ghosh, Ostry, and Tsangarides, 2009, Mussa and others, 2000, Bubula and Ötker-Robe, 2003, and Husain, Mody, and Rogoff, 2005), and constrain the use of other macroeconomic policies, hindering timely adjustment to a shock (e.g., Eichengreen and Mason, 1998, Ghosh, Ostry, and Tsangarides, 2009, and Ghosh and Ostry, 2009).

19. Empirical literature broadly supports the important role flexible exchange rates can play as a buffer against commodity price shocks. Adler, Magud, and Werner (2017) conclude, based on a large number of boom/bust episodes for 150 countries, that flexible exchange rates act as shock absorber for positive ToT shocks though this effect is statistically insignificant for negative ToT shocks. Carrière-Swallow, Magud, and Yepéz $(2017 \mathrm{a}, \mathrm{b})$ find, in a sample of 60 small open economies, that the cost of adjustment to adverse ToT shocks (the sacrifice ratio) falls with exchange rate flexibility, even with 
dollarized balance sheets and varying degrees of exchange rate passthrough. Devereux and $\mathrm{Yu}(2016)$ argue that a severe shock would have a smaller effect in a country with a flexible exchange rate and Schmitt-Grohe and Uribe (2016) find that in countries with downward rigidity in nominal wages, a large external shock can result in lower unemployment under flexible exchange rates. For 48 commodity exporters, Carriere-Swallow, Magud, and Yepez (2017) find that larger external adjustments contributed to higher growth among countries with flexible rates, which also used less buffers while keeping fiscal positions in balance during the shock; large depreciations, however, were also associated with higher inflation.

20. The empirical literature also suggests that the strength of the shock-absorbing ability of flexible exchange rates can differ across sectors and economies. CarrièreSwallow, Magud, and Yepéz (2017) show that manufacturing products tend to be more responsive to depreciation than commodities, suggesting that the scope for flexible exchange rates to support external adjustment may be more limited for commodity-exporters. IMF (2017) also finds that net export adjustments were the weakest in countries with fixed exchange rates, while countries with flexible regimes saw strong net export adjustments, but the adjustment was more due to a significant contraction in imports, likely reflecting lower sensitivity of commodity exports to the exchange rate. Similarly, Behar and Fouejieu (2016) show, for a sample of 24 oil exporters, that specific features of oil exporters may limit the extent of income and expenditure switching effects that typically facilitate external adjustment under exchange rate flexibility (e.g., less diversified economies with a limited nonoil export sector, globally-determined export prices that reduce export elasticity to exchange rate changes, high dependence on imports that reduce import sensitivity to the exchange rate, and labor market rigidities (e.g., wage stickiness, high reservation wages).

21. In what follows, this paper explores the role of exchange rate flexibility as a shock absorber, examining the macroeconomic effects of the recent commodity price collapse. It uses event study and PVAR approaches, to explore the evolution of key macroeconomic variables under alternative exchange rate regimes for a large sample of commodity exporters, followed by a more formal analysis of the regime choice.

\section{A. An Event Study Approach}

22. The event-study analysis compares the behavior of key macroeconomic and financial variables before and after the 2014 price collapse. With period $t$ denoting 2014, the year of commodity price collapse, the event study compares the pre-event period, $t-1$ to $t$ 4 , with the post-event period, $t+1$ to $t+4$, without controlling for other factors that may also affect macro performance, splitting the sample into the pegged regime group (hard and soft pegs) and the floating regime group (floating, managed floating, and free floating regimes). To control for the influence of a regime shift, the 13 countries that changed regimes over the sample period are excluded from the analysis, as well as the five countries with political instability during the sample period.

23. The results support the claim that exchange rate flexibility can facilitate absorption of commodity price shocks (Figures 6a-c). Countries with floating regimes had, on average, higher growth rates than those with pegged regimes and recovered more quickly. The differences in growth performance across the two episodes are statistically significant (based on t-tests) only for pegged regimes (Figure 7). While countries with floating regimes also had lower post-shock growth rates and higher inflation compared to pre-shock, the 
difference is not statistically significant. Moreover, the real effective exchange rate (REER) depreciated significantly in the floating group, while continuing to appreciate after the shock under pegs. The current account balance reversed from a comfortable surplus to a deficit in this group, with the significant fall in export receipts, while it was broadly stable before and after the commodity shock for the floating group. The fiscal balance also deteriorated considerably under pegs, which could reflect the need to implement fiscal stimulus, fiscal buffers that could be used to support demand, or greater dependence of fiscal revenues on commodities. As noted above, in year $\mathrm{t}+2$, most pegged countries implemented drastic fiscal consolidation. Public debt rose under both, but the rise is not statistically significant in either group.

Figure 6a. Macroeconomic Performance Before/After the Commodity Shock: Event Study ${ }^{1}$

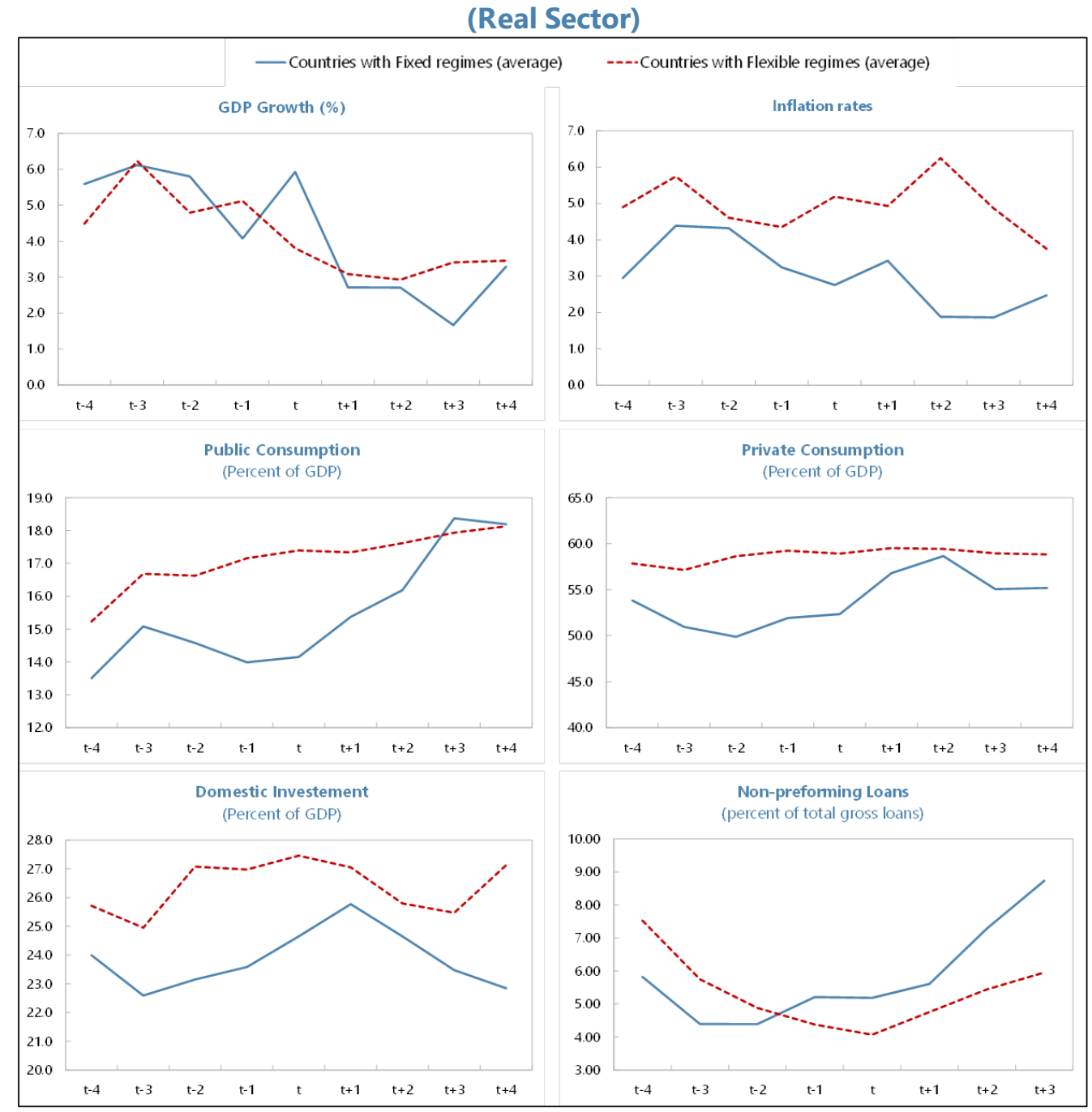

1 Pegged regimes include: Hard pegs (currency boards, dollarized economies) and soft pegs (conventional pegs, stabilized arrangements, crawling pegs, crawl-like arrangements, and exchange rates with a horizontal band). Flexible regimes include: Floating, other managed floating, and free floating regimes. Countries with pegged regimes include: Bahrain, Benin, Bolivia, Brunei Darussalam, Burkina Faso, Cameroon, Chad, Congo, R. of, Côte d'Ivoire, Ecuador, Equatorial Guinea, Eritrea, Gabon, Guyana, Kuwait, Mali, Namibia, Nigeria, Niger, Oman, Qatar, Saudi Arabia, Senegal, Togo, Timor-Leste, Turkmenistan, United Arab Emirates, and Uzbekistan. Countries with flexible regimes include: Algeria, Australia, Canada, Chile, Colombia, Ghana, Iceland, Kyrgyz R., Malaysia, Mongolia, Mozambique, Norway, Peru, South Africa, and Zambia. Commodity-exporting countries (with the ratio of commodity exports to total exports around $20 \%$ on average, in a given decade) that changed exchange rate regimes during 2013-17 or had political unrest are not included in this analysis. 
Figure 6b. Macroeconomic Performance Before/After the Commodity Shock: Event Study' (External Sector)

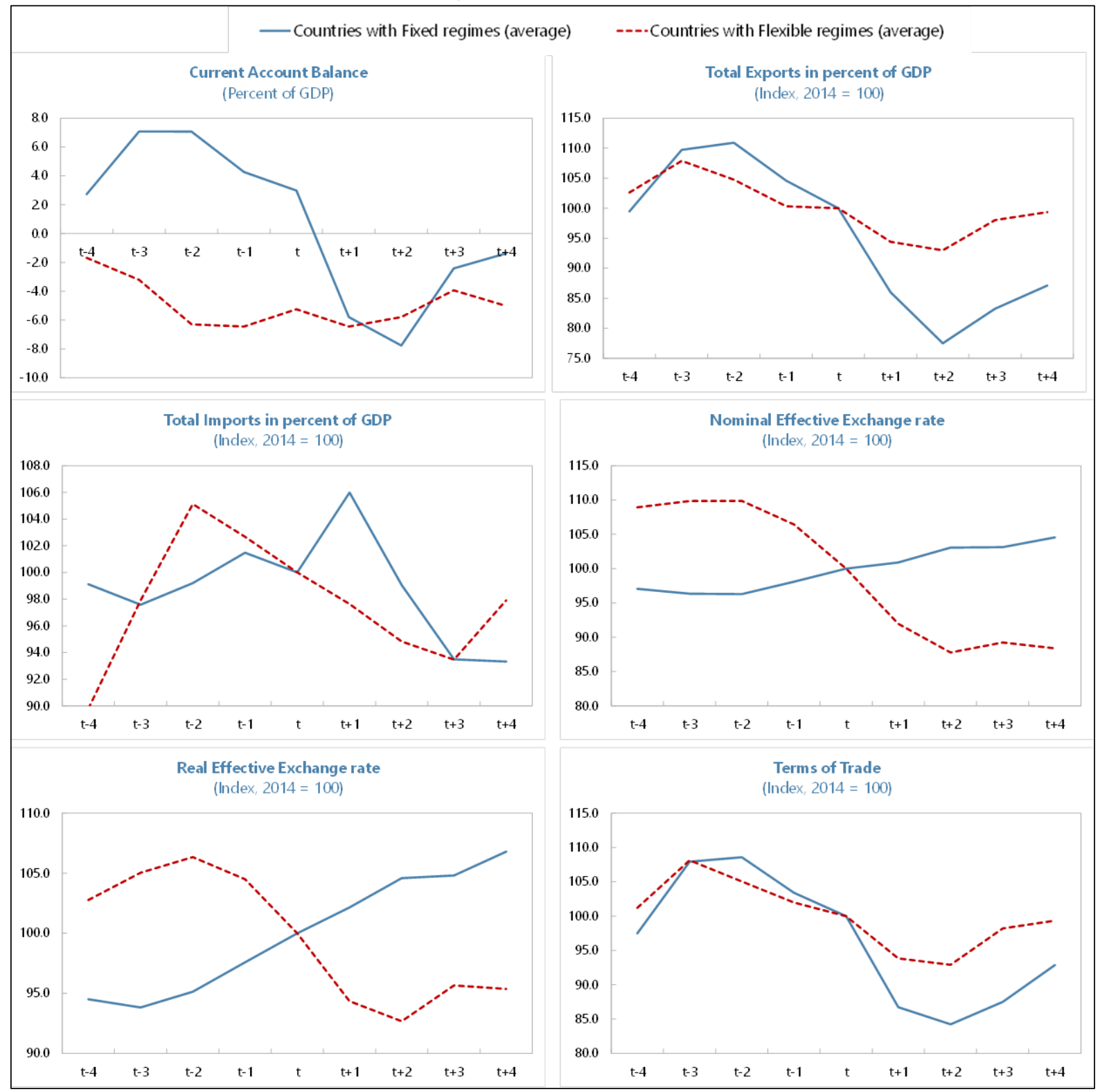

1 Pegged regimes include: Hard pegs (currency boards, dollarized economies) and soft pegs (conventional pegs, stabilized arrangements, crawling pegs, crawl-like arrangements, and exchange rates with a horizontal band). Flexible regimes include: Floating, other managed floating, and free floating regimes. Countries with pegged regimes include: Bahrain, Benin, Bolivia, Brunei Darussalam, Burkina Faso, Cameroon, Chad, Congo, R. of, Côte d'Ivoire, Ecuador, Equatorial Guinea, Eritrea, Gabon, Guyana, Kuwait, Mali, Namibia, Nigeria, Niger, Oman, Qatar, Saudi Arabia, Senegal, Togo, Timor-Leste, Turkmenistan, United Arab Emirates, and Uzbekistan. Countries with flexible regimes include: Algeria, Australia, Canada, Chile, Colombia, Ghana, Iceland, Kyrgyz R., Malaysia, Mongolia, Mozambique, Norway, Peru, South Africa, and Zambia. Commodity exporting countries (with the ratio of commodity-exports to total exports around $20 \%$ on average, in a given decade) that changed exchange rate regimes during 2013-17 or had political unrest are not included in this analysis. 
Figure 6c. Macroeconomic Performance Before/After the Commodity Shock: Event Study ${ }^{1}$ (Fiscal Sector)

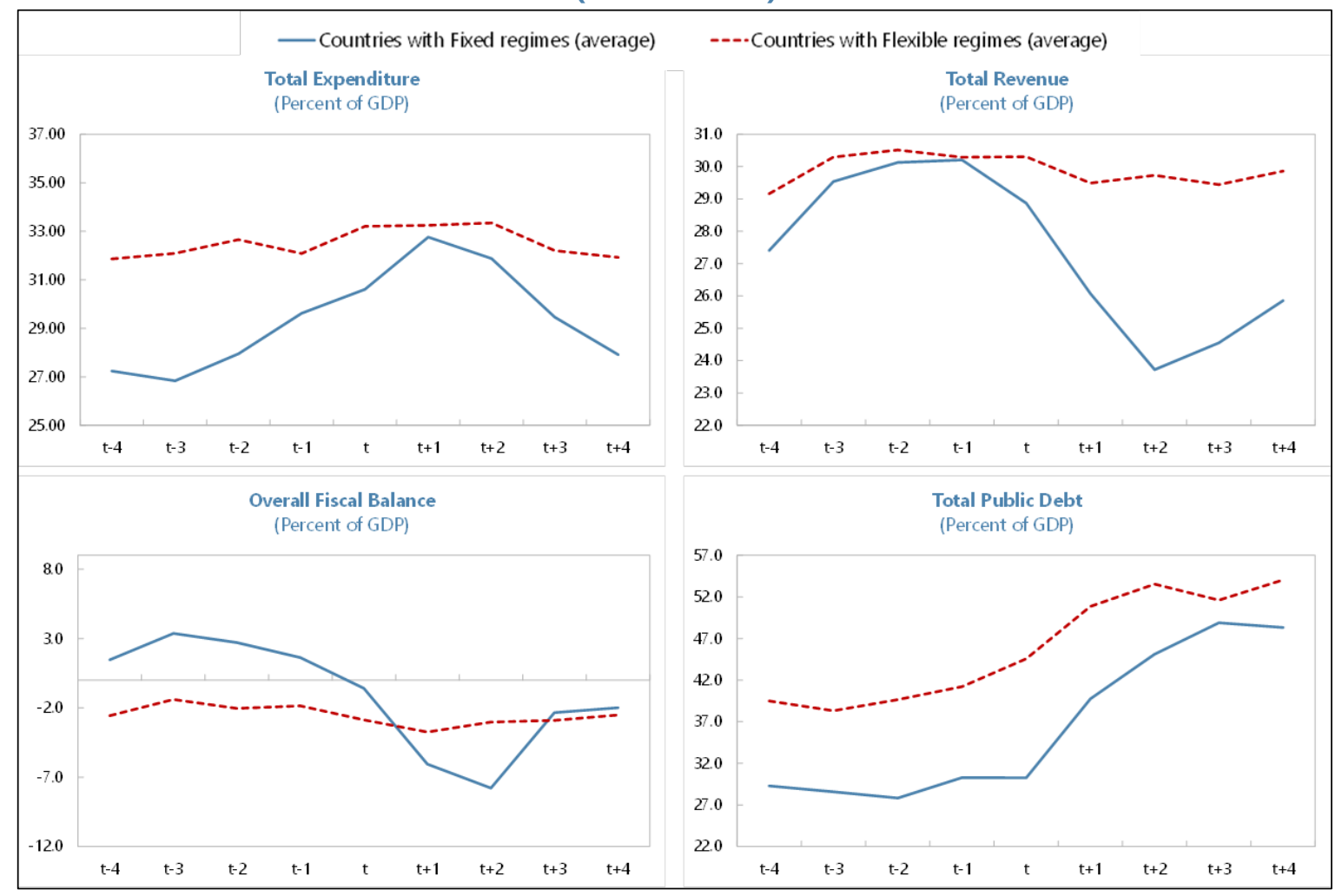

1 Pegged regimes include: Hard pegs (currency boards, dollarized economies) and soft pegs (conventional pegs, stabilized arrangements, crawling pegs, crawl-like arrangements, and exchange rates with a horizontal band). Flexible regimes include: Floating, other managed floating, and free floating regimes. Countries with pegged regimes include: Bahrain, Benin, Bolivia, Brunei Darussalam, Burkina Faso, Cameroon, Chad, Congo, R. of, Côte d'Ivoire, Ecuador, Equatorial Guinea, Eritrea, Gabon, Guyana, Kuwait, Mali, Namibia, Nigeria, Niger, Oman, Qatar, Saudi Arabia, Senegal, Togo, Timor-Leste, Turkmenistan, United Arab Emirates, and Uzbekistan. Countries with flexible regimes include: Algeria, Australia, Canada, Chile, Colombia, Ghana, Iceland, Kyrgyz R., Malaysia, Mongolia, Mozambique, Norway, Peru, South Africa, and Zambia. Commodity exporting countries (with the ratio of commodity-exports to total exports around $20 \%$ on average, in a given decade) that changed exchange rate regimes during 2013-17 or had political unrest are not included in this analysis.

Figure 7. Differences in Macroeconomic Performance Pre/Post Commodity Shock

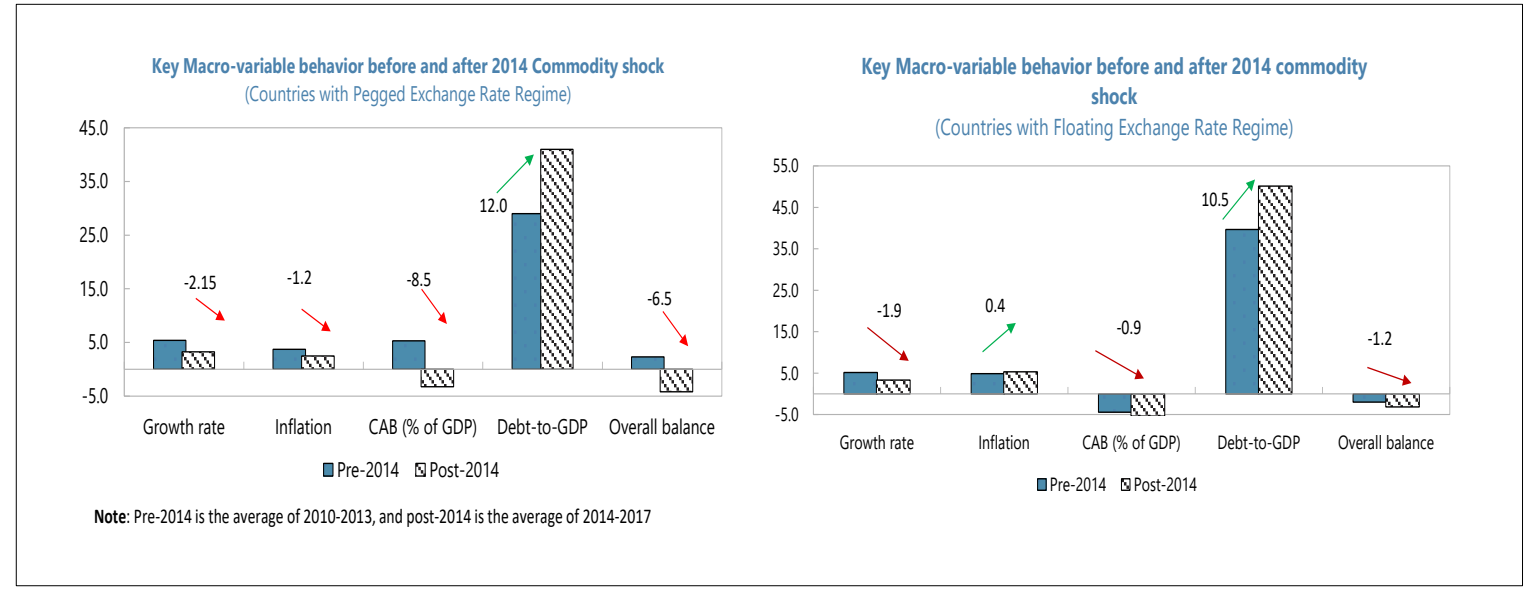

CInternational Monetary Fund. Not for Redistribution 


\section{B. The PVAR Approach}

24. The event study analysis above suggests that flexible regimes allow a smoother adjustment after a commodity price collapse but may not tell a full story. Event studies provide estimates of the short-run effects of a major event but do not consider other factors that could have affected economic performance around the commodity shock. A PVAR approach is used here to assess the dynamic relationship between macroeconomic volatility and exchange rate regimes and test whether economies with different regimes respond differently to exogenous shocks, controlling for other factors that may affect the outcome. The PVAR captures both static and dynamic interdependencies while accounting for crosssectional heterogeneities (Canova and Ciccarelli, 2013). The reduced-panel VAR specification takes the following form:

$$
Y_{i, t}=A(L) Y_{i, t}+C X_{i, t}+\delta_{i}+u_{i, t}
$$

where $Y_{i, t}$ is a vector of endogenous variables $\left[\operatorname{lnctt} \mathrm{i}_{\mathrm{i}, \mathrm{t}}, \ln _{\mathrm{i}, \mathrm{t}} \operatorname{lngov}_{\mathrm{i}, \mathrm{t}} \ln \operatorname{lner}_{\mathrm{i}, \mathrm{t}} \operatorname{lncp\mathrm {i}_{\mathrm {i},\mathrm {t}}]}{ }^{\prime}\right.$ for country $(i)$ at year $(t)$ comprising commodity ToT index $\left(\operatorname{lnctt} t_{i, t}\right)$, real GDP per capita $\left(\ln y_{i, t}\right)$, real government consumption growth $\left(\operatorname{lngov}_{i, t}\right)$, real effective exchange rate $\left(\right.$ lnreer $\left._{i, t}\right)$, and consumer price index $\left(\operatorname{lncpi} i_{i, t}\right)$. $A(L)$ is matrix polynomial in the lag operator of order $q=1 .{ }^{3}$ $X_{i, t}$ is a vector of exogenous (control) variables, $\delta_{i}$ is time-invariant country-specific factors, and $u_{i, t}$ is a vector of structural error terms.

25. Control variables included in the PVAR draw on the various factors that affect the choice of the exchange rate regime, including the characteristics of the economy (see also the next section): the size of the economy, proxied by the log of population (lnpop $\left.p_{i, t}\right)$; the level of financial development $\left(\right.$ inde $\left._{i, t}\right)$, proxied by broad money as a percentage of GDP; and the degree of trade openness $\left(\right.$ open $\left._{i, t}\right)$, proxied by the sum of total exports and imports as a percentage of GDP. All variables are expressed in log format.

26. To test the difference in macroeconomic adjustments to shocks under different exchange regimes, two more conditions are required. First, $A(L)$ and $C$ should be different across regimes, which can be achieved by interacting $A(L)$ and $C$ with a dummy variable for the exchange rate regime, $R_{i, t}$, where $R_{i, t}=1$ if the regime is flexible and zero otherwise. Second, to avoid the impact of exchange rate regime switch, only observations with the same exchange rate regime over at least 3 consecutive periods are included (Broda, 2004):

$$
R_{i, t-1}=R_{i, t}=R_{i, t+1}
$$

27. Implementing a VAR technique on panel data requires imposing the same underlying structure for each cross-sectional country in our sample (i.e., the coefficients in the matrix in the $A(L)$ are the same for all countries, which might not hold in practice (Love and Zicchion, 2006). To relax this assumption, and to account for cross-sectional heterogeneities, time-invariant country-specific factors are included in the Equation (1). However, in the presence of the lagged dependent variable on the right-hand side of the equation and the time-invariant country-specific factors, any attempt to estimate the model using conventional estimation method would yield inconsistent estimates because of the correlation between the lagged dependent variable and the error terms (Nickell, 1981). To

\footnotetext{
3 The lag length has been chosen using the Akaike information criteria.
} 
overcome this issue, Generalized Method of Moments (GMM) is used to estimate consistently the PVAR model.

28. A common challenge in the empirical literature is to identify the exogenous shocks to the ToT. To examine the impact of commodity price movements on macroeconomic variables, most empirical studies use prices of individual commodities or indices of aggregate commodity price movements (Gruss and Kebhaj, 2019). However, as noted in Gruss and Kebhaj (2019), this may be a poor approximation for ToT shocks. First, while most of commodity prices tend to move together, the correlation of unrelated commodities is very weak. Second, there is substantial heterogeneity in price variations within aggregate commodity categories. Even when a country specializes in a certain commodity category, an aggregate price index is likely to poorly track the ToT shock faced.

29. Accordingly, the analysis here uses country-specific measures of commodity ToT that take into account the composition of a particular country's commodity export and import basket weighted by its GDP (Appendix 1). The variations in this index provides an estimate of the windfall gains and losses of income associated with changes in international prices of these commodities. In this setting, the final impacts of an improvement in the commodity ToT will likely depend on whether it reflects a rise in the price of a commodity a country exports or a fall in the price of a commodity it imports. Using this index rather than commodity prices helps include different commodity exporters in the sample.

30. The analysis is based on unbalanced panel data of 63 commodity-exporting countries over the period 1980-2017. ${ }^{4}$ Macroeconomic data are from IMF's World Economic Outlook database (2019) and the World Bank's World Development Indicators (2019). Data on the de facto exchange regime classification are based on the IMF's Annual Report on Exchange Arrangements and Exchange Restrictions (AREAER) which categorizes 10 exchange rate regimes by the degree of exchange rate flexibility. The analysis groups the regimes of no separate legal tender (currency unions and fully-dollarized economies), currency boards, conventional pegs, stabilized arrangements, pegged exchange rates within horizontal bands, crawling pegs, and crawl-like arrangements as "pegged exchange rate regimes" and the rest as "floating regimes." The distribution of exchange rate regimes between 2013-17 suggests that most commodity-exporting countries maintain pegged exchange rate regimes (Section II).

31. The PVAR impulse-response functions (IRFs) of the key macroeconomic variables support the event-study findings that adjustment following a commodity ToT shock is smoother under flexible regimes. The IRFs of real GDP per capita, real exchange rate, real government consumption, and consumer price index to a 10 percent fall in the ToT show that a negative ToT shock has a recessionary and statistically significant impact under both fixed and flexible regimes. Under fixed regimes, real GDP per capita deteriorates by 1.2 percent and remains low in the following periods, compared with a 0.7 percent fall under

\footnotetext{
${ }^{4}$ As mentioned above, a country is classified here as a commodity exporter (fuel/metal) if the share of commodity exports in total goods exports is at least 20 percent on average in a given decade, ensuring most commodity exporters are included. The results of this analysis seem to be robust under different degrees of commodity dependence (see below) and different exchange regime classifications (e.g., Ilzetzki et al. (2019)).
} 
flexible regimes, and recovers more slowly, suggesting that the adjustment process of real GDP per capita to a negative ToT shock systematically differs across regimes (Figure 8). ${ }^{5}$

32. The differences in the adjustment of real GDP growth can be attributed to the response of the real exchange rate to the shock. From a theoretical perspective, under a flexible exchange rate regime, real depreciation is more accentuated than under fixed regimes and stabilizes the real economy through relative domestic price changes (Hoffmann, 2006); this is also supported by the stylized facts presented in Section II (also see Cashin, Cespedes, and Sahay, 2004). The real exchange rate response to a 10 percent decline in the commodity ToT shock is larger under flexible regimes (Figure 8), where the real exchange rate depreciates immediately by 1.8 percent, compared to only 0.4 percent depreciation under fixed regimes. The (somewhat-unexpected) jump in government spending under floating regimes could also have supported growth.

Figure 8. Baseline: Impu lse Responses to a 10 Percent Drop in Commodity Terms of Trade

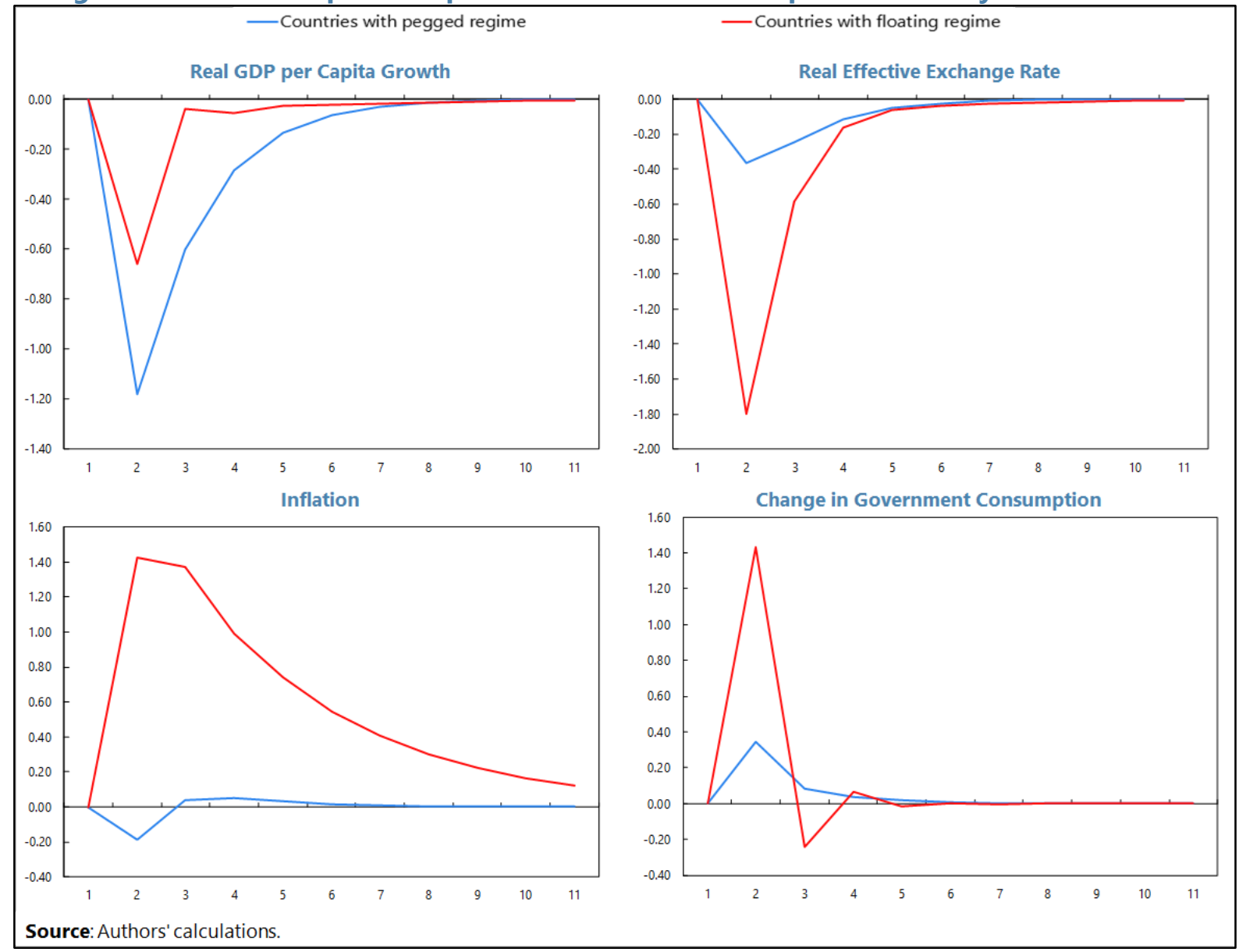

\footnotetext{
${ }^{5}$ In estimating the PVAR, the analysis assumes that the change in commodity ToT shock is exogenous from the perspective of individual countries, ensuring it is exogenous to domestic developments. Gruss and Kebhaj (2019) provides evidence showing that their commodity ToT index is indeed exogenous. The results are robust to alternative ordering in the external block (that is, assuming that ToT shocks affect economic activity contemporaneously). Panel roots test shows that all variables are non-stationary in levels but stationary in first differences. Accordingly, all variables are transformed by taking their first differences to exhibit stationarity.
} 
Figure 9. Impulse Responses of Real GDP per capita Growth to a 10-percent Negative Commodity ToT Shock under Alternative Model Specifications

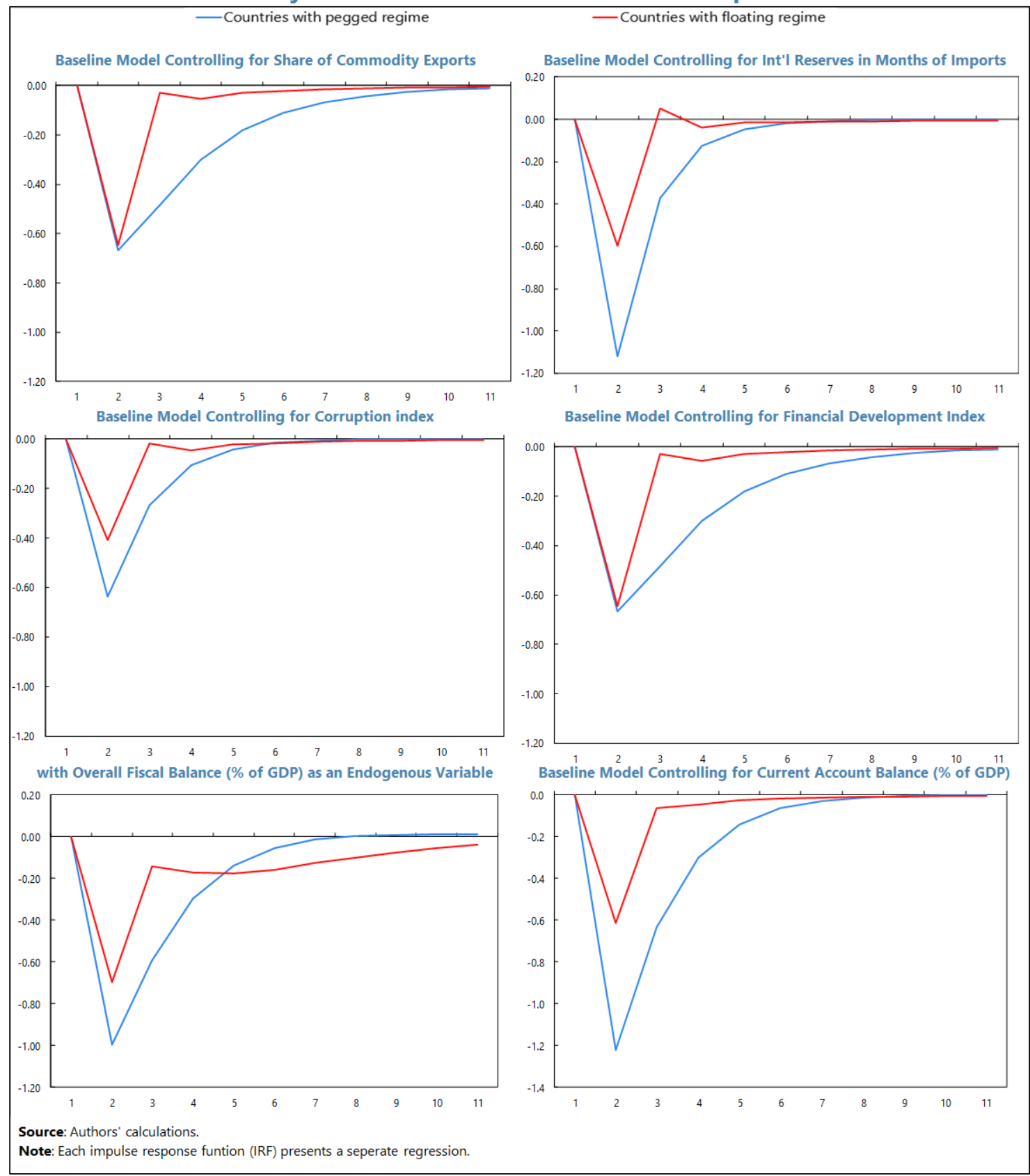

33. The finding of a less severe growth response to a negative ToT shock under flexible regimes holds under several robustness checks (Figure 9). The robustness checks include: using a different set of control variables (the share of commodity exports in total exports of goods and services, existence of buffers (proxied by foreign reserves in months of imports), alternative indicators of financial development, and institutional variables such as corruption, law and order, the quality of government bureaucracy, and index of government stability), and change in the current account balance as a percentage of GDP); and the overall fiscal balance as an endogenous variable instead of real government consumption. Each variable has been included one at a time in the baseline Equation (1), with each IRF 
representing a separate estimation. In all cases, the IRFs still show that real GDP per capita response to adverse commodity terms of trade shock is smoother under flexible than pegged regimes (either in terms of drop in growth or its pace of recovery after the shock). The results are also robust to other sensitivity analyses, including the exclusion from the sample of advanced economies and non-oil commodity-exporting countries to distinguish the possible differences in responses across different commodity exporters. ${ }^{67}$

\section{Assessing The Exchange Rate Regime CHOICE}

34. Given the relatively less disruptive adjustment to commodity price shocks under flexible exchange rates, why do many commodity exporters maintain pegged exchange rate regimes? The Optimum Currency Area (OCA) literature (Mundell, 1961) offers a large set of criteria with a bearing on a country's choice of exchange rate regime (Table 6). In general, pegged regimes are easier to implement when inflation and capital mobility is low, reserve levels and trade integration with the anchor country are high, economic shocks are nominal in nature or similar with the anchor country, labor markets and fiscal policy are flexible, and the production/export base is well-diversified. More synchronized business cycles and the lack of monetary policy credibility to achieve disinflation increase the benefit of sharing anchor country's monetary policy. In the absence of flexible fiscal policy and labor/product markets, flexible exchange rates can facilitate relative price adjustment and reallocate labor in the direction that helps reduce the negative effects of shifts in demand.

\section{Regime choice should hence be seen from a lens of multiple considerations. A}

key consideration in this regard is the structural characteristics of an economy, including the importance of the commodity sector in output, exports, and government revenues (Khan, 2009), the sensitivity of exports to exchange rate changes, and the extent of economic diversification. The chosen regime should yield international competitiveness, external stability (low trade and current account imbalances), internal stability (low inflation), balance sheet stability, a credible monetary policy, and low transaction costs (Husain, 2006). Excessive exchange rate volatility can raise transaction costs in international trade and finance by increasing uncertainty. Various criteria affecting the regime choice may clash, making the regime choice a challenge.

36. Actual regime choices may, therefore, differ from what is suggested by the OCA literature, and depend on how countries address the tradeoffs across various economic criteria and consider noneconomic criteria in their regime choices. Country authorities may be reluctant to adopt flexible rates - the so-called fear of floating - even when they see benefit from doing so-reflecting concerns about losing policy credibility in the absence of a credible alternative nominal anchor and adequate capacity to implement alternative monetary frameworks; high exchange rate passthrough to inflation; absence of tools and markets to manage exchange rate risk; and adverse effects of exchange rate movements on public and private balance sheets with mismatched currency positions.

\footnotetext{
${ }^{6}$ Results are not reported but are available upon request from the authors.

${ }^{7}$ An additional robustness check, for future research, could be to test empirically whether the monetary policy regime such as inflation targeting can play an effective role in dealing with ToT shocks and see how a country with such a framework might react to deviations from the target caused by the ToT shock.
} 
Table 6. Factors Affecting the Choice of Exchange Rate Regime for Commodity Exporters

\begin{tabular}{|c|c|}
\hline CRITERIA & Implications for the Desired Degree of EXChange Rate FleXibiLity \\
\hline \multicolumn{2}{|l|}{ Initial Conditions } \\
\hline Very high inflation & $\begin{array}{l}\text { The more divergent a country's inflation rate from its trading partners', the greater the need for frequent } \\
\text { exchange rate adjustments. This makes either a free or a managed float, wide bands around a central parity, } \\
\text { or a crawling peg regime more feasible. But for a country with hyperinflation where inflation inertia is low } \\
\text { and money demand is unstable, more rigid forms of pegs may increase credibility of stabilization effort and } \\
\text { achieve rapid disinflation. }\end{array}$ \\
\hline Large external imbalance & $\begin{array}{l}\text { The larger the external imbalances at the outset, the greater is the need for a more flexible exchange rate } \\
\text { (either crawling pegs or free or managed floating rates). }\end{array}$ \\
\hline Level of foreign reserves & $\begin{array}{l}\text { The lower the level of international reserves, the less feasible it is to maintain an exchange rate peg or } \\
\text { narrow bands, unless monetary policy is clearly subordinated to the exchange rate objective. }\end{array}$ \\
\hline \multicolumn{2}{|c|}{ Characteristics of the economy } \\
\hline Size of the economy & The larger the economy, the stronger is the case for a flexible rate. \\
\hline Openness & $\begin{array}{l}\text { The more open the economy, the stronger the case for a fixed rate or narrow bands because of the potential } \\
\text { cost to international transactions of frequent exchange rate adjustments; however, openness may also } \\
\text { increase the vulnerability to external shocks and may require more frequent exchange rate adjustments and } \\
\text { thus a more flexible arrangement. }\end{array}$ \\
\hline $\begin{array}{l}\text { Diversification of } \\
\text { exports/output }\end{array}$ & $\begin{array}{l}\text { Output/export diversification makes a country less vulnerable to terms of trade shocks and is less likely to } \\
\text { need exchange rate flexibility. A pegged regime would limit the capacity to absorb adverse external shocks if } \\
\text { production and exports are not diversified. }\end{array}$ \\
\hline $\begin{array}{l}\text { Trade and political } \\
\text { integration }\end{array}$ & $\begin{array}{l}\text { The higher the extent of trade integration with partner countries, the stronger the case for a pegged } \\
\text { exchange rate or common currency. }\end{array}$ \\
\hline Flexibility of labor markets & $\begin{array}{l}\text { The less flexible the labor market, the stronger the case for more flexible exchange rates (including pegs } \\
\text { within bands). }\end{array}$ \\
\hline $\begin{array}{l}\text { Fiscal flexibility / } \\
\text { sustainability }\end{array}$ & $\begin{array}{l}\text { Fiscal policy sustainability facilitates survival of a pegged exchange rate system; fiscal flexibility is important } \\
\text { to sustain a pegged regime in the absence of the exchange rate instrument as shock absorber. }\end{array}$ \\
\hline Mobility of capital & $\begin{array}{l}\text { High capital mobility may constrain the feasibility of pegged rates and pegs within narrow bands (empirically, } \\
\text { pegged and intermediate regimes have been found to be more crisis prone - bipolar view). Greater exchange } \\
\text { rate flexibility may also be an element of the optimal response to strong capital inflows, including by } \\
\text { discouraging short-term speculative inflows due to greater degree of exchange rate uncertainty. }\end{array}$ \\
\hline $\begin{array}{l}\text { Financial market } \\
\text { development }\end{array}$ & The greater the degree of financial market development, the more feasible it is to implement flexible regime. \\
\hline FX exposure & $\begin{array}{l}\text { The greater the exposure of public, private and financial institution balance sheets to FX risk (and the share } \\
\text { of FX liabilities in total liabilities), the less desirable to have exchange rate flexibility. }\end{array}$ \\
\hline \multicolumn{2}{|c|}{ Type of shocks to the economy } \\
\hline Foreign nominal shocks & The more prevalent are foreign nominal shocks, the more desirable to have greater exchange rate flexibility. \\
\hline Domestic nominal shocks & The more prevalent are domestic nominal shocks, the more desirable to have pegged exchange rates. \\
\hline Real shocks & $\begin{array}{l}\text { The greater the country's susceptibility to real shocks, the more beneficial to have greater exchange rate } \\
\text { flexibility. }\end{array}$ \\
\hline Asymmetric shocks & $\begin{array}{l}\text { If shocks affecting the economy and its trading partners tend to be asymmetric, more flexible rates are } \\
\text { desirable. }\end{array}$ \\
\hline \multicolumn{2}{|l|}{ Policymakers' objectives } \\
\hline Inflation reduction & If the more pressing policy objective is rapid disinflation, pegged exchange rate regimes may be preferable. \\
\hline $\begin{array}{l}\text { Correcting external } \\
\text { imbalances }\end{array}$ & $\begin{array}{l}\text { If the more pressing policy objective is to restore competitiveness and reduce external imbalances, more } \\
\text { flexible exchange rate regimes may be preferable (e.g., through crawling pegs, wide crawling or fixed bands). }\end{array}$ \\
\hline Output stabilization & If output stabilization is the main policy objective, more flexible exchange rate regimes may be preferable. \\
\hline $\begin{array}{l}\text { Credibility of } \\
\text { policymakers }\end{array}$ & $\begin{array}{l}\text { The lower the anti-inflation credibility of policymakers, the greater the attractiveness of a pegged exchange } \\
\text { rate as a nominal anchor by borrowing credibility of a partner country central bank. }\end{array}$ \\
\hline
\end{tabular}

Sources: Eichengreen and Mason (1998); Ötker-Robe and Vávra, 2007; and IMF, 2016 and literature cited therein.

\section{CInternational Monetary Fund. Not for Redistribution}


Perceptions of political or adjustment costs associated with abandoning a peg, or difficulties in assessing the appropriate regime or time to exit may also add to the fear of floating (ÖtkerRobe and Vávra, 2007 and IMF, 2016).

37. This section analyzes empirically the choice of exchange rate regime in a sample of commodity-exporting countries to assess the factors that may have a bearing on their regime choices. It estimates the probability of choosing a particular exchange rate regime as a function of a set of macroeconomic and structural factors, including those suggested by the OCA literature:

$$
y_{\mathrm{i}, \mathrm{t}}=x_{\mathrm{i}, \mathrm{t}-1}^{\prime} \boldsymbol{\beta}+c_{\mathrm{i}, \mathrm{t}-1}^{\prime} \boldsymbol{\alpha}+w_{\mathrm{i}, \mathrm{t}-1}^{\prime} \delta+\varepsilon_{\mathrm{i}, \mathrm{t}}
$$

where $i$ denotes the country and $t$ denotes time. $\boldsymbol{\beta}, \boldsymbol{\alpha}$, and $\boldsymbol{\delta}$ are parameters to be estimated, and $\boldsymbol{x}, \boldsymbol{c}$, and $\boldsymbol{w}$ represent the exogenous and control variables. The dependent variable $(y)$ is a dummy that takes the value 1 if the exchange rate in country $i$ is flexible and 0 otherwise. A positive sign for an estimated coefficient means that an increase in the associated variable implies a higher probability of choosing a flexible regime, compared to a pegged regime.

\section{The control variables distinguish between three groups of factors affecting a} country's exchange regime choice: (1) the OCA factors (the degree of trade openness, proxied by the sum of total exports and imports relative to GDP; economic size, proxied by total population or GDP; the degree of export diversification, proxied by the export concentration index; the level of development, proxied by real GDP per capita; capital account openness (proxied by the capital control index); and the level of financial development (proxied by the IMF financial development index); (2) Country-specific macroeconomic factors and initial conditions (exchange rate volatility; foreign reserves in months of imports; the inflation rate (and inflation volatility); terms of trade; the current account balance; fiscal room (proxied by the overall fiscal balance); and public debt); and (3) Institutional factors to approximate policy credibility (indicators to proxy independence and credibility of monetary policy, democratic institutions, and political stability). Appendix II describes the data sources, summary statistics, and the matrix of correlations between the variables. All independent variables are lagged by one year to address endogeneity.

39. The probability of choosing a flexible exchange rate regime is estimated by a random-effects logit model. The estimation uses unbalanced panel data for 63 commodityexporting countries over the period 1980-2017, with the random-effects logit model to account for country heterogeneity. Estimating the model alternatively by pooled-logit and random-effects probit models do not affect the results significantly.

40. The results, reported in Table 7, are broadly consistent with the findings of other empirical studies of exchange rate regime choice. Namely, no clear and robust set of macroeconomic, structural, or institutional variables can explain systematically the choice of exchange rate regimes. Significant and robust estimates are obtained only for a few control variables: the level of financial development (with a significant coefficient in 4 out of 8 specifications, with the expected positive sign), the degree of export diversification (with a significant coefficient in 6 of the 8 specifications, with a negative sign, suggesting that the higher the export concentration, the lower the probability to adopt a flexible regime), the public debt-to-GDP ratio (significant in 3 of 8 specifications, with an expected positive sign), 
and the degree of capital account openness (with a significant coefficient with the expected sign in only 2 specifications). Size has a positive and significant coefficient in one specification and none of the available institutional proxies used seem statistically significant determinants of regime choice.

Table 7. Determinants of Exchange Regime Choice: Empirical Results

\begin{tabular}{|c|c|c|c|c|c|c|c|c|c|}
\hline \multicolumn{10}{|c|}{$\begin{array}{l}\text { The Determinants of the Exchange Rate Regime Choice } \\
\text { Dependent Variable: dummy variable equals one if ER regime is Flexible and zero otherwise: 1980-2017 }\end{array}$} \\
\hline \begin{tabular}{|l|} 
Variables \\
\end{tabular} & Baseline & Model 2 & $\begin{array}{l}\text { Model } 3 \\
\end{array}$ & $\begin{array}{ll}\text { Model } 4 \\
\end{array}$ & Model 5 & Model 6 & Model 7 & Model 8 & Model 9 \\
\hline \multirow{2}{*}{ Log of Population } & -1.56 & 0.85 & -2.10 & -1.54 & 0.97 & -0.16 & -4.61 & 1.23 & 0.62 \\
\hline & -1.42 & 1.33 & -0.66 & $-1.74 * * *$ & 0.18 & -0.13 & -0.92 & $1.77 * * *$ & 0.21 \\
\hline \multirow{2}{*}{ log of GDP per capita } & -1.01 & 0.23 & 0.08 & -0.71 & 0.00 & 0.47 & 0.01 & 0.99 & -0.32 \\
\hline & -1.17 & 0.23 & 0.05 & -0.89 & 0.00 & 0.23 & 0.01 & 1.09 & -0.11 \\
\hline \multirow{2}{*}{ Degree of Openness } & -0.01 & -0.03 & 0.00 & -0.01 & -0.01 & -0.07 & 0.00 & -0.02 & -0.08 \\
\hline & -0.67 & -1.66 & 0.04 & -0.63 & -0.25 & -0.74 & -0.16 & -1.24 & -1.27 \\
\hline \multirow{2}{*}{ Financial Development Index } & 13.97 & 11.35 & 13.60 & 13.55 & 9.37 & 12.27 & 16.47 & 6.76 & 0.59 \\
\hline & 2.39* & $1.66 * * *$ & $117^{*}$ & $2.68 *$ & 0.57 & 0.65 & 1.27 & 1.18 & 0.03 \\
\hline \multirow{2}{*}{ Export Concentration Index } & -8.88 & -5.73 & -7.03 & -8.44 & -9.78 & -7.87 & -11.68 & -8.45 & -23.48 \\
\hline & $-2.7^{*}$ & $-1.96 * *$ & -1.47 & $-2.89 *$ & $-2.06 * *$ & -0.77 & -1.56 & $-2.58^{*}$ & $-1.81^{* * *}$ \\
\hline \multirow{2}{*}{ Capital Mobility Index } & 0.42 & 0.67 & 0.70 & 0.38 & 0.49 & 0.68 & 0.38 & 0.84 & -2.17 \\
\hline & 1.36 & 2.17 & 0.25 & 1.34 & 1.29 & 0.40 & 1.03 & $2.42^{*}$ & -1.38 \\
\hline \multirow{2}{*}{ Inflation Volatility } & 0.09 & 0.12 & 0.18 & 0.09 & 0.05 & 0.21 & 0.10 & 0.13 & 0.25 \\
\hline & 0.86 & 0.74 & 0.72 & 0.88 & 0.46 & 0.25 & 0.68 & 0.70 & 1.06 \\
\hline \multirow{2}{*}{ Democratic Institutions } & -2.22 & -4.62 & -4.30 & -1.89 & 2.44 & 5.47 & -3.18 & -4.62 & 16.80 \\
\hline & -0.84 & -1.56 & -0.67 & -0.81 & & 1.44 & -0.72 & -1.37 & 0.80 \\
\hline \multirow{2}{*}{ Political Risk } & 0.18 & -0.19 & 0.10 & 0.14 & 0.25 & 0.78 & 0.16 & -0.07 & -0.84 \\
\hline & 0.59 & -0.48 & 0.19 & 0.47 & 0.27 & 1.12 & 0.45 & -0.18 & -1.20 \\
\hline \multirow{2}{*}{ Total Public debt to GDP } & & 0.07 & & & & & & 0.07 & 0.08 \\
\hline & & & & & & & & 3.10* & $1.66^{* * *}$ \\
\hline Term of trade Index & & & $\begin{array}{l}-2.50 \\
-1.94 * * *\end{array}$ & & & & & & \\
\hline \multirow[t]{2}{*}{ Current Account Balance (\% of GDP) } & & & & 0.01 & & & & & -0.15 \\
\hline & & & & 0.38 & & & & & $-2.24^{*}$ \\
\hline \multirow{2}{*}{ Reserves in months of imports } & & & & & -0.09 & & & & 0.27 \\
\hline & & & & & -0.10 & & & & 2.06 \\
\hline \multirow{2}{*}{ Overall balance (\% of GDP) } & & & & & & 0.08 & & & 0.28 \\
\hline & & & & & & 0.60 & & & $1.91^{* * *}$ \\
\hline \multirow{2}{*}{ REER Volatility } & & & & & & & 0.01 & 0.02 & 0.01 \\
\hline & & & & & & & 1.01 & 1.62 & 0.32 \\
\hline \multirow{2}{*}{ Constant } & 17.82 & -1.60 & & 13.15 & 2.25 & -2.18 & 18.51 & -7.23 & 11.91 \\
\hline & 2.03 & -0.19 & & 1.92 & 0.15 & -0.16 & 1.30 & -1.01 & 0.43 \\
\hline No. of Observations & 1374 & 1204 & 1374 & 1374 & 1086 & 1011 & 1372 & 1202 & 1011 \\
\hline No. of Groups & 63 & 63 & 63 & 63 & 63 & 63 & 63 & 63 & 63 \\
\hline
\end{tabular}




\section{Policies to Support EXChange Rate Regime Choices and Transitions}

41. Taking these considerations and policy tradeoffs into account, some commodity exporters may judge that maintaining pegged exchange rates is the preferred, or the only viable, choice. Credibly committing to low inflation may be seen particularly challenging and costly in the absence of a strong institutional track record to anchor inflation expectations and pegged regimes may be seen as the best way to deliver on a price stability objective, in so far as exchange rate stability is important for price stability. Until such track record is established, reducing shock vulnerability may call for commitment to an exchange rate anchor and supporting it by prudent macroeconomic and structural policy frameworks and avoiding policies that can add to market pressures. Countries with an otherwise credible pegged regimes may also find it costly to abandon the peg in response to a ToT shock, in particular those with a very limited non-commodity sector to take advantage of a depreciated currency, or may lack the capacity or infrastructure to implement flexible exchange rates.

42. The two subsections below discuss the necessary ingredients to strengthen resilience to future shocks under both pegged and flexible exchange rate regimes. ${ }^{8}$

Section V.A considers how existing pegged or tightly managed exchange rate regimes can be sustained, if the best (or the only feasible) option is judged to be to maintain the existing regime, notwithstanding shock-absorbent benefits of flexible regimes. Section V.B then reviews, drawing on country experiences, alternative regime options and modalities of how to transition to greater flexibility and the "key ingredients" of a successful transition if authorities view that exiting from the prevailing regime enhances resilience to future adverse shocks to commodity prices.

\section{A. Supporting the Prevailing Pegged Exchange Rate Regime}

43. The inability to let the exchange rate absorb the impact of external shocks means that macroeconomic and structural policies must bear the burden of adjustment under pegged regimes. In the absence of flexible exchange rates, internal devaluation may be needed to restore external balance through adjustment in prices, wages, and employment. Increasing the flexibility of product and labor markets and could also facilitate adjustment and diversifying the product base helps reduce heavy dependence on shock-exposed sectors (Eichengreen and others, 1998; IMF, 2013) and increase the resilience of the economy to future shocks. Any (discrete) exchange rate adjustment that may be necessary as part of an overall policy response to market pressure should be accompanied by supporting macroeconomic and structural measures to sustain the new level of the peg.

\section{High exposure to ToT shocks makes adequate buffers essential under an} exchange rate commitment. Without adequate foreign reserve buffers, authorities may not be able to defend the peg. Availability of fiscal buffers and flexible fiscal policies that adjust through the cycle (countercyclical fiscal policy) could also help in responding to shocks. Building ample buffers during commodity booms can provide resources to support relaxed fiscal policy when the cycle turns (as seen in several GCC and Latin American countries during the recent shock). In the absence of fiscal space, credible fiscal consolidation becomes crucial to sustain the peg and limit debt accumulation. As discussed in Section II, the

8 The discussion draws heavily on IMF (2016) and Ötker-Robe and Vávra (2008). 
majority of commodity-exporting countries have limited ability to relax fiscal policy to contain the adverse impacts of the shock on economic activity.

\section{Successful operation of a pegged regime also requires subordinating monetary} policy to the exchange rate objective. In an economy with an open capital account and pressure on foreign reserves, there is little scope, if any, for an independent monetary policy, which must be set to arrest capital outflows and support the peg. Even where the capital account is not fully open, monetary policy inconsistent with the peg makes it vulnerable to market pressure.

46. Prudent financial policies are also key to sustain the peg. A resilient financial system provides greater room to tighten interest rates to defend the peg and reduces the potential fiscal and financial stability effects of such defense. A weak financial system may exacerbate exchange market pressures by raising doubts about authorities' willingness or ability to defend the exchange rate through interest rate hikes (Eichengreen and others, 1998) as the latter adversely affect borrowers' repayment capacity and banks' asset quality. Resilience to FX risks is particularly important under a peg that provides an implicit exchange rate guarantee and tends to encourage foreign currency borrowing. Appropriate prudential measures can limit a buildup of unhedged positions and help contain adverse effects of a discrete exchange rate adjustment needed to ease market pressures on the peg.

47. High exposure to commodity prices may also suggest a potential role for countercyclical macroprudential policy to mitigate a buildup of systemic risk. Such risks may accumulate due to possible feedback loops between growth, commodity prices, financial asset prices, export revenues, and government spending. Countercyclical tools targeting systemic risk arising from the procyclicality of export revenues can help financial institutions build capital and liquidity buffers, particularly where bank-sovereign linkages are prominent. A relaxation of macroprudential measures to alleviate the procyclicality in downturns is feasible, however, only to the extent relevant macroprudential buffers were built beforehand. The GCC countries and some advanced oil-producing countries implemented a range of macroprudential tools to build financial sector resilience (IMF, 2015a).

48. Capital flow management measures (CFMs) and FX market intervention may also be useful tools to defend the peg in certain circumstances (IMF, 2012). A consistent set of macroeconomic, structural, and financial sector policies should be the first line of defense in dampening capital outflows pressuring the peg. CFMs should generally be used only in crisis situations or when a crisis is considered to be imminent. In countries with fixed exchange rates with limited scope for exchange rate adjustments, (unsterilized) FX market intervention may be needed to support the necessary macroeconomic and structural policy adjustments. Under non-crisis conditions, interventions in a fixed exchange rate regime should be rules-based to provide a clear commitment to maintaining the pegged regime.

\section{B. Moving to Greater Exchange Rate Flexibility}

49. Some commodity exporters may choose to switch to more flexible exchange rates for a multitude of reasons. In addition to providing a greater degree of monetary policy autonomy and flexibility to respond, and build resilience, to sharp fluctuations in commodity prices, flexible exchange rates can discourage a buildup of large unhedged 
foreign currency positions and limit one-way bets against the currency by reducing implicit exchange rate guarantees that are typically offered by exchange rate pegs, and in so doing, stimulate prudent risk management and FX market development.

50. Successful transitions to exchange rate flexibility require a careful approach, to put in place a mix of essential ingredients: (1) a credible nominal anchor to guide inflation expectations under the new monetary policy framework with flexible exchange rates; (2) a well-functioning FX market that facilitates management of exchange rate risks; (3) systems to facilitate and monitor FX risk management; and (4) a coherent intervention policy consistent with the new regime (Duttagupta, Fernandez, and Karacadag, 2004-Box 1). Sound macroeconomic and structural policies support the transition by establishing fiscal and monetary discipline and a resilient financial system capable of coping with FX risks.

51. Establishing these ingredients takes time and requires substantial capacitybuilding efforts. Inadequate preparation affects the pace and manner in which countries move to greater flexibility and the type of the transition regime and could increase the possibility of being pushed by the market to a disorderly float. For example, Brazil, the Czech Republic, and Uruguay, which were implementing various forms of pegs in the 1980s and early 1990s, were forced out of their pegged regimes under market pressure and the level of their preparedness affected the ease of transition. Others, such as Chile, Israel, and Poland, had gradual transitions involving a step-by-step move to a full float over a period of 10-15 years (Eichengreen, Mason, and others, 1998, and Ötker-Robe and Vávra, 2007).

\section{What Regime to Exit to?}

\section{The choice of the regime to exit to is relevant to the extent that the exit is in a} period of relative calm, at the initiative of country authorities. When the exit is called by the market under pressure, the very high cost of defending the exchange rate leaves the country with no choice but to float and typically endure a sharp depreciation until credibility is restored. The extensive literature on exchange regime choice provides some options on which regime to exit to, considering the country's structural characteristics, initial conditions, policy objectives, and the host of shocks, pointing, in particular, to more flexible forms of pegs or a float when inflation and capital mobility is high, reserve levels are low, labor market and fiscal flexibility is limited, production and exports are not well-diversified, and typical shocks faced are real rather than nominal in nature (Eichengreen et al., 1998).

53. A limited degree of economic diversification suggests that a basket peg may offer some flexibility in coping with commodity shocks, if floating is not immediately feasible. A properly-chosen basket peg can reduce effective exchange rate variability and, by avoiding larger moves in bilateral exchange rates, reduces the risk of excessive appreciation or depreciation associated with single currency pegs. Basket pegs also allow the exchange rate to continue its role as a nominal anchor as authorities develop a market-based monetary policy framework and develop financial markets, which are needed if/when greater flexibility is introduced. Disclosing the basket composition and weights and a consistent policy mix support the credibility of a basket peg. 


\section{Box 1. Ingredients of a Successful Move to Exchange Rate Flexibility}

Alternative Nominal Anchor and Monetary Policy Framework: Under exchange rate flexibility, the exchange rate anchor needs to be replaced with a new nominal anchor and a monetary policy framework redesigned around that anchor. A credible monetary policy framework is essential in stabilizing market expectations and ensuring monetary stability especially if the exit is under market pressure. Many countries moving to greater flexibility favored inflation targeting (IT) frameworks. However, a credible alternative such as IT requires extensive preparation, which means that planning ahead for the transition is critical for an orderly exit and preserving confidence in the monetary policy framework. Experience shows that the level of preparedness to adopt a new monetary policy framework affects the smoothness and the length of the transition. In countries that exited gradually, the adoption of a full-fledged IT framework followed a lengthy transition period, reflecting the difficulty of establishing the extensive institutional requirements; that is, countries surrendered the anchor role of the exchange rate only gradually, with inflation and exchange rate targets pursued simultaneously in the interim. The clarity of which target had the priority in the event of a conflict was important to establish credibility. With fast exits, adopting IT started after the float, requiring intensive capacity building and efforts to ensure a credible monetary policy framework.

Effective Capacity for Monetary Policy Implementation: Successful conduct of the new monetary policy framework involves a number of institutional, technical, and operational ingredients. Progress in many areas can be self-reinforcing, arguing for efforts to press ahead on as many fronts as possible, including: a clear mandate and operational independence to pursue price stability, operationalized with a publicly announced medium-term inflation target; technical capacity to develop and implement a transparent forward-looking monetary policy strategy, a clear and effective framework for monetary control, with capacity to align short-term rates with the announced policy stance; a framework for forecasting and managing banking system liquidity; and effective communication with the market. Experience suggests that adequate capacity to conduct monetary policy facilitates implementation of new monetary frameworks and supports monetary policy credibility and stability under flexible exchange rates. Efforts to establish this capacity need to begin well before the introduction of flexibility. Reasonably well-developed financial markets support the interest rate channel of monetary transmission, while their absence undermines the capacity for monetary control.

Systems to Manage Exchange Rate Risks: Exposure to FX risk has an important bearing on the exit pace, the type of flexible exchange rate regime adopted, and intervention policies. Market participants need to develop internal risk management and information systems to measure risks, and an adequate prudential and supervisory framework must be in place to monitor direct and indirect exposures. Experience suggests that early investment in these capacities can reduce the risk, and mitigate the cost, of disorderly exits and limit contagion to the financial system. A relatively stable financial sector with little FX exposure makes exits less challenging, even if they occur under pressure. The capacity to manage FX risks can develop along with an explicit recognition and regulation of FX risks. A cautious development of derivatives markets supports risk hedging. Experience also suggests that greater flexibility and FX risk management capacity could be mutually reinforcing. Reduced implicit exchange rate guarantee implied by greater flexibility stimulates risk recognition and contribute to development of instruments to hedge risk, suggesting introducing flexibility through increasingly more flexible forms of a peg. Reduced FX intervention can also make FX risks explicit, imposing the responsibility to manage the risk on agents that incur the risk.

FX Market Development: Operating a flexible regime works well only when there is a liquid and efficient FX market for price discovery. A well-functioning FX market allows the exchange rate to respond to market forces, helps minimize disruptive day-to-day fluctuations, and facilitates risk management. Developing the market requires eliminating market-inhibiting regulations, improving market infrastructure, and increasing information flows while phasing out central bank market-maker role. Allowing some flexibility is a key step in limiting the chicken-and-egg problem: exchange rate flexibility needs a deep market and better risk management, but deeper markets and risk management cannot materialize without some flexibility and two-way risks. Experience suggests that deepening FX markets is a gradual process and begins generally after some exchange rate flexibility is permitted. Spot FX markets are generally the first to develop, followed by derivative markets introduced more gradually along with documentation requirements and prudential regulations to limit speculation, as central banks replace market-maker role with active market participation, widen/eliminate narrower inner bands or undeclared targets, and support development of interbank and securities markets to facilitate pricing of hedging instruments.

Coherent FX Intervention Strategy: Given the scope for exchange rate volatility, moving to flexibility needs a coherent intervention strategy and principles to enhance credibility of the new regime. It is important to signal commitment to a market-determined rate and avoid sending confusing messages about policy intentions and suppress the nascent markets and market signals. Intervention strategies can be considered along a continuum with a tight rules-based approach at one end, and high discretion with virtually no intervention at the other. Transparency on the goal of intervention is important in building confidence in the new regime, especially after forced exits. Correcting for significant misalignments is a likely first step in determining intervention goals. With misalignment, introducing flexibility too slowly would result in a loss of scarce reserves, while delaying a return to an equilibrium with genuine two-way risk. Countries need to assess their own institutional and market characteristics to determine the intervention approach.

Sources: Duttagupta, Fernandez, and Karacadag (2004) and Ötker-Robe and Vávra (2007). 
54. More flexible forms of peg regimes, ranging from crawling pegs to pegs within (fixed/crawling) bands, offer greater flexibility to cope with shocks, while continuing to anchor inflation expectations. By allowing the currency to adjust periodically, crawling pegs (vis-à-vis a single currency or a basket) can help limit competitiveness losses typically associated with fixed pegs, while still serving as an inflation anchor if the rate of crawl is set less than inflation differentials with trading partners. Narrow currency bands provide some exchange rate flexibility within the band as the key ingredients of a fully-flexible regime are put into place. However, high capital mobility could make it difficult to sustain such pegs in the absence of ample reserve/fiscal buffers or consistent mix of policies, as the limited flexibility may continue to encourage one-way bets against the peg (Bubula and Ötker-Robe, 2001). More flexible pegged regimes (within wider (fixed/crawling) bands) offer greater flexibility, while preserving the anchor role of the exchange rate.

\section{Crawling pegs and band regimes have been introduced as a step toward} greater exchange rate flexibility. A number of countries adopted crawling pegs, typically with a narrow band of less than 2 percent, to allow for a smooth and gradual adjustment in the exchange rate to preserve external competitiveness, while maintaining an exchange rate anchor (e.g., Bangladesh, Burundi, China, Dominican Republic, Honduras, Jamaica, Tunisia). In some cases, crawling pegs were followed by a switch to a float, while in others with a reversal to stabilized arrangements/fixed pegs after the initial move. A number of countries adopted crawling pegs within increasingly wider bands in their transition to floating regimes, as the key ingredients of floating regimes were gradually put in place (e.g., Chile, Israel, and Poland in the late 1980s to early 2000s, and Costa Rica, Kazakhstan, and Russia in the late 2000 s to 2010 s-Figure 10 and Box 2).

\section{Modalities of Transition to Greater Flexibility}

56. The pace and timing of exit from a peg regime and its sequencing with other policies involve difficult tradeoffs and considerations that are often country-specific. In general, countries can make a successful transition to greater flexibility if the move is from a position of calm in the market (Eichengreen, 2004; Eichengreen and others, 1998). ${ }^{9}$ The chances of a successful transition are enhanced by replacing the exchange rate anchor with a credible nominal anchor and a clear commitment to price stability, and reinforcing that commitment by institutional reforms that ensure a sound financial sector and greater fiscal and monetary policy discipline. If taken from a position of strength, a faster exit signals determination, but the speed at which the building blocks can be established is often the key and judging the right time to exit and what regime to exit to is typically a challenge.

57. Pace. Country experiences suggest that gradual transitions to a float through increasingly more flexible forms of pegged regimes allow time to prepare for an orderly exit (Ötker-Robe and Vávra, 2007 ${ }^{10}$ ). Premature introduction of exchange rate flexibility can be damaging and make the policy change more prone to a subsequent reversal (as a number of

\footnotetext{
${ }^{9}$ Empirically, countries facing appreciation pressures were found to rarely respond by moving to exchange rate flexibility, but instead switch only when faced with depreciation pressure (Detragiache, Mody, Okada, 2005).

10 The paper provides detailed experiences of three countries (Chile, Israel and Poland) that had smooth and successful transitions to floating exchange rates and three countries (Brazil, Czech Republic, and Uruguay) that switched to floating regimes in the context of a currency crisis in the late 1980 s to early 2000 s.
} 
countries experienced during the recent commodity shock), while adequate preparation helps avoid costly crisis exits or moderate the severity of crisis exits. However, since putting in place the building blocks can take time, too much emphasis on meeting all the preconditions may unduly prolong the transition, increasing the risk of being forced out by markets in a disorderly exit at an inopportune time. It is therefore important to strike the right balance between being cautious and taking advantage of the mutually-reinforcing relationship between flexibility and capacity building.

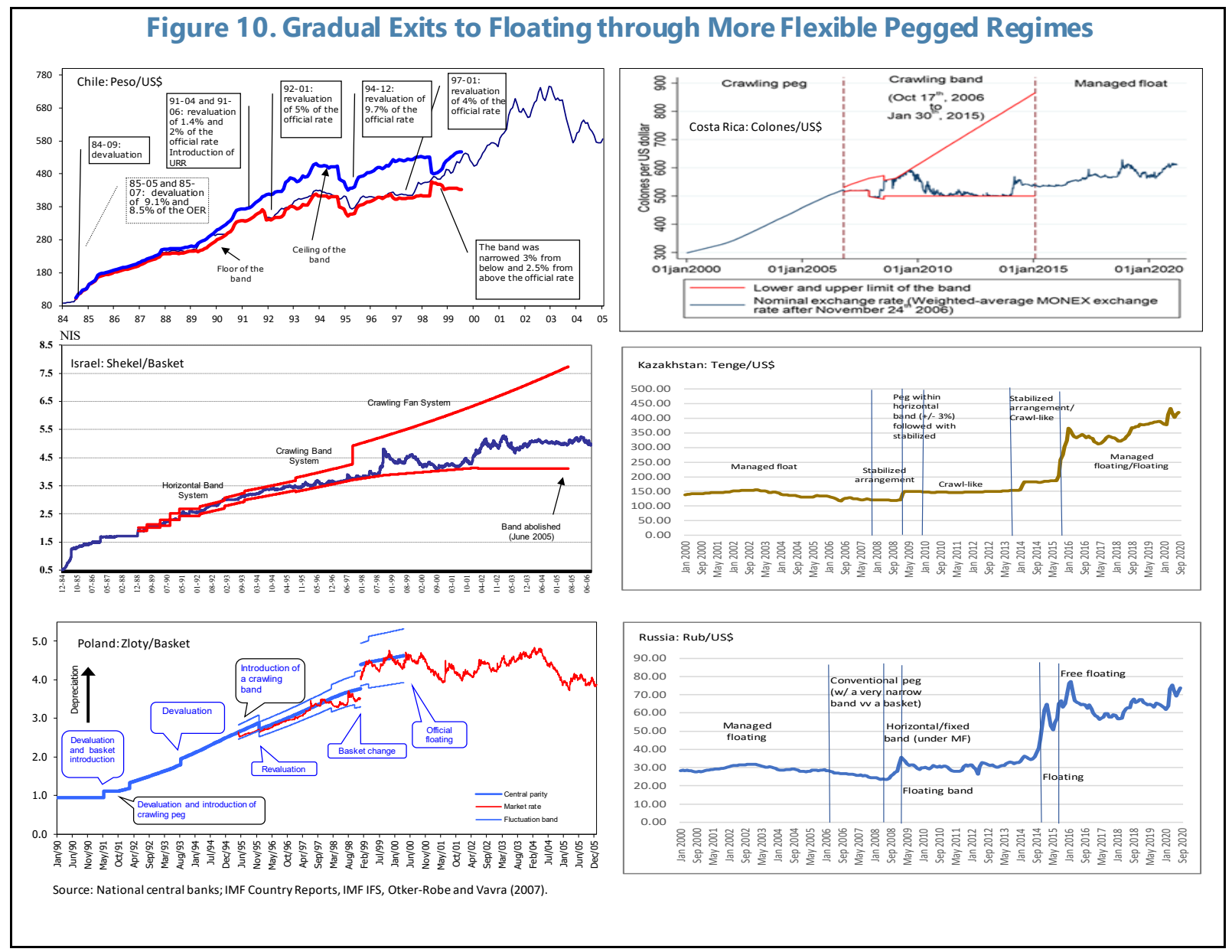

58. Accompanying policies. Regardless of the pace and form, exits to flexibility should be accompanied by prudent macroeconomic and structural policies to prevent the exchange rate from overshooting, or in the case of gradual exits, to prevent the rate from immediately hitting the edges of a band. Strong policies were crucial in stabilizing markets following abrupt exits under market pressure and making the transition more durable. Disruptions could be contained if the exits were combined with a comprehensive policy package that contained an appropriate mix of macroeconomic and structural policies aimed to address root causes of market pressures (e.g., in Brazil and the Czech Republic, the collapse of the pegged regimes under market turbulence in the 1990s was not followed by a return to pegs, with the period of instability contained by tight policies and rapid establishment of the key elements of a float).

59. Communication. Clear communication is a necessary condition for a successful transition to a more flexible exchange rate regime. Authorities must explain not only the 
rationale for the decisions taken, but also the planned policy steps in the short/medium term to reduce uncertainty (especially during gradual transitions) and enable market participants hedge for FX risks. Also crucial is to present the regime change as part of a comprehensive policy strategy, stressing monetary and fiscal discipline as key ingredients for a stable exchange rate, and structural policies for safeguarding competitiveness in transition. Determining the appropriate level of transparency in communicating the exchange rate strategy can be challenging, but is crucial for the new regime's credibility.

60. Sequencing. There is no unique sequencing of reforms on the path to greater flexibility, but experience suggests that allowing flexibility early on would permit two-way variations in the exchange rate (e.g., by gradually widening the band or limiting intervention) and help limit one-way currency bets or scope for destabilizing market strategies that can trigger policy reversals. Such variation also stimulates markets and provides incentives for risk management. Experiences also suggest that having the main ingredients of flexibility in place before the switch to a full float provided a coherent transition process and contributed to the orderly nature of gradual exits, suggesting that the elements taking the longest time to build and help overcome the fear of floating should begin as early as possible (e.g., laying the groundwork for the monetary framework and market development). Agreeing on the principles of the transition and the features of the eventual regime can also be helpful in establishing a framework for the exit process.

\section{Box 2 provides experiences of a number of countries that moved to greater flexibility through more flexible forms of pegged regimes in recent years. An event} analysis covering ten countries that switched from less flexible pegs (fixed pegs or stabilized arrangements) to more flexible pegs (crawling pegs or band regimes) suggests that countries experienced, on average, broadly unchanged growth and inflation, an immediate worsening of the current account that was reversed subsequently, a steady rise in public debt, and increased unemployment and nonperforming loans (NPLs) in the subsequent three years following the exit, compared to the year before the exit. With a significant variation in outcomes across countries and a multitude of factors that can affect the outcomes, a closer look at a subset of the ten countries (Angola, Costa Rica, Kazakhstan, and Russia) offer better insights for countries contemplating such a decision.

62. The experiences of the four countries corroborate the key lessons from the earlier country experiences: Moving to flexibility gradually, while putting in place the key ingredients of a flexible exchange rate, can help prepare markets for an eventual float (as in Costa Rica, Kazakhstan, and Russia) and address some of the fear-of-floating concerns (e.g., exchange rate passthrough, highly-dollarized balance sheets with mismatched currency positions, and weak monetary policy transmission). The design features of the band regimes (with gradual and asymmetric widening of the bands) seem to have allowed for a gradual increase in flexibility and provided greater scope for two-way exchange rate movements and ability to absorb shocks, while helping reduce the risk of policy reversals. Discrete exchange rate adjustments around the move to a band regime and an alternative nominal anchor provided by inflation targeting regimes also seem to help sustain the shift to flexibility and support positive outcomes. The experiences also underscore the role of supportive monetary, fiscal, and financial sector policies, good communication, and fiscal/financial buffers in making the exits durable, limiting the risk of overshooting, reversing the deterioration in economic performance following the exits, and lending credibility to the new regime. 


\section{Box 2. Transitions to Greater Flexibility Through More Flexible Pegged Regimes}

This Box examines the experiences of a selected group of commodity and non-commodity exporting countries that introduced greater exchange rate flexibility in recent years by initially moving to more flexible pegged regimes (such as crawling pegs and bands) from fixed peg or stabilized exchange rate arrangements. The objective is not to provide a full-blown analysis of the exit experiences, but rather to see how key macroeconomic aggregates behaved in the subsequent years to the exit, to explore if the exits were associated with improved or worsened performance. Given the wealth of other factors that may have affected the performance, it dives deeper into the experiences of a subset of these countries to get a better insight for the developments.

For the purposes of the exercise, the analysis focuses initially on the exit episodes of ten countries: 5 commodity exporters (Angola, Burundi, Jamaica, Kazakhstan, Russia) and 5 non-commodity exporters (Bangladesh, China, Costa Rica, Dominican Republic, Honduras), which adopted/exited from crawling peg or crawling band regimes in relatively more recent years, to gain additional insights to what had been documented in Ötker-Robe and Vavra (2007) for earlier exit episodes. It then expands further on the experiences of the three commodity exporters (Angola, Kazakhstan, Russia), whose recent switch to floating regimes were accelerated by the 2014 commodity price shock. It also zooms into the experience of Costa Rica, a non-commodity exporter, since it provides a more recent example of a gradual, step-by-step move from a less flexible peg regime to a float through successive increases in peg flexibility, while maintaining an anchor role for the exchange rate as it prepares for a floating regime.

\begin{tabular}{|l|l|}
\hline Country & Regime Transitions \\
\hline Angola & Stabilized $\rightarrow$ Crawl-like (2014) $\rightarrow$ Managed Float (2015) $\rightarrow$ Stabilized (2016) $\rightarrow$ Managed Float (2018) \\
Bangladesh & Stabilized $\rightarrow$ Crawl-like (2010) $\rightarrow$ Managed Float (2011) $\rightarrow$ Stabilized (2013) $\rightarrow$ Crawl-like (2017) \\
Burundi & Stabilized $\rightarrow$ Crawl-like (2016) \\
China & Stabilized $\rightarrow$ Crawl-like (2010) $\rightarrow$ Managed Float (2015) \\
Costa Rica & Crawling peg $\rightarrow$ Widening Crawling Bands (2006) $\rightarrow$ Crawl-like/Managed Float (2015) $\rightarrow$ Floating (2018) \\
Dominican Rep. & Stabilized $\rightarrow$ Crawling peg / Crawl-like (within a narrow band) (2010) \\
Honduras & Stabilized $\rightarrow$ Crawling peg (2011) / Crawl-like (within a narrow band) (2013) \\
Jamaica & Stabilized $\rightarrow$ Crawl-like (2011) $\rightarrow$ Stabilized (2016) $\rightarrow$ Floating (2017) \\
Kazakhstan & Stabilized $\rightarrow$ Fixed Band (2009) $\rightarrow$ Crawl-like (2010) $\rightarrow$ Stabilized/Crawl-like (2013) $\rightarrow$ Managed Float/Floating (2015) \\
Russia & Conventional Peg $\rightarrow$ Crawl-like/Floating Band (2008) $\rightarrow$ Floating (2014) $\rightarrow$ Free Floating (2015) \\
\hline
\end{tabular}

In six of the ten cases, regime transitions involved moving in steps from less flexible pegs to an ultimate float, notwithstanding a brief period of reversal of the initial move from a fixed peg in a few cases (Angola, Jamaica, and Kazakhstan), while a few others have continued to maintain (relatively more flexible) pegged regimes (Bangladesh, Burundi, Dominican Republic, and Honduras). Following the exit, exchange rates depreciated significantly in some cases (Figures 9, 10), especially where the exits had also been associated with a discrete currency adjustment (e.g., Angola, Burundi, Costa Rica, Jamaica, Honduras, Kazakhstan).

Macroeconomic performance following the exits was mixed across countries and indicators, reflecting a variety of factors, including in some cases regime reversals. Growth was broadly unchanged on average over the exit year and subsequent three years, compared with the pre-exit year (Figure 10), but fell sharply in some (Angola, Russia), combined also with the direct impact of the commodity price collapse (other factors, such as the global financial crisis, or sanctions in the case of Russia, also played a role); growth increased in several others (Burundi, Dominican Republic, and to some extent Jamaica, Kazakhstan). Similarly, inflation was little changed on average, but rose sharply in some (Angola, Dominican Republic, Russia, China), while falling markedly in a few others (Costa Rica, Jamaica, Kazakhstan) and was more muted in some cases (Bangladesh, Honduras). The current account balance deteriorated on average (in part reflecting real effective exchange rate appreciation), although the deterioration was followed by a correction in subsequent years. The worsening of the fiscal balance was limited for most countries, but public debt ratios (and to a limited extent unemployment rates) deteriorated steadily in most.

A closer look into the exit experiences of a subset of the countries (Angola, Costa Rica, Kazakhstan, and Russia) provides some insights on the factors underlying the macroeconomic landscape around the exits. All four countries chose to move to floating regimes more gradually, while acknowledging that greater exchange rate flexibility would create monetary policy room to cope with external shocks, with the exchange rate acting as a built-in stabilizer (Table 8). For all four countries, the desire to attain and protect price stability with the high exchange rate passthrough to inflation, highly-dollarized private and financial sector balance sheets with currency mismatches, and weak transmission mechanism that constrain monetary policy effectiveness were among the factors underlying the reluctance to float. More flexible forms of pegs (such as crawling/floating bands) were seen as a way to allow markets adjust to exchange rate fluctuations, while continuing to use the exchange rate as a nominal anchor as the authorities worked to establish the necessary infrastructure for floating exchange rates and inflation targeting frameworks. The global financial crisis in 2007-08 and the 2014 commodity shock seem to have provided a push for the transition. 


\section{Box 2. Transitions to Greater Flexibility Through More Flexible Pegged Regimes (concluded)}

The experiences confirm the key lessons from the earlier country experiences documented in Ötker-Robe and Vavra (2007). In particular, gradually putting in place the key ingredients of ER flexibility (an alternative monetary policy framework with a credible anchor, strengthened monetary policy transmission with effective instruments, well-developed money and FX markets supported by appropriate regulations and risk management tools, well-functioning banking systems, and effective intervention mechanisms) helped prepare markets for an eventual float, address some of the fear of floating concerns, and hence were key to the overall positive outcomes of the regime transitions. In the case of Costa Rica, Kazakhstan, and Russia, the interesting design features and parameters of the crawling bands (e.g., asymmetric band limits or asymmetric adjustment of crawl rates) allowed the bands to gradually widen, increasing the scope for exchange rate movements and the ability to absorb shocks with two-way exchange rate variation, which, in turn, helped reduce the risk for policy reversals, decrease somewhat the dollarization from its high levels, and stimulate markets. Exiting to band regimes and floating after sufficient preparation and adjustment, in particular to replace gradually the exchange rate with a credible nominal anchor and reduce imbalances in the economy and FX markets, likely played a role in better macroeconomic outcomes and limit reversals in flexibility (in Angola, the scarcity of FX, including through administrative measures, put continued pressure on the exchange rate and constrained imports and output, adding to inflation pressures and reducing the ability to maintain, or establish credibility for, exchange rate flexibility). The large step devaluation to adjust FX market imbalances helped reduce depreciation expectations in the case of Kazakhstan, helping the authorities to use the band fully.

The experiences also underscore the importance of supporting polices and infrastructure to make the exit durable and sustainable and limit the risk of exchange rate overshooting. In Costa Rica, for example, external and fiscal balance improved briefly with supportive policies (in part in the context of a Fund-supported program in 2009). In Kazakhstan, the exchange rate depreciated sharply, inflation increased, and bank soundness indicators worsened following the float but improved subsequently, as the authorities undertook measures to stabilize the markets and improved communication of their plans consistently. The fiscal space and a large sovereign wealth fund also helped keep the overall fiscal position strong and limit financing and fiscal adjustment risks. Similarly, in Russia, the move to floating in 2014 was part of a comprehensive response to the oil shock, supported by tight monetary policy, measures to reduce financial stability risks in the banking system, fiscal support measures (e.g., limiting wage indexation) to contain second round effects of depreciation, availability of reserve and fiscal cushions (including a sovereign wealth fund), and good communication strategy helped reverse the economic deterioration and lend credibility to the new framework.
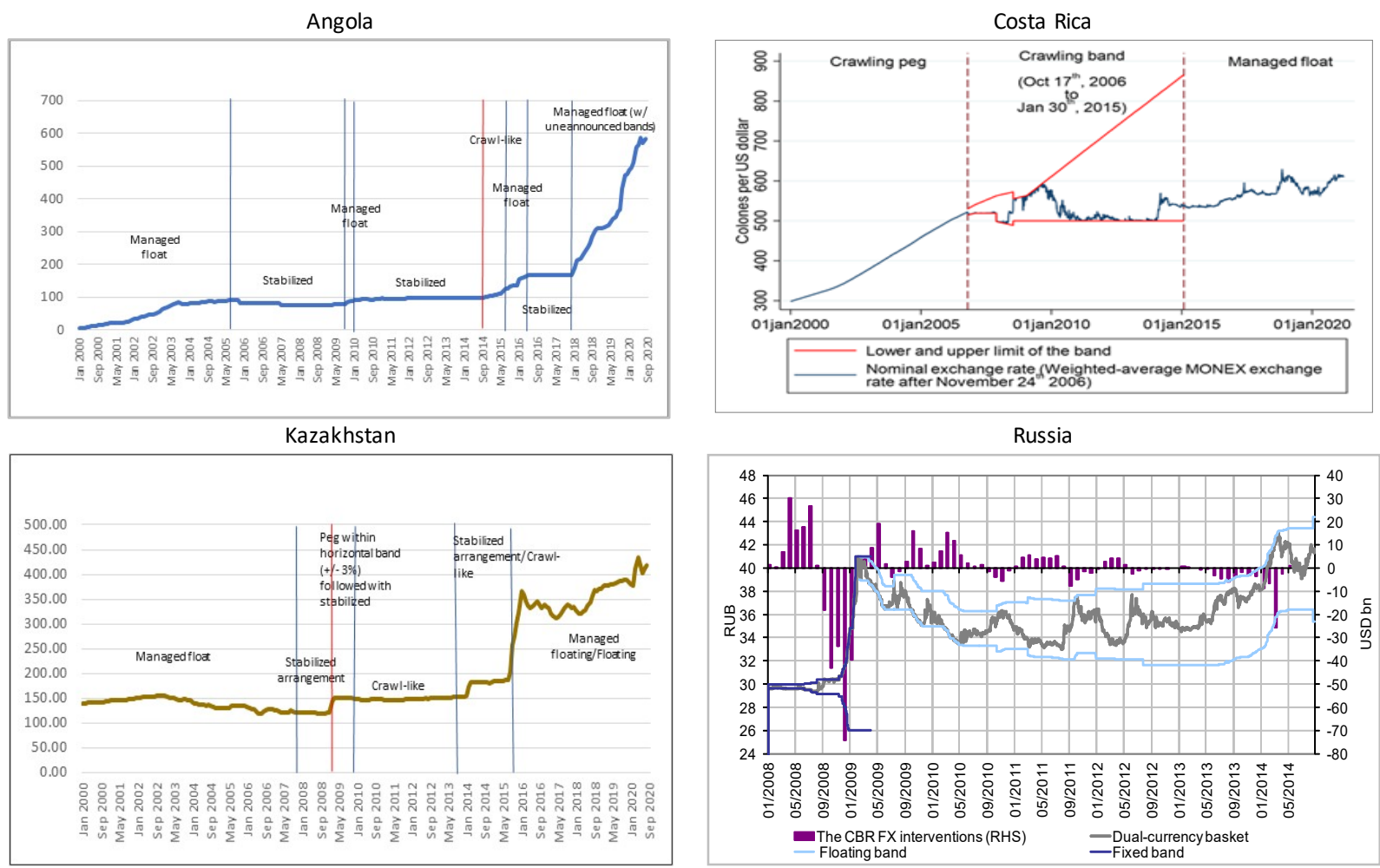

Sources: AREAER reports (various issues); Cubero and others (2018); IMF Country Reports; and National Central Banks. 
Figure 11. Exit Episodes Toward Greater Flexibility

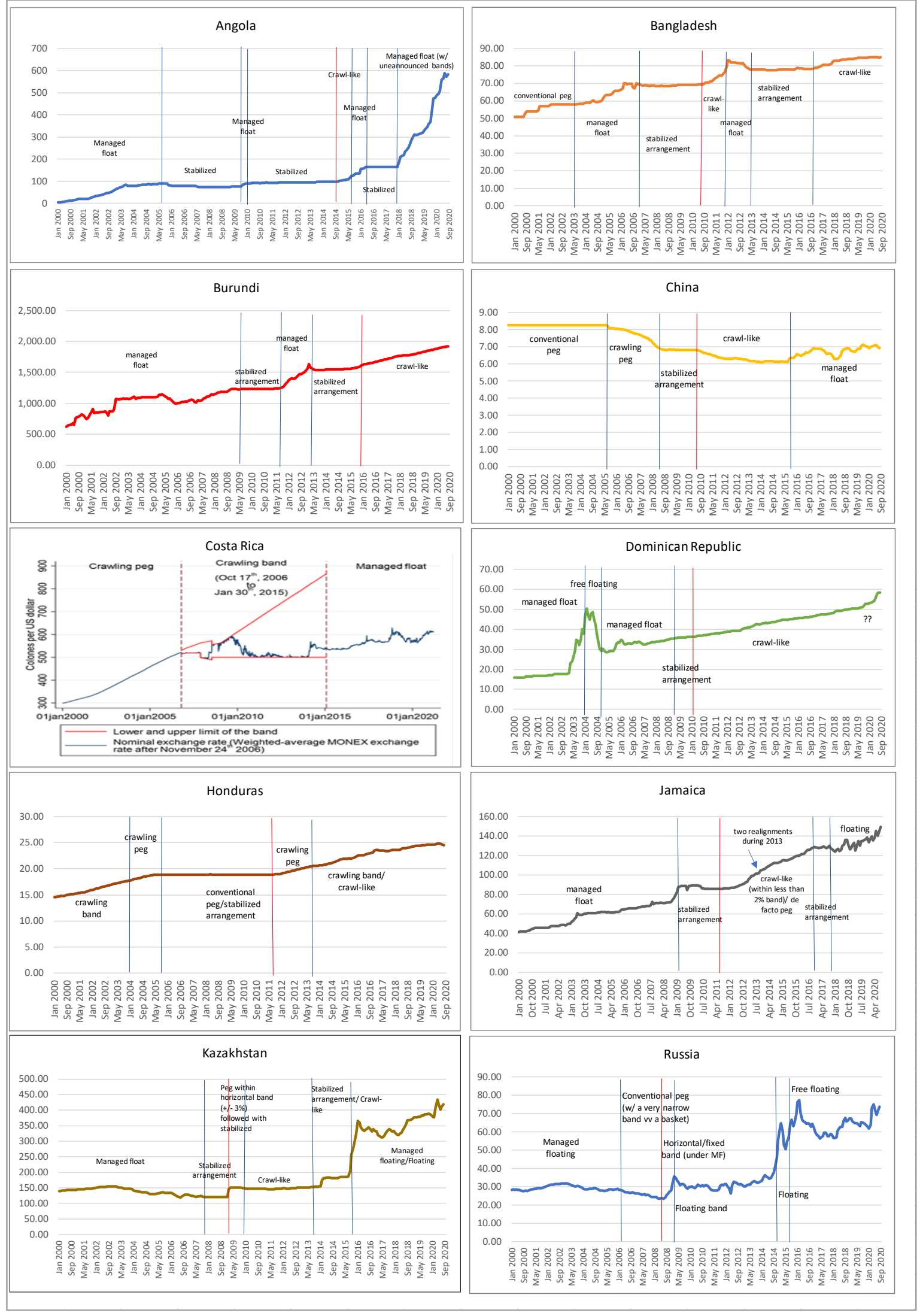

Sources: Cubero and others (2018), IMF Country Reports, IMF IFS, National authorities. Red bars refer to the initial exit period.

CInternational Monetary Fund. Not for Redistribution 
Figure 12. Evolution of Key Economic Indicators Before and After the Exit to More Flexible ER Regime

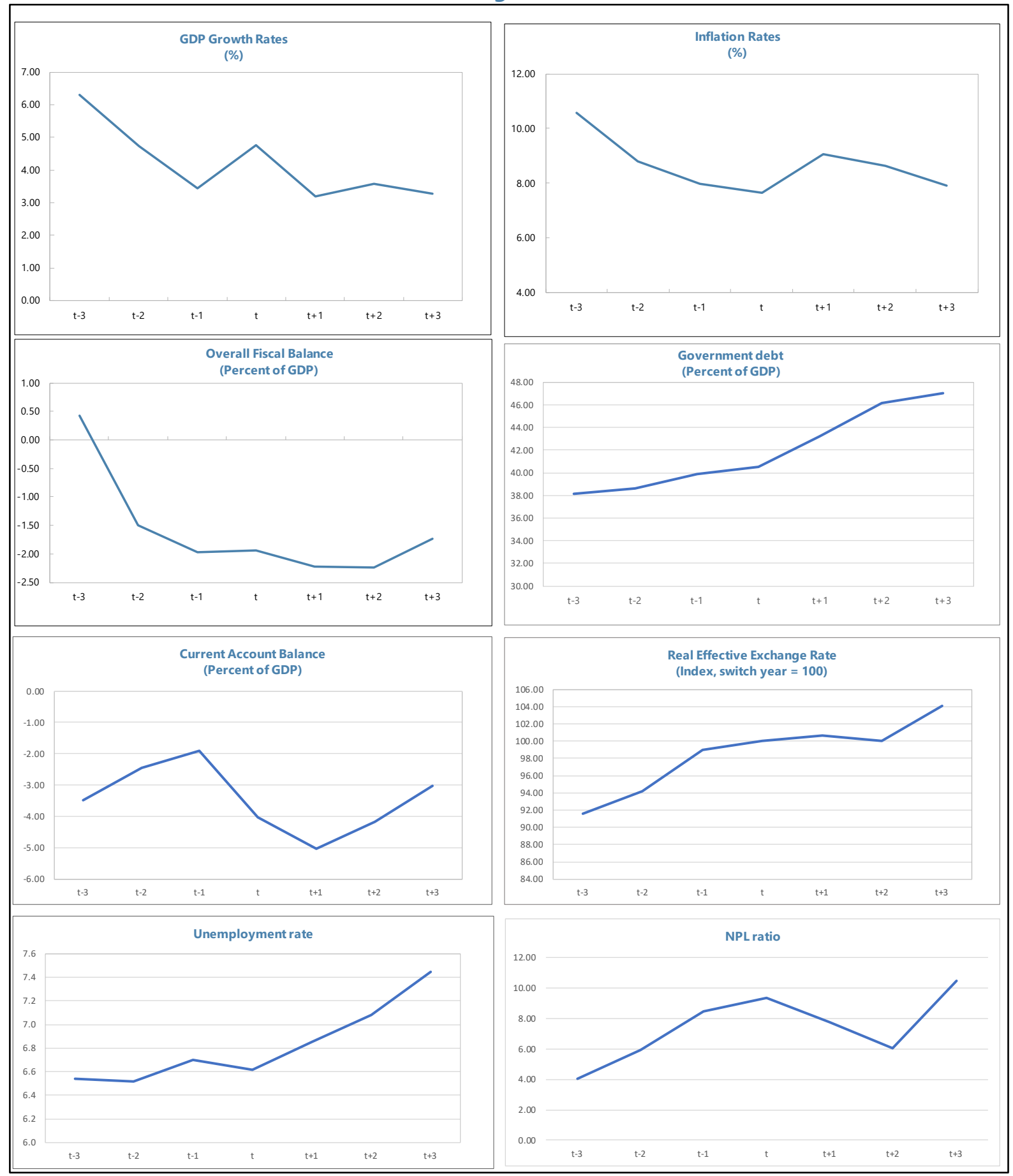

Sources: Authors' computations. Yeart denotes the year when of the first move from a less flexible to more flexible pegged regime. 
Table 8. Detailed Country Experiences with Exit to Greater Exchange Rate Flexibility

\begin{tabular}{|c|c|c|c|c|}
\hline Country (1 $\left(1^{\text {st }}\right.$ exit) & Angola (2014) & Costa Rica (2006) & Kazakhstan (2009) & Russia (2008) \\
\hline $\begin{array}{l}\text { Regime } \\
\text { transition }\end{array}$ & $\begin{array}{l}\text { Move to flexibility in several steps, including a } \\
\text { reversal and step devaluations } \\
\text { Stabilized (within } 2 \% \text { band) } \rightarrow \\
\text { Crawl-like (within } 2 \% \text { band) } \rightarrow \\
\text { Managed float } \rightarrow \\
\text { Stabilized } \rightarrow \text { Managed float } \\
\text { (unannounced band vis-à-vis } \epsilon \text { ) (2018) }\end{array}$ & $\begin{array}{l}\text { Gradual move to floating through increasingly } \\
\text { more flexible peg } \\
\text { Crawling peg } \rightarrow \text { Crawling band } \\
\text { (3\% width } \rightarrow \text { Gradually widening with } \\
\text { asymmetric adj of band limits/crawl rates; no } \\
\text { central parity) } \\
\rightarrow \text { Crawl-like/Managed Float } \\
\rightarrow \text { Floating (2018) }\end{array}$ & $\begin{array}{l}\text { Gradual move to floating including brief } \\
\text { reversals; step devaluations } \\
\text { Stabilized ( } 2 \% \text { band) } \rightarrow \text { Fixed Band ( } \pm 3 \% \text { band } \\
\text { and step devaluation) } \rightarrow \text { Stabilized } \\
\rightarrow \text { Crawl-like (asymmetric widening of band) } \\
\rightarrow \text { Stabilized ( } 2 \% \text { band } v-v \text { basket; devaluation } \\
1.5 \% \text { band } v-v \$ \text { ) } \rightarrow \text { Crawl-like with wider band } \\
\rightarrow \text { Managed Float } \rightarrow \text { Floating (2015) }\end{array}$ & $\begin{array}{l}\text { Gradual transition to floating through a gradual } \\
\text { increase in ER flexibility } \\
\text { Conventional Peg (basket) } \rightarrow \\
\text { Narrow Fixed Band (briefly) } \rightarrow \\
\text { Crawl-like/Floating Band } \\
\text { (adjusted/widened based on FX interventions) } \rightarrow \\
\text { Floating } \rightarrow \\
\text { Free Floating (2014) }\end{array}$ \\
\hline $\begin{array}{l}\text { Policy } \\
\text { considerations } \\
\text { in regime } \\
\text { transitions and } \\
\text { outcomes }\end{array}$ & $\begin{array}{l}\text { Desire to introduce ER flexibility to cope with oil } \\
\text { shocks, but cautiously, with ER still seen as the } \\
\text { main nominal anchor to rapidly reduce inflation/ } \\
\text { maintain price stability. Underlying the cautious } \\
\text { approach: } \\
\text { - Concern about high ER passthrough } \\
\text { - High dollarization in the financial sector with } \\
\text { currency mismatch in bank balance sheets } \\
\text { - Weak monetary transmission mechanism and } \\
\text { lack of proper monetary instruments to } \\
\text { implement an alternative framework } \\
\text { Outcome: ER: Depreciated sharply from Sep 2014 } \\
\text { to end-2016 as the gradual/smooth depreciation } \\
\text { allowed under crawl-like and managed floating } \\
\text { regimes and administrative measures did not help } \\
\text { eliminate the imbalance in the FX market, } \\
\text { resulting in an eventual sharp depreciation. } \\
\text { Inflation rose sharply, with a weaker currency and } \\
\text { high ER passthrough, impact of FX scarcity on } \\
\text { imports and output, higher domestic fuel prices } \\
\text { given the subsidy reform, monetary transmission } \\
\text { lags, and lack of an alternative nominal anchor/ } \\
\text { instruments after the exit. Growth fell sharply } \\
\text { given the impact of scarce FX on imports and } \\
\text { resource allocation, worsened by the direct } \\
\text { impact of the oil shock (oil made up } 95 \% \text { of } \\
\text { exports). External balance: Worsened with the } \\
\text { sharp fall in oil exports; REER remained over- } \\
\text { valued with high ER passthrough; subsequent } \\
\text { improvement through falling imports. Fiscal } \\
\text { balance deteriorated less (fiscal tightening) but } \\
\text { public debt rose. Financial: Soundness indicators } \\
\text { worsened with ER depreciation, higher NPLs given } \\
\text { a weaker economy, liquidity and recapitalization } \\
\text { needs; dollarization remained high. }\end{array}$ & $\begin{array}{l}\text { Desire to introduce gradual ER flexibility (with } \\
\text { asymmetric adj's to floor/ceiling and crawl rate } \\
\text { allowing a gradually widening band) to: Create } \\
\text { monetary policy room to cope with large } \\
\text { capital flows/enhance MP effectiveness in } \\
\text { transitioning to IT; address fiscal deficits, high } \\
\text { inflation, and dollarization seen during the } \\
\text { crawling peg period; and limit adverse effects } \\
\text { of ER volatility on price/ financial stability in a } \\
\text { highly dollarized economy. Gradual exit } \\
\text { (communicated as part of the transition to } \\
\text { greater ER flexibility) allowed to: } \\
\text { - Respond to external shocks while } \\
\text { maintaining the nominal anchor role of ER as } \\
\text { gradual progress was made to adopt IT as a } \\
\text { new monetary framework after floating } \\
\text { - Progress in strengthening monetary policy } \\
\text { transmission and implementation } \\
\text { - Put in place FX/interbank market and risk } \\
\text { management infrastructure (regulations for } \\
\text { hedging, unification of segmented money } \\
\text { market, FX intervention mechanism etc.) } \\
\text { - Introduce FX risk, given scope for ER move } \\
\text { within a wide band; and reduce dollarization } \\
\text { (more on deposit side). } \\
\text { Outcome: ER remained stuck to the limits of } \\
\text { the band much of the band period (depending } \\
\text { on the direction of capital flows and external } \\
\text { factors (GFC)), except from } 2015 \text {, with FX } \\
\text { interventions to defend the band. Global } \\
\text { food/oil price shock derailed initially the } \\
\text { disinflation strategy, but wider bands helped } \\
\text { lower inflation (reduced CB losses and ER } \\
\text { passthrough) allowed room to adjust to capital } \\
\text { flows. Growth, fiscal balance and debt } \\
\text { improved; also supported by IMF program. }\end{array}$ & $\begin{array}{l}\text { Desire to introduce ER flexibility to enhance } \\
\text { monetary policy effectiveness, help respond to } \\
\text { commodity shocks, limit unhedged positions. } \\
\text { Do so by gradually reducing ER role in } \\
\text { monetary policy through wider ER bands. } \\
\text { Cautious approach reflects concerns about: } \\
\text { - Loss of depositor confidence } \\
\text { - Adverse impact of depreciation on banks and } \\
\text { corporates with large FX exposure } \\
\text { - Disinflation while building IT preconditions } \\
\text { Outcome: The } 2008 \text { and } 2014-15 \text { commodity } \\
\text { shocks facilitated transition to floating and IT } \\
\text { (IT formally introduced in Aug } 2015 \text { with the } \\
\text { exit). Introducing ER band with a significant } \\
\text { step adj. appears to have stabilized FX } \\
\text { pressures, reduced depreciation expectations, } \\
\text { with the ER moving comfortably to band } \\
\text { center, supported by higher oil prices. The } 2015 \\
\text { move to float, by first widening ER band, and } \\
\text { then floating resulted in a sharp depreciation } \\
\text { and a surge in prices but inflation fell toward } \\
\text { the CB's target range and the currency } \\
\text { stabilized. Authorities undertook measures to } \\
\text { stabilize markets and improved communication } \\
\text { of their plans consistently and credibly. But } \\
\text { depreciations added to the pressure on banks. } \\
\text { Deposit dollarization still elevated but fell in } \\
2016 \text { while loan dollarization stabilized. Overall: } \\
\text { Floating the ER is seen as an important } \\
\text { landmark to have helped the economy adjust } \\
\text { to negative terms of trade shocks. In reducing } \\
\text { the adverse effects, substantial fiscal space } \\
\text { helped, with the overall fiscal position } \\
\text { remaining strong and financing and fiscal } \\
\text { adjustment risks mitigated by the large } \\
\text { sovereign wealth fund. }\end{array}$ & $\begin{array}{l}\text { Desire to introduce a floating ER as a critical } \\
\text { component of the IT regime and price stability. } \\
\text { Flexible ER seen as a built-in stabilizer, helping the } \\
\text { economy adjust to changing external conditions } \\
\text { (e.g., oil shock), smoothing their impact, and } \\
\text { allowing monetary policy autonomy under an } \\
\text { open capital account that can complicate price } \\
\text { stability and competitiveness goals. Introduce } \\
\text { flexibility progressively to: } \\
\text { - Moderate markets' adjustment to ER moves } \\
\text { - Protect price stability with high ER passthrough } \\
\text { - Allow time to build IT infrastructure: monetary } \\
\text { policy model/instruments, internal capacity for } \\
\text { IT, communication strategy, risk mgt, etc.) } \\
\text { Outcome: During the 2008 exit and 2011 global } \\
\text { market turmoil, ER depreciated but rebound } \\
\text { swiftly. After float in } 2014 / 15, \text { it depreciated } \\
\text { sharply also because of geopolitical factors. } \\
\text { Inflation surged with greater and faster than } \\
\text { expected passthrough, growth dropped sharply, } \\
\text { also reflecting oil shock and sanctions, and } \\
\text { financial soundness worsened. But, depreciation } \\
\text { moved RER towards medium-term fundamentals, } \\
\text { ruble recovered, and inflation brought under } \\
\text { control. The float was part of a comprehensive } \\
\text { response to the oil shock (tighter policy rates, FX } \\
\text { liquidity to banks, capital support, temporary } \\
\text { regulatory forbearance, double insured deposits } \\
\text { to limit financial stability risks and credit crunch, } \\
\text { fiscal stimulus with limiting wage indexation to } \\
\text { contain } 2^{\text {nd }} \text { round effects of depreciation). Low } \\
\text { balance sheet mismatches provided room for } \\
\text { flexible ER and SWF helped support systemically } \\
\text { important enterprises and banks. Communication } \\
\text { of information on ER policy and FX operations } \\
\text { helped credibility of the new framework. }\end{array}$ \\
\hline
\end{tabular}

Sources: IMF Country Reports; National Central Banks; Cubero and others (2019). 


\section{CONCLUSIONS AND POLICY IMPLICATIONS}

63. This paper reviewed the policy challenges that sharp drops in commodity prices can pose for commodity-exporting economies and looked at the role of the exchange rate as a shock absorber. It analyzed quantitatively the evolution of key macroeconomic variables around commodity shocks under alterative exchange rate regimes. It explored, conceptually and empirically, the factors that can affect commodity exporters' exchange rate regime choices, and discussed the supporting policies that should accompany any given regime choice, pegged or flexible, to make that choice sustainable, drawing on the experience of countries that moved from pegged to more flexible exchange regimes in recent decades.

64. The severe ToT shock associated with collapsing commodity prices in 2014-2016 precipitated a sharp deterioration in economic performance, underscoring the policy challenges commodity exporters can face. The countries saw a steep fall in economic growth, increased unemployment, deterioration in their fiscal, trade and current account balances, particularly under pegged exchange rate regimes, a significant loss of foreign reserves, rising public debt, and a sharp exchange rate depreciation (under flexible exchange rates). A combination of policy measures were adopted to mitigate the impact of the shock, guided by the availability of policy space and willingness to let the exchange rate adjust.

65. From a theoretical and empirical viewpoint, exchange rate flexibility can serve as a shock absorber for open economies facing severe To T shocks and ease the burden of adjustment. The findings of this paper support this premise: Commodity-exporting countries with floating regimes had, on average, higher growth rates than those with pegs and recovered more quickly after the shock (a robust result under different model specifications and methods), and had current account and fiscal balances broadly stable following the shock, while those with pegged regimes experienced a reversal of a comfortable current account surplus with a sharp drop in export receipts and had considerable fiscal deterioration. It should be acknowledged, however, that for highly undiversified economies, there may be limited scope for greater flexibility to help achieve more favorable external or fiscal performance following a commodity price shock in the near to medium term.

66. Despite empirical support for a buffering role for the exchange rate, many commodity exporters maintain pegged exchange rate regimes. Countries may be reluctant to adopt flexible exchange rates, even when they see benefits from doing so in the absence of a credible alternative anchor to protect price stability, or adequate capacity, infrastructure, or tools to implement alternative monetary frameworks and mitigate adverse exchange rate effects on inflation or balance sheets. The empirical analysis covering 63 commodity exporters offers no robust set of economic, structural, or institutional variables that can systematically explain regime choices, apart from financial development, export concentration, public debt, and, to some degree, capital account openness. These findings highlight the complexity with which tradeoffs across various criteria can result in very diverse regime choices across countries.

67. It is a reasonable decision, then, for some commodity exporters to hold on to pegged exchange rates as the best way to deliver on a price stability objectiveparticularly where a strong institutional track record or capacity to implement exchange rate 
flexibility is lacking (or in economies with a very low degree of export diversification). Until such record or capacity are established, countries can limit their vulnerability to future shocks and boost their resilience to shocks by committing to an exchange rate anchor, so long as policies that can add to market pressures are avoided and the peg is supported by adequate financial and fiscal buffers; prudent monetary, fiscal, financial, and structural policy frameworks that can absorb shocks instead of the exchange rate; and efforts to increase flexibility of labor and product markets and diversify the export base.

68. At the same time, other commodity exporters may choose (including under market pressure) to move to flexible exchange rates, to help absorb, and build resilience to, future commodity shocks. Doing so successfully requires a careful approach, with strong and timely efforts to put in place the essential ingredients of exchange rate flexibility - including, (i) a credible nominal anchor to replace the exchange rate, (ii) wellfunctioning financial markets to conduct market-based monetary policy and facilitate risk management, (iii) a coherent intervention policy, (iv) and sound macroeconomic and structural policies that boost credibility and limit volatility in the exchange rate. Establishing these ingredients takes time, and the level of preparation would shape the pace greater flexibility is introduced, as well as the ease of transition and durability of the new regime.

69. These choices involve difficult tradeoffs and deliberations that are often country specific. Basket pegs have been used by some countries when floating was not immediately feasible or beneficial from a competitiveness point of view, with properlychosen basket pegs helping to limit the risk of excessive real appreciation/depreciation, while allowing the exchange rate to continue its anchor role. More flexible pegs (e.g., band regimes) facilitated a smooth transition to floating in a number of countries, where a greater scope for exchange rate adjustment introduced flexibility more gradually, while preserving the anchor role of the exchange rate, and allowed the authorities to work on addressing the fear-of-floating concerns. Two-way exchange rate variations typically helped limit currency bets that could trigger policy reversals, stimulated markets, and provided incentives for risk management. Supportive policies were essential to prevent exchange rates from overshooting, hitting immediately the edges of a band, or reversing the transition.

70. What does all this imply for the Caribbean commodity exporters that rely heavily on commodities as the main source of foreign exchange and income and maintain pegged/stabilized exchange rate regimes? As with many commodity-exporting countries, the recent commodity shock resulted in a sharp deterioration of the fiscal, external, and growth performance, especially where the share of the commodity sector in economic activity, export receipts, and government revenues is very high, the production and export structures are highly concentrated, and pegged exchange rate regimes rule out relative price adjustment through the exchange rate. The prolonged deterioration of economic performance underscores the importance of building resilience to similar future shocks.

71. Country-specific advice on regime choice is beyond the scope of this paper, but the paper's analyses and detailed country experiences may offer some food for thought. Greater exchange rate flexibility can be a potentially useful tool to build resilience to future shocks and boost efforts to diversify and reduce heavy reliance on the commodity sector. However, potential benefits of such a move need to be assessed from a lens of how the move 
could affect an economy, where prices of a few key exports are set internationally, high import dependence facilitates passthrough of exchange rates to inflation, replacing a longstanding, well-understood exchange rate anchor could raise fears of a credibility loss, and exchange rate changes may have adverse effects on public/private balance sheets while the development of financial markets and capacity to implement alternative monetary frameworks are still in the works.

\section{These well-known sources of fear-of-floating, while surmountable, can create} formidable policy tradeoffs for the Caribbean commodity exporters. The ability to adopt greater flexibility depends crucially on mitigating these sources of fear of floating. Some commodity exporters could hold on to their pegs, or introduce flexibility only gradually, so long as the peg is supported with a consistent mix of macroeconomic and structural policies and buffers that support the economy through the cycle, the prevailing vulnerabilities in the financial system are addressed to limit adverse balance sheet effects, and the diversity and flexibility of product and labor markets are enhanced to absorb shocks. A credible monetary policy framework (such as inflation targeting) could eventually replace the exchange rate as a nominal anchor. But establishing these foundations takes time and require extensive capacity-building, suggesting to start with those elements that help overcome the fear of floating and that take longer time to build. 


\section{APPENDIX I: COMMODITY TERMS-OF-TRADE INDEX}

For each country, the change in the commodity ToT index (CTT) corresponds to the weighted sum of annual variations in global prices of commodities, weighted by the country's net exports of each commodity as a share of GDP (Source: Gruss, B. and S. Kebhaj (2019)). The change in the commodity ToT for a given country $i$ in year $t$ is obtained as:

$$
\Delta \log (\operatorname{Index})_{i, t}=\sum_{j=1}^{J} \Delta P_{j, t} \omega_{i, j, t} \text { with } \omega_{i, j, t}=\frac{1}{3} \sum_{s=1}^{3} \frac{\chi_{i j, t-s_{-}} m_{i j, t-s}}{G D P_{i, t-s}}
$$

Where

- $\quad \mathrm{P}$ is the logarithm of the price of commodity $j$ at period $t$.

- $\quad \mathrm{x}$ and (m) denote the exports (imports) value of commodity $j$ of country $i$ in year $t$.

- $\quad \omega$ presents the time-varying weights which reflect changes over time in the basket commodities traded but are predetermined vis-à-vis the price change in each period. This suggest that, changes in the commodity ToT index reflect changes in prices only and not in the volumes traded.

- Commodities are sorted into four broad categories:

- Energy - Coal, crude oil, and natural gas.

- Metals-Aluminum, cobalt, copper, diamond, gold, iron ore, lead, nickel, platinum, tin, titanium, uranium, and zinc.

- Food-Bananas, barley, beef, cocoa, coconut oil, coffee, corn, fish, fish meal, groundnuts, lamb, olive oil, oranges, palmoil, poultry, rapeseed oil, rice, shrimp, soybean meal, soybean, soybeans oil, sugar, sunflower oil, swine, tea, and wheat.

- Rawmaterials - Cotton, hard logs, sawn hardwood, hides, rubber, soft logs, sawn softwood, and wool.

Table - Country Sample

\begin{tabular}{|l|l|l|l|l|}
\hline Asia & Africa & Europe & Middle East \& Central Asia & Western Hemisphere \\
\hline Brunei Darussalam & Algeria & Denmark & Azerbaijan & Belize \\
Indonesia & Angola & Estonia & Bahrain & Bolivia \\
Lao PDR & Burkina Faso & Norway & Belarus & Canada \\
Malaysia & Cameroon & Russia & Egypt & Chile \\
Mongolia & Chad & & Iran & Colombia \\
Papua New Guinea & Congo DR & & Iraq & Ecuador \\
Singapore & Congo, R. & & Kazakhstan & Guyana \\
Vietnam & Equatorial Guinea & & Kuwait & Jamaica \\
& Gabon & Libya & Mexico \\
& Ghana & Oman & Peru \\
& Guinea & Qatar & Suriname \\
& Liberia & & Trinidad and Tobago \\
& Mali & & Saudi Arabia & Venezuela \\
& Mauritania & Sudan & \\
& Nigeria & Tunisia & \\
& Senegal & Turkmenistan & \\
& South Africa & UAE & \\
& Zambia & Uzbekistan & \\
& & Yemen & \\
& & &
\end{tabular}




\section{APPENDIX II. DATA DESCRIPTIONS AND SOURCES FOR THE CHOICE OF EXCHANGE RATE REGIMES}

\begin{tabular}{|c|c|}
\hline Data Sources & Definitions of Variables \\
\hline $\begin{array}{l}\text { 1. The World Bank's World } \\
\text { Development Indicators, } 2019\end{array}$ & $\begin{array}{l}\text { - Real GDP per capita } \\
\text { - Openness: The sum of exports and imports of goods and services } \\
\text { measured as a share of GDP. } \\
\text { - Inflation rate: consumer price index (annual \%). } \\
\text { - Total population. }\end{array}$ \\
\hline $\begin{array}{l}\text { 2. International Monetary Fund's } \\
\text { World Economic Outlook } \\
\text { database, } 2019\end{array}$ & $\begin{array}{l}\text { - CAB/GDP: Current Account Balance as a percentage of } \\
\text { GDP. } \\
\text { - Fiscal balance/GDP: Overall fiscal balance as a percentage } \\
\text { of GDP } \\
\text { - Terms of Trade: Terms of goods and se rvices Trade index. } \\
\text { - REER: real effective exchange rate } \\
\text { - Public debt; central government's gross debt as a } \\
\text { percentage of GDP }\end{array}$ \\
\hline 3. United Nations 2019: & $\begin{array}{l}\text { Export concentration index. An index value closer to } 1 \text { indicates a } \\
\text { country's exports or imports are highly concentrated on a few } \\
\text { products. On the contrary, values closer to } 0 \text { reflect exports or } \\
\text { imports are more homogeneously distributed among a se ries of } \\
\text { products. }\end{array}$ \\
\hline 4. Chinn and Ito 2018 & $\begin{array}{l}\text { - Capital mobility index. The Chinn-Ito index (KAOPEN) is an index } \\
\text { measuring a country's degree of capital account openness. The } \\
\text { index was initially introduced in Chinn and Ito (Journal of } \\
\text { Development Economics, 2006). KAOPEN is based on the binary } \\
\text { dummy variables that codifythe tabulation of restrictions on } \\
\text { cross-border financial transactions reported in the IMF's Annual } \\
\text { Report on Exchange Arrangements and Exchange Restrictions } \\
\text { (AREAER). }\end{array}$ \\
\hline $\begin{array}{l}\text { 5. The Political TerrorScale } \\
\text { (http://politicalterrorscale.org/) }\end{array}$ & $\begin{array}{l}\text { - Political Risk: is an index, Political Terror Scale-USState } \\
\text { Department, } 1 \text { (very low), and } 5 \text { (veryhigh). }\end{array}$ \\
\hline 6. Freedom House database, 2019 & $\begin{array}{l}\text { Democratic institutions: our own compilation based on data for } \\
\text { political rights and civil liberties. Countries are ranked from } 1 \\
\text { (most free) to } 7 \text { (least free) in both indices. Our index is defined as } \\
{[14 \text { - (political rights + civil rights) / 12] and so it ranges from } 0} \\
\text { (least free) to } 1 \text { (most free). }\end{array}$ \\
\hline
\end{tabular}




\begin{tabular}{|llllll|}
\hline \multicolumn{5}{|c|}{ Summary Statisitcs } \\
\hline & & & & & \\
\hline Variable & Obs & Mean & Std. Dev & Min & Max \\
\hline & & & & & \\
Total popualtion & 2,414 & 24.5 & 41.0 & 0.2 & 264.2 \\
Real GDP per capita & 2,367 & 10518.7 & 17180.7 & 134.0 & 113682.0 \\
Degree of opennes & 2,394 & 75.6 & 39.1 & 0.0 & 290.5 \\
Reserves (in months of imports) & 1,779 & 4.7 & 5.8 & 0.0 & 79.2 \\
Current account balance (\% of GDP) & 2,393 & -1.5 & 15.0 & -242.2 & 106.8 \\
Overall fiscal balance (\% of GDP) & 1,725 & -1.6 & 23.0 & -549.8 & 40.6 \\
REER & 2,260 & 123.7 & 123.8 & 19.0 & 3522.2 \\
Inflation voltality & 2,424 & 0.4 & 0.3 & 0.0 & 1.0 \\
Export Concentration Index & 1,592 & 0.5 & 0.2 & 0.1 & 1.0 \\
Capital Mobility Index & 2,234 & -0.2 & 1.5 & -1.9 & 2.3 \\
Political risk & 2,341 & 2.8 & 1.1 & 1.0 & 5.0 \\
Financial development index & 2,304 & 0.2 & 0.2 & 0.0 & 1.0 \\
Democratic institutions & 2,424 & 0.4 & 0.3 & 0.0 & 1.0 \\
\hline
\end{tabular}

\begin{tabular}{|c|c|c|c|c|c|c|c|c|c|c|c|c|c|}
\hline \multicolumn{14}{|c|}{ Corrleation Matrix } \\
\hline & 1 & 2 & 3 & 4 & 5 & 6 & 7 & 8 & 9 & 10 & 11 & 12 & 13 \\
\hline Log of population & 1.00 & & & & & & & & & & & & \\
\hline Log of real GDP per capita & -0.23 & 1.00 & & & & & & & & & & & \\
\hline Degree of openness & -0.47 & 0.18 & 1.00 & & & & & & & & & & \\
\hline Financial development index & 0.08 & 0.69 & 0.02 & 1.00 & & & & & & & & & \\
\hline Export Concentration Index & -0.22 & -0.04 & 0.18 & -0.36 & 1.00 & & & & & & & & \\
\hline Capital Mobility Index & -0.16 & 0.48 & 0.21 & 0.47 & -0.17 & 1.00 & & & & & & & \\
\hline Inflation volatility & 0.04 & -0.09 & -0.03 & -0.09 & 0.07 & -0.12 & 1.00 & & & & & & \\
\hline Democratic institutions & 0.01 & 0.28 & -0.07 & 0.45 & -0.41 & 0.26 & -0.05 & 1.00 & & & & & \\
\hline Political risk & 0.46 & -0.37 & -0.20 & -0.34 & 0.20 & -0.35 & 0.07 & -0.42 & 1.00 & & & & \\
\hline CAB (\% of GDP) & -0.10 & 0.39 & 0.06 & 0.17 & 0.18 & 0.18 & -0.05 & 0.00 & -0.11 & 1.00 & & & \\
\hline Reserves (in months of imports) & 0.15 & 0.20 & 0.06 & 0.08 & 0.16 & 0.03 & -0.05 & -0.08 & 0.12 & 0.22 & 1.00 & & \\
\hline Overall fiscal balance ( $\%$ of GDP) & 0.11 & 0.13 & 0.07 & 0.08 & 0.12 & 0.07 & -0.05 & 0.12 & -0.08 & 0.25 & 0.02 & 1.00 & \\
\hline REER deviation & -0.03 & -0.01 & -0.11 & -0.01 & -0.01 & -0.05 & 0.04 & -0.11 & -0.02 & -0.03 & -0.09 & 0.00 & 1.00 \\
\hline
\end{tabular}

\begin{tabular}{|lll||}
\hline \multicolumn{3}{|c||}{ Country Sample } \\
\hline Algeria & Ghana & Papua New Guinea \\
Angola & Guinea & Peru \\
Armenia & Guyana & Qatar \\
Australia & Iceland & Russia \\
Azerbaijan & Indonesia & Saudi Arabia \\
Bahrain & Iran & Senegal \\
Belarus & Iraq & South Africa \\
Bolivia & Jamaica & Sudan \\
Brazil & Kazakhstan & Suriname \\
Brunei Darussalam & Kuwait & Tajikistan \\
Burkina Faso & Lao P.D.R. & Timor-Leste \\
Cameroon & Liberia & Togo \\
Canada & Libya & Trinidad and Tobago \\
Chad & Malaysia & Turkmenistan \\
Chile & Mali & United Arab Emirates \\
Colombia & Mauritania & Uzbekistan \\
Congo, Democratic Republic of & Mexico & Zambia \\
Congo, Republic of & Mongolia & \\
Côte d'Ivoire & Mozambique & \\
Ecuador & Niger & \\
Egypt & Nigeria & \\
Equatorial Guinea & Norway & \\
Gabon & Oman & \\
\hline
\end{tabular}

\section{(C)International Monetary Fund. Not for Redistribution}


Appendix III. Sample of Countries that Switched Exchange Rate Regimes; 2013-2017

\section{Countries that Switched Exchange Rate Regimes based on} the First Move: 2013-2017

\begin{tabular}{|c|c|}
\hline Peg to Floating & Floating to peg \\
\hline $\begin{array}{l}\text { Azerbaijan (2015): } 4==>8==>4 \\
\text { Argentina (2015): } 6==>9^{*} \\
\text { Armenia (2015): } 6==>9 \\
\text { Belarus (2015): } 6==>8 \\
\text { Cambodia (2015): } 4==>8 \\
\text { DRC (2016): } 4==>8 \\
\text { Egypt (2015): } 4==>8==>9==>4 \\
\text { Guatemala (2015): } 4==>8 \\
\text { Guinea (2015): } 4==>8==>4 \\
\text { Haiti (2015): } 6==>8 \\
\text { Lithuania (2014): } 2==>10 \\
\text { Jamaica (2017): } 6==>9 \wedge \\
\text { Kazakhstan (2015): } 4==>9 \\
\text { PNG (2014): } 4==>6==>9 \\
\text { Russain (2014): } 6==>9==>10 \\
\text { South Sudan (2015): } 3==>8==>4^{*} \\
\text { Suriname (2016): } 4==>8==>4 \\
\text { Switzerland (2015): } 6==>9 \\
\text { Tunisia (2016): } 6==>9 \\
\text { Venezuela (2016): } 3==>8^{*} \\
\text { Zimbabwe (2016): } 1==>8^{*}\end{array}$ & $\begin{array}{l}\text { Afghanistan (2017): } 9==>6^{\wedge} \\
\text { Czech Republic (2015): } 8==>4==>9 \\
\text { Iran (2014): } 8==>6 \\
\text { Indonesia (2017): } 9==>4^{\wedge} \\
\text { Kenya (2016): } 9==>4 \\
\text { Malawi (2016): } 9==>4 \\
\text { Mauritania (2014): } 8==>4==>6 \\
\text { Myanmar (2017): } 8==>4 \wedge \\
\text { Nigeria (2015): } 8==>4 \\
\text { Pakistan (2016): } 8==>4 \\
\text { Rwanda (2014): } 8==>6==>8==>6 \\
\text { Serbia (2016): } 9==>4==>6 \\
\text { Sudan (2015): } 8==>4==>8 \\
\text { Tanzania (2016): } 9==>4\end{array}$ \\
\hline Less Flexible Peg to more Flexible Peg & More Flexible Peg to less Flexible Peg \\
\hline $\begin{array}{l}\text { Angola (2014): } 4==>6==>8==>4 \\
\text { Bangladesh (2017): } 4==>6^{\wedge} \\
\text { Burundi (2016): } 4==>6 \\
\text { Costa Rica (2016): } 4==>6 \\
\text { Ethiopia (2017): } 4==>6^{\wedge} \\
\text { Libya (2014): } 3==>6==>3^{*} \\
\text { Sri Lanka (2015); } 4==>6 \\
\text { Tajikistan (2014): } 4==>6==>8==>4\end{array}$ & $\begin{array}{l}\text { Croatia (2016): } 6==>4 \\
\text { Honduras (2014): } 6==>5 \\
\text { Iraq (2014): } 4==>3 \\
\text { Lao P.D.R. (2015): } 6==>4 \\
\text { Uzbekistan (2017): } 6==>4 \wedge\end{array}$ \\
\hline
\end{tabular}

\section{Notes:}

* countries excluded from the sample due to political instability or due to economic crises.

A countries exculded from the sample because the regime switch occurred in 2017.
No separate legal tender
Currency board
Conventional peg
Stabilized arrangement
Crawling peg
Crawl-like arrangement
Pegged exchange rate within horizontal bands
8 Other managed arrangement
9 Floating
10 Free floating 


\begin{tabular}{|llll|}
\hline \multicolumn{4}{c|}{ Sample } \\
\hline From Pegged to & $\begin{array}{l}\text { From Floating } \\
\text { to Pegged }\end{array}$ & $\begin{array}{l}\text { From less } \\
\text { flexible peg to } \\
\text { more flexible } \\
\text { regime }\end{array}$ & $\begin{array}{l}\text { From more } \\
\text { flexible peg to } \\
\text { less flexible peg }\end{array}$ \\
Azerbaijan & Czech Republic & Angola & Iraq \\
Argentina & Iran & Burundi & Lao P.D.R. \\
Armenia & Kenya & Costa Rica & Uzbekistan \\
Belarus & Malawi & Libya & Croatia \\
Cambodia & Mauritania & Sri Lanka & Honduras \\
DRC & Nigeria & Tajikistan & \\
Egypt & Pakistan & & \\
Guatemala & Rwanda & & \\
Guinea & Serbia & & \\
Haiti & Sudan & & \\
Lithuania & Tanzania & & \\
Kazakhstan & & & \\
PNG & & & \\
Suriname & & & \\
Russia & & & \\
Switerland & & & \\
\hline
\end{tabular}




\section{REFERENCES}

Adler, G., N. Magud, and A. Werner, 2017. "Terms-of-Trade Cycles and External Adjustment." IMF Working Papers 2017/029. International Monetary Fund.

Behar, A. and A. Fouejieu, 2016.'External Adjustment in Oil Exporters: The Role of Fiscal Policy and the Exchange Rate." IMF Working Paper 16/107 (June).

Broda, C., 2004, "Terms of Trade and Exchange Rate Regimes in Developing Countries," Journal of International Economics 63.

Bubula, A. and I. Ötker-Robe, 2003. "Are Pegged and Intermediate Exchange Rate Regimes More Crisis Prone?.” IMF Working Paper 03/223 (December).

Carriere-Swallow, Yan, Nicolas E. Magud, and Juan Yepez (2017), "External Adjustment to Terms-of-Trade Shifts," in Regional Economic Outlook: Western Hemisphere, April 2017, International Monetary Fund (Washington).

Carriere-Swallow, Yan, Nicolas E. Magud, and Juan Yepez (2018), "No Pain, All Gain? Exchange Rate Flexibility and the Expenditure-Switching Effect," IMF WP 18/213.

Carriere-Swallow, Yan, Nicolas E. Magud, and Juan Yepez (2021), "Exchange Rate Flexibility, the Real Exchange Rate, and Adjustment to Terms of Trade Shocks," Review of International Economics, forthcoming.

Cashin, P., L. Cespedes, and R. Sahay, 2004. "Commodity Currencies and the Real Exchange Rate," Journal of Development Economics 75.

Corden, W. M., 1994. Economic Policy, Exchange Rates, and the International System. University of Chicago Press.

Detragiache, E., A. Mody, and E. Okada, 2005. "Exits from Heavily Managed Exchange Rate Regimes." IMF Working Paper 05/39 (February).

Duttagupta, Rupa, and Gilda Fernandez, and Cem Karacadag, 2004. "From Fixed to Float: Operational Aspects of Moving Toward Exchange Rate Flexibility." IMF Working Paper 04/126.

Eichengreen, Barry, Paul Masson, Hugh Bredenkamp, Barry Johnston, Javier Haman, Esteban Jadresic, and Inci Ötker, 1998, "Exit Strategies: Policy Options for Countries Seeking Greater Exchange Rate Flexibility”, IMF Occasional Paper 168 (Washington).

Eichengreen, B., 2004. "Chinese Currency Controversies," University of California. Berkeley. http://emlab.berkeley.edu/users/eichengr/research/asiancurrencies7jun9-04.pdf.

Frankel, Jeffrey, 2003, “A Proposed Monetary Regime for Small Commodity-Exporters: Peg the Export Price ("PEP”), International Finance (Blackwell Publishers).

Friedman, Charles, and Inci Ötker-Robe, 2009, "Country Experiences with the Introduction and Implementation of Inflation Targeting," IMF Working Paper 09/161 (July).

Gruss, B. and S. Kebhaj, 2019. "Commodity Terms of Trade: A New Database”, IMF Working Paper 19/21.

Ghosh, A. and J. D. Ostry, 2009. "Choosing an Exchange Rate Regime: A New Look at an Old Question: Should Countries Fix, Float or Choose Something In Between," Finance and Development (December), Washington D.C. 
Husain, Aasim, Ashoka Mody, and Kenneth Rogoff, 2005. "Exchange Rate Regime Durability and Performance in Developing versus Advanced Economies." Journal of Monetary Economics 52: 35-64.

Husain, A., 2006, “To Peg or Not to Peg. A Template for Assessing the Nobler.” International Monetary Fund, Working Paper 06/54, February 2016, Washington D.C.

R. Arezki, P. Breuer, V. Haksar, T. Helbling, P. Medas, M. Sommer, and an IMF Staff Team. 2015. "Global Implications of Lower Oil Prices.” SDN/15/15 (July) (Washington: International Monetary Fund)

Ilzetzki, E., C. M. Reinhart, and K. S. Rogoff, 2019. "Exchange Arrangements Entering the 21st Century: Which Anchor Will Hold?” Quarterly Journal of Economics 134 (2).

International Monetary Fund Annual Report on Exchange Arrangements and Exchange Restrictions, Various issues.

International Monetary Fund, 2012. "The Liberalization and Management of Capital Flows - an Institutional View."

,2013, "Macroeconomic Issues in Small States and Implications for Fund Engagement" (February 20). , 2015a. "Adjusting to Lower Commodity Prices." World Economic Outlook. International Monetary Fund (October 6).

, 2015b, "Oil Prices, Financial Stability and Use of Countercyclical Macroprudential Policies in the GCC," Golf Cooperation Council Annual Meetings of Ministers of Finance and Central Bank Governors (November 10).

, 2015c, "Evolving Monetary Policy Frameworks in Low-Income and Other Developing Countries." OF/DIS/15/172 (October 26).

, 2016, "Commodity Price Shocks and Greater Exchange Rate Flexibility: Why, If, To What, and How." Macro Financial Notes 2016/1 (February 1). Washington DC.

, 2017a, "If Not Now, When? Energy Price Reform in Arab Countries." (Paper prepared for Annual Meeting of Arab Ministers of Finance (April)

,2017b, Chapter 3, "External Adjustment to Terms-of-Trade Shifts," In Regional Economic Outlook, Western Hemisphere, Washington DC, April.

Khan, Moshin S., 2009, "The GCC Monetary Union: Choice of Exchange Rate Regime", Working Paper series, WP 09-1. Peterson Institute for International Economics, April 2009, Washington DC.

Mundell R.A. (1961), "A Theory of Optimum Currency Areas," American Economic Review 51(4):657-665.

Ötker-Robe, Inci, and David Vavra, and a team of economists, 2007, "Moving to Greater Exchange Rate Flexibility-Operational Aspects Based on Lessons from Detailed Country Experiences," IMF Occasional Paper 256 (Washington: International Monetary Fund). 